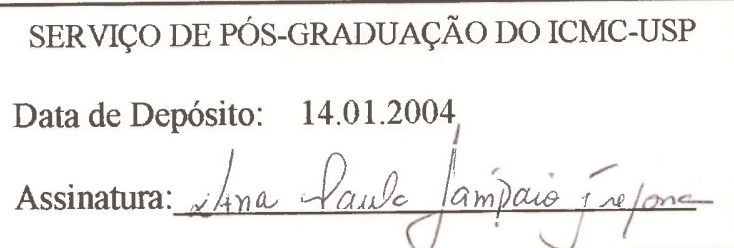

\title{
Ferramentas de avaliação de desempenho para servidores web: análise, implementação de melhorias e testes
}

\author{
Hermes Pimenta de Moraes Júnior.
}

Orientador: Prof. Dr. Marcos José Santana

Dissertação apresentada ao Instituto de Ciências Matemáticas e de Computação - ICMC-USP, como parte dos requisitos para obtenção do título de Mestre em Ciências de Computação e Matemática Computacional.

USP - São Carlos

Janeiro/2004 
A Comissão Julgadora:

Prof. Dr. Marcos José Santana

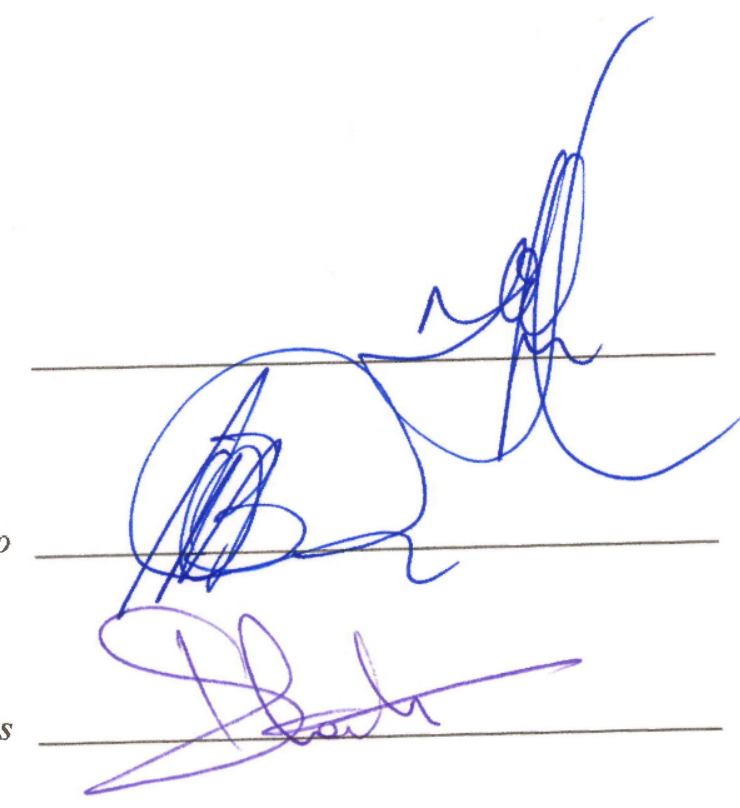




\section{Dedicatória}




\section{Agradecimentos}

Em primeiro lugar gostaria de agradecer aos profesures. Narcos e Regina Santana. Ao professor por ter-me proporcionado muito além da on:-ntaçäo acadêmica e pela paciencia demonstrada em diversas ocasióes. À professora, pés. idéias e sugestões apresentadas nas inúmeras conversas que tivemos.

A Luciana Garcia, minha namorada, pelo comprieirismo e apoio ao longo deste último ano. Não esquecendo a dedicaşão demonstraç nas correçoes gramaticais do meu texto.

Ao amigo Mário Meireles, pela grande ajuda presda por meio dos esclarecimentos de dúvidas que pareciam não terminar.

Ao amigo Márcio Augusto, pelos e-mails antológes enviados para a lista do grupo e por sempre estar disposto a ajudar nos momentos ma: dificeis.

Aos amigos Luciano (Lulu) e Douglas (porquin.. pelas brincadeiras e palhaçadas apresentadas no laboratório de tempos em tempos. E smbém por sempre perderem para o meu time no vôlei.

As Professuras Sarita e Elisa pelas diversas veze..... que me ajudaram.

Aos grandes amigos que encontrei na USP: Álvaro. Caio, Edmilson, Juliano, Kalinka, Michel, Omar, Renato (JapaGay), Renato Bulcão, Simone e Thais.

A USP, por toda a infraestrutura e oportunidades disponibiliza a seus alunos.

Ao CNPq, pelo apoio financeiro sem o qual este trbalho não poderia ser realizado. 


\section{Sumário}

1 Introduçāo 1

1.1 Contextualização . . . . . . . . . . . . . . . . . . . 1

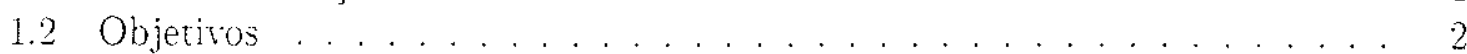

1.3 Estrutura . . . . . . . . . . . . . . . . . . . . 3

2 Avaliação de Desempenho 5

2.1 Introduç̃o . . . . . . . . . . . . . . . . . . . . . . 5

2.2 Técnicas para Avaliação de Desempenho . . . . . . . . . . . . 6

2.2 .1 Técnicas de Aferição . . . . . . . . . . . . . . . . . . . 6

2.2 .2 Modelagem . . . . . . . . . . . . . . . . . . . . 8

2.2 .3 Soluções para o Modelo . . . . . . . . . . . . . . . . . 10

2.3 Consideraçoes Finais . . . . . . . . . . . . . . . . . . . . . . . . 12

3 Visão Geral da Web 14

3.1 Introduç̃o . . . . . . . . . . . . . . . . . . . . . . . . . . 14

3.2 Infraestrutura . . . . . . . . . . . . . . . . . . . 15

3.3 Protocolos . . . . . . . . . . . . . . . . . . . . . 16

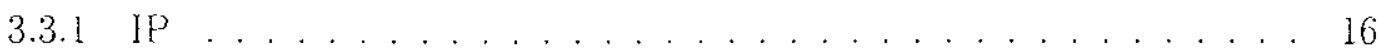

$3.3 .2 \mathrm{TCP} \ldots \ldots \ldots \ldots \ldots \ldots$

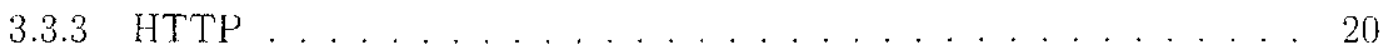

3.4 Caracterização de Carga da Web . . . . . . . . . . . . . . 23

3.4 .1 . Netodologia para a caracterizacão de carga . . . . . . . . . . 24

3.4 .2 Cargas ern rajadas . . . . . . . . . . . . . . . . . . 26

3.5 Arquitetura de Servidores Web . . . . . . . . . . . . . 27

3.6 Considerações Finais . . . . . . . . . . . . . . . . . . . . . . . . . . 29

4 Benchmarks para Servidores Web 31

4.1 Introdução . . . . . . . . . . . . . . . . . . . . . 31

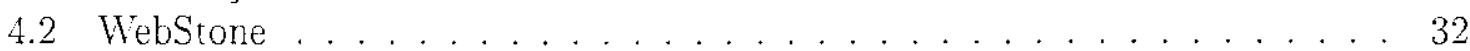

4.2 .1 Configuração . . . . . . . . . . . . . . . . . . . 32

4.2 .2 Arquitetura . . . . . . . . . . . . . . . . . . . . 38

4.2 .3 Carga de trabalho . . . . . . . . . . . . . . . . 39

4.2.4 Resultados apresentados pelo WebStone . . . . . . . . . . . 40

4.3 Httperf . . . . . . . . . . . . . . . . . . . . . . 41

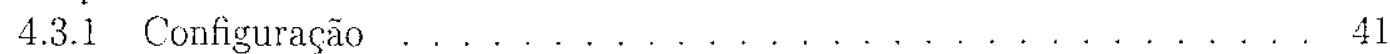

4.3 .2 Arquitetura . . . . . . . . . . . . . . . . . . 43

4.3 .3 Carga de trabalho . . . . . . . . . . . . . . . . . 45

4.3.4 Resultados apresentados pelo httperf . . . . . . . . . . 46

4.4 Considerações finais . . . . . . . . . . . . . . . . . . . . . 49 
5 Modificações no Httperf $\quad 52$

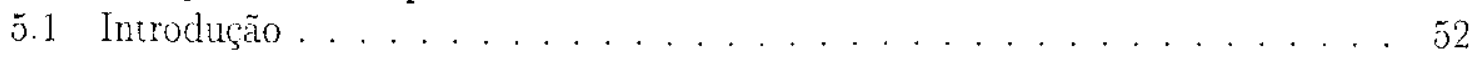

5.2 Logs de servidores web . . . . . . . . . . . . . . 53

$5.2 .1 \log$ do site da Copa do Mundo de $1998 \ldots \ldots . . . . . . .55$

$5.2 .2 \log$ do site Navemundo . . . . . . . . . . . . . . . . 57

5.2 .3 log de testes com o WebStone . . . . . . . . . . . . 57

5.3 Imịlementação . . . . . . . . . . . . . . . . . . . . . . . . .

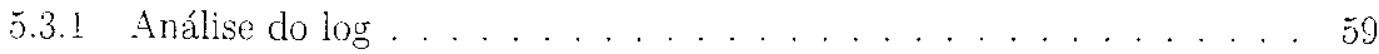

5.3 .2 Construção do histograma . . . . . . . . . . . . . . . . . 60

5.3 .3 Geração dos arquivos . . . . . . . . . . . . . . . . . . 63

5.4 Teses experimentos. . . . . . . . . . . . . . . . 63

5.4.1 Plataforma utilizada para realização dos experimentos . . . . . . 63

5.4 Descriç̃o dos experimentos . . . . . . . . . . . . . . . 64

5.4 .3 Resultados . . . . . . . . . . . . . . . . . . 65

5.5 Considerações finais . . . . . . . . . . . . . . . . . . . 71

6 Conclusōes e Trabalhos Futuros $\quad 73$

6.1 Consideraçôes finais . . . . . . . . . . . . . . . . . . 73

6.2 Contribuiçoes deste trábahlo . . . . . . . . . . . . . . . . . . 74

6.3 Dificuldades encontradas . . . . . . . . . . . . . . . . . 74

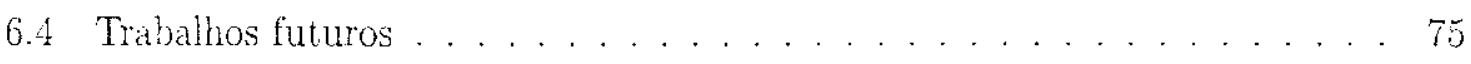

$\begin{array}{ll}\text { Referências Bibliográficas } & 77\end{array}$ 


\section{Lista de Figuras}

2.1 Relação entre propostas de avaliação e técnicas de aferição. . . . . . . . 8

2.2 Rede de Filas Ilustrando Processos Competindo pelo Processador. . . . . . 9

2.3 Uma Rede de Petri Ilustrando Processos Competindo pelo Processador. . . 10

2.4 Processos Competindo por um Processador (statecharts). . . . . . . . . . . 11

2.5 Solução Preferencial para um Modelo. . . . . . . . . . . . . . 12

3.1 Cabeçalho IP . . . . . . . . . . . . . . . . . . . . . . . . . 17

3.2 Enderesos IP especiais . . . . . . . . . . . . . . . . . . 18

3.3 Cabeģalho TCP . . . . . . . . . . . . . . . . . . . . . 19

3.4 Exemplo de uma requisição HTTP . . . . . . . . . . . . . . . . 21

3.5 Exemplo de uma resposta HTTP . . . . . . . . . . . . . . . . 22

3.6 Tráfego da Web em rajadas. (Crovella \& Bestavros, 1997) . . . . . . . 26

4.1 Arquitetura do benchmark WebStone. . . . . . . . . . . . . . . . . 39

4.2 Relação entre os módulos do httperf. . . . . . . . . . . . . . . . . . . 44

4.3 Estatísticas de desempenho obtidas pelo httperf. . . . . . . . . . . 46

5.1 Exemplo de um $\log$ em formato CLF . . . . . . . . . . . . 55

5.2 Algoritmo acrescentado ao httperf . . . . . . . . . . . . . . . . 59

5.3 Histograma criado a partir do log da Copa do Mundo . . . . . . . . . . . 61

5.4 Estrutura VETOR . . . . . . . . . . . . . . . . . . . 62

5.5 Distribuição de arquivos - $\log$ Navemundo $\ldots \ldots \ldots . \ldots . \ldots 5$

5.6 Distribuição de arquivos - $\log$ Copa do Mundo . . . . . . . . . . . 66

5.7 Distribuição de arquivos - $\log$ WebStone . . . . . . . . . . . . 66

5.8 Histograma para o $\log$ Navemundo . . . . . . . . . . . . . 67

5.9 Histograma para o log Copa do Mundo . . . . . . . . . . . . . 67

5.10 Histograma para o $\log$ WebStone . . . . . . . . . . . . . 68

5.11 Tempo de resposta $-\log$ Navemundo . . . . . . . . . . . . . 68

5.12 Tempo de resposta - log Copa do Mundo . . . . . . . . . . . . . 69

5.13 Tempo de resposta $-\log$ WebStone . . . . . . . . . . . . . . 69

5.14 Número de erros $-\log$ Navemundo . . . . . . . . . . . . 70

5.15 Número de erros - log Copa do Mundo . . . . . . . . . . . . . . . . 70

5.16 Número de erros - $\log$ WebStone . . . . . . . . . . . . . . . 71 


\section{Lista de Tabelas}

3.1 Partição de carga baseada em utilização de recursos . . . . . . . . . . . 25

4.1 Parâmetros utilizados na execução dos testes . . . . . . . . . . . . . . 34

4.2 Arquivo filelist usado nos testes. . . . . . . . . . . . . . . 34

4.3 Exemplo de resultados obtidos pelo WebStone . . . . . . . . . . . . 40

4.4 Quadro comparativo entre o Webstone e o httperf . . . . . . . . . . . 51

5.1 Campos presentes en um $\log$ CLF . . . . . . . . . . . . 54

5.2 Tipos de arquivos requisitados - Copa do Mundo . . . . . . . . . . . . 56

5.3 Tipos de arquivos requisitados - Navemundo . . . . . . . . . . 58

5.4 Máquinas utilizadas para execução dos experimentos . . . . . . . . . 64 


\section{Resumo}

Este trabalho apresenta o projeto e implementação de melhorias na ferramenta httperf, que é um benchmark para servidores Web. A melhoria inplementada constitui na interpretação de logs para a extração de parânetros de carga de trabalho. Para tanto, foi necessária a criação de um ferramenta à parte, que trabalha o arquivo de log e retira os parâmetros a serem utilizados pelo httperf.

O desenvolvimento do trabatho foi baseado em uma rovisão bibliográfica cobrindo avaliação de desempenho de sistemas computacionais, características da Web e ferramentas/bcnchmarks especializados em sistemas bascados na Veb. Apresenta ainda uma discussão sobre arquiteturas de servidores Web c o uso dos benchmarks na avaliação desses servidores. Foi desenvolvido um estudo sobre as ferramentas, onde foram analisadas suas características, com o intuito de identificar características não abordadas. mas julgadas importantes nesse tipo de avaliação. A partir dosse estudo selecionou-se algumas das características identificadas que foram incorporadas à ferramenta escolhida. Finalmente, a ferramenta que recebeu as alteraçoes foi avaliada por meio de diversos experimentos, quando os resultados obtidos mostraram que a implementação desenvolvida era viável. 


\section{Abstract}

This work presents the design and implementation of improvements for httperf - a benchmark tool for Web servers. The improvements are basically the interpretation of logs for extracting workload parameters. The creation of another tool was necessary to extract from the log the parameters to be used by httperf.

Work development was based in reviewing the literature on performance evaluation of computing systems, Web characteristics and benchmarks for Web based systems. Discussion about Wob server architecture and benchmark using for server evaluation are also presented. A study about similar tools (such as httperf) was made, where characteristics were analyzed to identify the ones not approached yet, being relevant for performance evaluation. Some were identified, selected and inserted in the chosen tool. Finally, changes were incorporated to the tool, which was then evaluated through several experiments; results show the developed improvements are usable. 


\section{Capítulo 1}

\section{Introdução}

\subsection{Contextualização}

Com a idéia inicial de criar una rede que não pudesse ser destruída por bombardeios e fusse cizpaz de ligar pontos estratégicos, como centros de pesquisa e tecnolugia. surgiu em 1969, a Arpanet. O que começou como um projeto de estratégia nilitar, con a finalidade de atender às demandas do DoD (Departamento de Defesa dos Estados Lnidos), acabou se transformando no que hoje é conhecido como a Internet (Tanenbaum, 2002).

Para alcançar os objetivos almejados, foi necessário criar uma estrutura totalmente descentralizada, com todos os pontos (nós) tendo o mesmo status. Os dados cleveriam caminhar de forma independente, em qualquer sentido. Assim, se um nó fusse perdido, destruído, o restante da rede continuaria operando nomalnente.

Os pontos de comunicação da rede cresceram rapidamente, interligando cada vez mais instituiçoes de pesquisa e órgãos do governo. Em 1989, quando a Internet já havia alcansado dimensões que extrapolavam os limites dos Estados Unidos, Tim Berners-Lee, físico ligado ao CERN (Centro Europeu de Pesquisa Nuclear), propôs uma nova estrutura arquitctural para acessar documentos interligados espalhados em milhares de máquinas. A idéla inicial era de uma teia de documentos ligados e surgiu da necessidade cle cooperação entre grandes grupos internacionais de pesquisadores que utilizavam documentos de tipos variados e em constante mutação. Essa nova estrutura deu origem à World Wide Web, on simplesmente Web (Tanenbaum, 2002).

Apesar de ter surgido apenas como um serviço dentro de toda a Internet, a Web se tornou um dos principais fatores que impulsionaram o crescimento da Rede. Pode-se dizer que a Web foi a responsável pela popularização do uso da Internet, de tal forma que algumas pessoas mais leigas a confundem com a própria Internet. Serviços disponíveis há muito mais tempo, como e-mail e FTP, passaram a ter, nos navegadores wet, sua forma de interface preferencial com os usuários. 
Desde a idéia inicial, as técnicas empregadas na Web evoluíram muito (Orfati et al., 1909; Iran Herman, 2003), sempre visando o aumento das aplicaçoes que se pode executar sobre a estrutura oferecida, ou seja, serviços e novos recursos que os usuários podtem ubter. Com isso, a Web conseguiu transformar a Internet de um ambicnte para fins de pecquisa, restrito a centros acadêmicos e instituiçôes governamentais, para um sistema altamente explorado, no que tange à educação, ao entretenimento, e principalmente ao comercio.

Em relação a este último ponto e devido ao crescimento explosivo apresentado pela Web, empresas e instituiçoes que ofereciam serviços baseados na Rede. se viram cada vez mais dependentes de servidores con grande capacidade para garantirem o suctsso de seus negócios. A grande demanda de requisiçoes sempre saturava até mesmo sistemas com grande desempenho. Tomou-se então necessário o freqüente incremento na cajpacidade dos sistemas responsáveis pelo atendimento a essas requisições. podendo esse aumirnto ser obtido através de diversas maneiras como replicação (mimoming) (Stading at al. 2002), melhor utilizaçäo de caches (Fan et al., 2000) e molhores servidores http (J. H.1. 1993; Apache Software Foundation, 2003).

Atualmente, grande parte dos trabalhos feitos para se medir o descmpenho de sotuture na Web tem so concentrado na caracterização precisa de cargas getadas nos servidos. em ternos do tipos de arquiros requisitados. tamanho das transferências e out ras estatisticas relacionadas (Arlitt \& Williamson, 1996: Abdelzaher \& Bhatti, 1999). Existem exernplos que utilizam diretamente cargas reais (Maltzahn et al. 1997), coutros que utilizam cargas geradas sinteticamente (Nosberger \& Jin, 1998; Crowella et al., 1999; Ninderaft. 2002), baseadas en invariantes observadas no tráfego real da Web. Esse último método ajpesenta falhas que se apresentam quando há a necessidade de definir cargas que se aproximem, o máximo possível, de cargas reais. Aquele primeiro método apresenta dificuldades relacionadas à reprodução de cargas reais.

A avaliação de servidores Web não é trivial. Existem diversas ferramentas, que implementam diferentes métodos, disponíveis para executar essa tarefa. Não há, no critanto, nonhuma forma ideal, deixando esso problema ainda em aberto.

\subsection{Objetivos}

O presente trabalho tem como objetivo o estudo de mecanismos utilizados para avaliaşão de servidores web, em particular as ferramentas que utilizam cargas sintéticas. Com isso, pretende-se chegar a uma comparação das ferramentas abordadas e identificar características chaves, que auxiliem essas ferramentas a alcançar cargas mais próximas do real. A partir desse estudo e das características identificadas, são selecionados uma característica e um mecanismo que irá recebê-la por neio de implementação. Assim, o objetivo principal deste trabalho é incluir melhorias em uma ferramenta existente para que ela seja capaz de gerar cargas mais próximas do real, alcançando, dessa forma, melhores resultados 
nas avaliações de servidores.

Atualmente, podem ser encontradas diveras ferramentas (benchmarks) para a avaliagão de servidores Web. Entre as mais citadas na literatura especializada estão Wobstone (Minderaft, 2002), Surge (Crovella tt al. 1999). SPECweb (SPEC, 1999) e Httpert (Nosberger \& Jin, 1998).

Quanto às características, diversas podem ser acrescentadas a esses mecanismos ou ferramentas. Lim exemplo importante é a capacidade de leitura de logs gerados por servidores Web. Esses logs possuem informacões à respeito de tudo o que foi visto pelo servidor como: número de requisiçoes aierdidas; tipo e tempo entre chegadas dessas requisicones. A extração de parâmetros de carga presentes nesses logs representa uma importante forma de se caracterizar a carga a que o servidor foi exposto.

De forma mais especifica, o que se pretende é fazer com quo un benchmark escolhido dê uma passo a mais em diresão à obtenção de cargas de trabalho mais próximas do real por noio do tratamento e extraçäo de parànetros de logss.

\subsection{Estrutura}

No Capítulo 2, discute-se a avaliação de desempenbo de sistemas. Säo apresentadas as técnicas de aferição (Protótipos, Bencrinals e Coleta do Dados) e de nodelagem (Redes de Filas, Redes de Petri e Staterats). Posteriomente e feila uma discussão sobre a resolução de modelos, com a apresentagão dos tipos de solução, que podem sor por abordagem Analítica ou por Simulaşào.

O Capítulo 3 desta clissertação apresenta a infratestrutura da Internet, seus protocolos (TCP/IP, HTTP) e serviços principais, destakando-se a Web. É feita também uma revisão sobre estudos recentes a respeito da caracterização de carga na Web e sobre arquitcturas de servidores Web. Sobre os servidores é destacada a estratégia de concorrência utilizadia por cada um deles. São discutidos servidores do tipo Iterativo, (que usam um processo por requisisão), do tipo Thread pool e do tipo Ĺnica thread.

Os benchmarks, ou ferramentas, utilizados para a avaliação de servidores Web, são apresentadas no Capítulo 4. Em particular sảo discutidos os benchmarks WebStone, e httperf, escolhidos por serem os mais abordados na literatura. Ao final deste capítulo é feita uma breve comparação entre os dois nnchmoms, escolhendo-se um para receber as implementações propostas.

O Capítulo 5 aborda o desenvolvimento do objetivo proposto pelo trabalho. Assim, algumas consideraçôs são feitas sobre os berchmarks adotados, as decisões do projeto e os detalhes de implementação envolvendo a nora ferramenta construída e as características adicionadas ao httperf. São apresentados ainda nesse capítulo, os resultados obtidos através de experimentos realizados com a nova ferramenta alcançada. 
Para finalizar, as conclusões, contribuições do trabalho, dificuldades encontradas e sugestoes para trabalhos futuros são apresentadas no Capítulo 6 . 


\section{Capítulo 2}

\section{Avaliação de Desempenho}

\subsection{Introdução}

Uma figura de desempenho de un sistema computacional corresponde ao resultado de thra araliasa da quantidade de serviços prestados ao longo de um determinado período de tempo. O desempenho de um sistema computacional é, antes de tudo, observado por sens usuários a partir dos tempos de respostas observados. Embora rão constitua um parâmetro confiável, a qualidade de um sistemá é, de certa forma avaliada de acordo com o grau de contentamento do seus usuários. Assim, quando há descontentamento entre um grupo de usuários de um determinado sistema, toma-se necessária um avaliação minuciosa a fim de se determinar possiveis gargalos.

A araliagno de desempenho om Sistemas Computacionais Distribuídos pode ser empregadla, nat uraliaçào de sistemas exislentes, na avaliaçäo de sistemas em desenvolvimento, ou na sflegro de um sistema determinado (Francês, 1998). No primciro caso, poden-se destacar cono possíveis objetivos a maximização da eficiência e da utilização de um deteminado recurso e a minimizaça do tempo de resposta e do custo de processamento de uma carga de trabalho. No caso de sistemas inexistentes, a avaliação deve ser capaz de fazer previsóes sobre o comportamento do novo sistema. Dessa forma a avaliação de desempenło está presente desde a concepção do sistema até sua instalacão e utilização diária. Para a seleção de novos sistemas são fcitas comparaçoes entre os desemponhos de diversus sistemas e a escolha é feita de acordo com um parâmetro específico.

Apesar da avaliação de desempenho ser de grande importancia, muitas vczes ela é negligenciada, o que acarreta consequiências graves para as atividades do sistema em questão. Esse descaso. na maioria das vezes, é atribuido a dois fatores: à falta de conhecimento de ferramentas para efetuar a avaliaşăo, on à dificuldade de realizá-la - apesar da utilização dessas ferramentas. De modo geral, dependendo do sistema em foco e do tipo desejado de avaliaşão. é possível utilizar-se técnicas de aferição (benchmarks prototipação, coleta de dados). ou modelagem (com solugão analítica ou por simulação). 


\subsection{Técnicas para Avaliação de Desempenho}

Para a avaliasão de desempenho de um sistema, o avaliador deve coletar informaçóes referentes aos parâmetros significativos à avaliação. Técnicas de avaliação são, justamente; métodos para a obtenção dessas informações. Isso pode ser feito através do próprio sistena (técnicas de aferição - benchmarts, coleta de dados e prototiparão) ou a partir de modelagem do sistema.

Os sistenas computacionais atuais atingiram uma grande complexidade tomando a uilização de técnicas de aferição em sua avaliaģão tanbém bastante complexa. Dessa forma as técnicas de modelagem tên sido amplamente utilizadas na araliacäo do sistemas (m) geral.

Entretanto. o emprego de técnicas baseadas em modelos requer que estes sejam resolvidos, e que sua confiabilidade seja garantida. Isso pode ser obtido através do conhecimento prévio de que sua base conceitual esteja correta. Sem essas "garantias" não se pode dizer llada além de que os resultados obtidos apenas refletem o comportamento do sistema real.

\subsubsection{Técnicas de Aferição}

Quando o sistena a ser avaliado já existe on está em fase final de desenvolvimento, o estudo de seu desempenho pode ser feito através da experimentação direta. Pode-se utilizar o sistema e coletar dados a sent respeito dirctamente.

Em relaça à modelagem, as técnicas do aferiçäo apresentam vantagens - abservadas através de resultados mais precisos - e desvantagens - a necessidade de se ter um sistema disponível. Nos dois casos. é necessário garantir que a própria técnica não interfira no comportamento do sistema e comprometa os resultados obtidos.

Algumas das principais técnicas de aferição são (Orlandi, 1995): os protótipos, os benchmarks e a coleta de dados. A seguir, essas técnicas serão discutidas.

\section{Protótipos}

A construção de protótipos representa uma simplificação de um sistema computacional, mantendo, contudo, a mesma funcionalidade. Os protótipos consideram algumas características en detrimento de outras e podem ser considerados um meio termo entre o sistema final e as expectativas que se tem dele, quando ele ainda não existe. Essa técnica possui um custo menor do que a construção do sistema real, apesar de ainda relativamente elevado em relação às demais técnicas de aferição. Há outra dificuldade ao se construir um protótipo: deteminar quais características são essenciais ao sistema. 


\section{Benchmarks}

Benchmarks são programas usados para o teste de software hardware ou sistemas computacionais completos (Collin, 1993). Na medição do desempenho de sistemas computacionais, os benchnarks podem utilizar tanto tarefas mais gerais (operaçóes de $1 / 0$ ), quanto tarefas específicas (como representação de polígonos ou operaçoes sobre matrizes). En suma, qualquer aspecto de desenpenho do um sistema computacional que importe aos usuários pode ser objeto de medição por meio de benchmarks. Entretanto, alguns cuidados devem ser observados em relação à utilização dos benchmarks. Primeiro, por se tratar de uma técnica de aferişão, deve-se verificar se o próprio benchmark não influenciará no comportamento do sistema. Outra dificuldacle reside na escolha da unidade usada como referência para realização da comparação. A utilização, por exemplo, de unidades como VIIPS (Millions of Instructions Per Second) ou FLOPS (FLoating Point Operutions Per Second) gera bastante controvérsia, pois elas fornecem valores perigosamente absolutos, mesmo diante de fatores distintos (como arquiteturas RISC e CISC), que podem influenciar sobremaneira os resultados.

Em virtude da importancia desse assunto no contexto geral do trabalho, ele será discutido mais detalhadamente em un capítulo à parte.

\section{Colcta de dados}

Como mencionado, as técnicas de aferição são os métodos que oferecem os resultadus mais precisos. Dentre essas técnicas, a coleta de dados é a mais precisa.

Uma utilizacão bastante interessante pode ser dada à coleta de dados: os resultados obtidos por meio dessa técnica podem ser usados para comparaçoes com os resultados obtidos a partir de modelos do mesmo sistema. Esse procedimento pode ser empregado como parte da validação de um modelo.

A coleta de dados pode ser realizada através de dois recursos: os monitores de hardware e os monitores de software.

- Monitores de hardware: são hardwares específicos empregados para coletar e analisar alguns dados pertinentes ao objeto em estudo (Orlandi, 1995). Os Monitores de hardware devem ser também não intrusivos, isto é, devem limitar-se a obter os sinais sem alterá-los, mantendo fidelidade aos valores originais.

- Monitores de software: são usados nos casos em que se deseja observar características específicas de softuare como, por exemplo, a verificação da existência ou não de uma fila de espera, associada a algum recurso do sistema.

A Figura 2.1 mostra alguns exemplos de utilizações das técnicas mencionadas acima. As formas geométricas idênticas indicam uma relação(técnica, proposta de avaliaşão) mais 


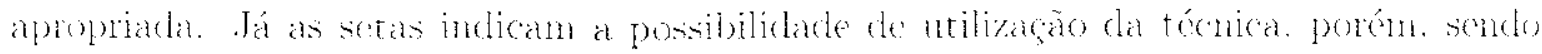
moms aconsethata. I)esia forma. a Coleta de? Dardos por exemplo. pode ser utilizata

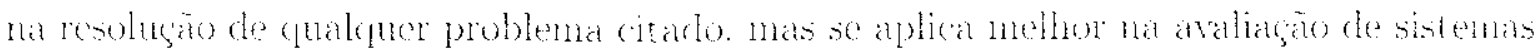
existeriters.

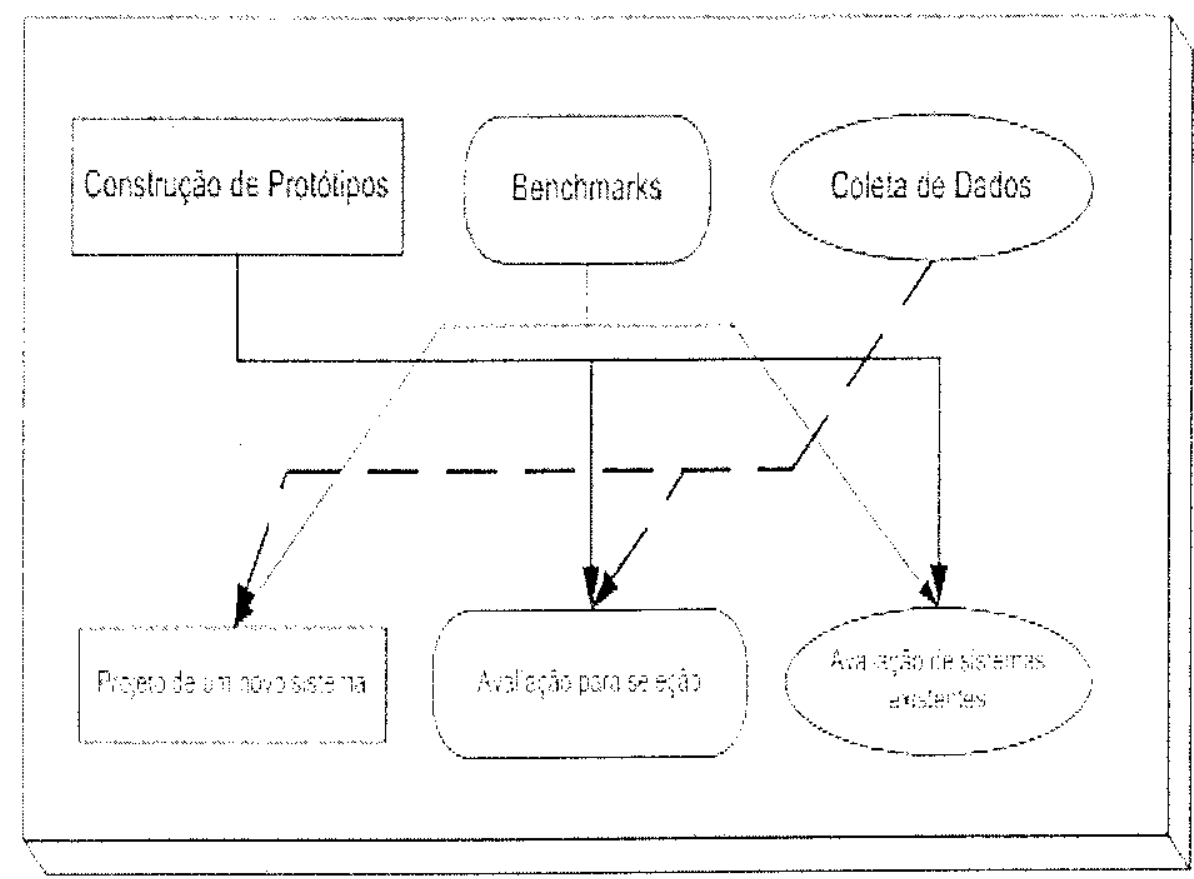

Figna 2.1: Rolatüo ontre propostan de avaliaçio e técnicas de aferigăo.

\subsubsection{Modelagem}

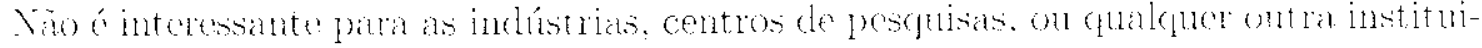

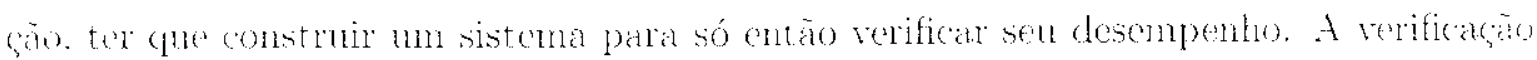

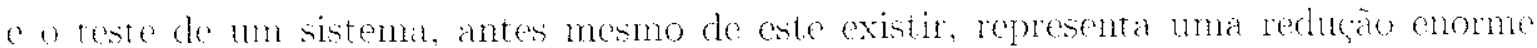

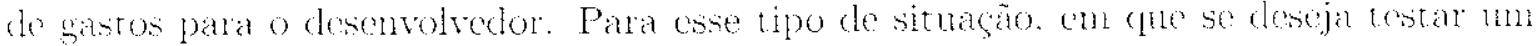
sistema sem que ele exista, on que sua experimentaga prática seja batante conplexa é que se propore a modelagem.

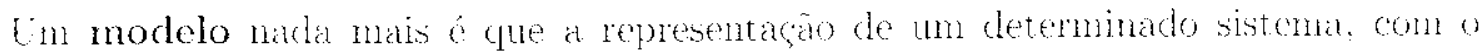
intuito de evidenciar suas caracteristicas mais importantes. Os modelos sofrem alterages conn o tenpo pois o estado de um sistena também se altera dessia format. Assimn os modelos podem ser classificados en relatgano ao tempo cono: discretos ou contínus. Una $10 \%$ que a alteraço de estado em computadores ocorre a intervalos discretos de tempo. para a modelagen desse tipo de sistema sào usados tambén modelos discretos.

Existem várias técnicas para modelar un sistema computaciomal. Thés técnicas tém sido amplamente utilizadas e possuem vantagens e desvantagens confome o domínio de aplicagào considerado: redes de filas, redes de Petri e statecharts. A seguir ada unat 
dessas técnicas é detalhada.

\section{Redes de Filas}

Na computação, há diversas ocasióes em que aparecom "disputas" por algum recurso, cono por exemplo, acesso a disco, utilização da CPL; acesso à rede. Nessas ocasióes é inevitável o surgimento de filas. Para modelar esses sistemas, foi criada uma ténica baseada na teoria de filas (um ramo das probabilidades) denominada rede de filas.

Una rede de filas consiste de duas entidades: centros de serviços e usuários. As primeiras são entidades quo oferecm serviços dos quais os usuários usufruem (Soares; 1992). Un centro de serviço pode ser constitúfo de un ou mais servidores que correspondem aos recursos no sistema modelado. Há ainda uma área de espera (fila) para os usuários que estão requisitando serviços mas ainda não conseguiram acesso. Como exemplo, uma situação que ocorre constantemente em sistemas computacionais é a disputa pelo processador por diversos processos. A Figura 2.2 ilustra essa situação.

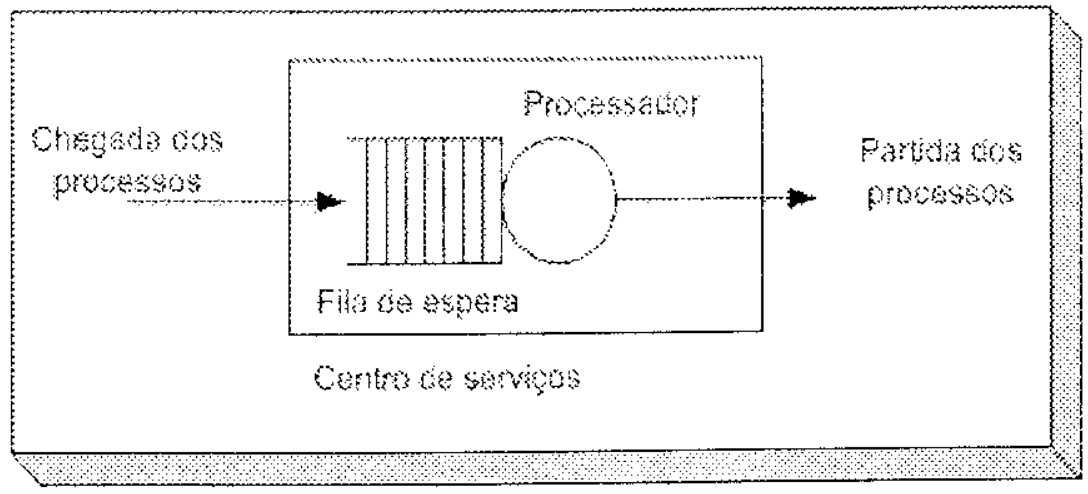

Figura 2.2: Rede de Filas Ihustrando Processos Competindo pelo Processador.

\section{Redes de Petri}

Redes de Petri é uma técnica quo permite a representação de sistenas utilizando uma forte base matemática. Essa técnica possui a particularidade de permitir modolar sistenas paralelos, concorrentes, assíncronos e não-determinísticos (Naciel et al., 1996).

A representação gráfica de uma rede de Petri básica, ilustrando a mesma situação mostrada na Figura 2.2 através de redes de filas, é apresentada na Figura 2.3. O gráfico possui três componentes: um ativo chamado transição (barra), outro passivo denominado lugar (círculo) e os arcos direcionados, que são elementos de ligação entre os dois primeiros. Os lugares equivalem às variáveis de estado e as transiçoes corresponden às ações realizadas pelo sistema. Os arcos poden ser únicos ou múltiplos. 


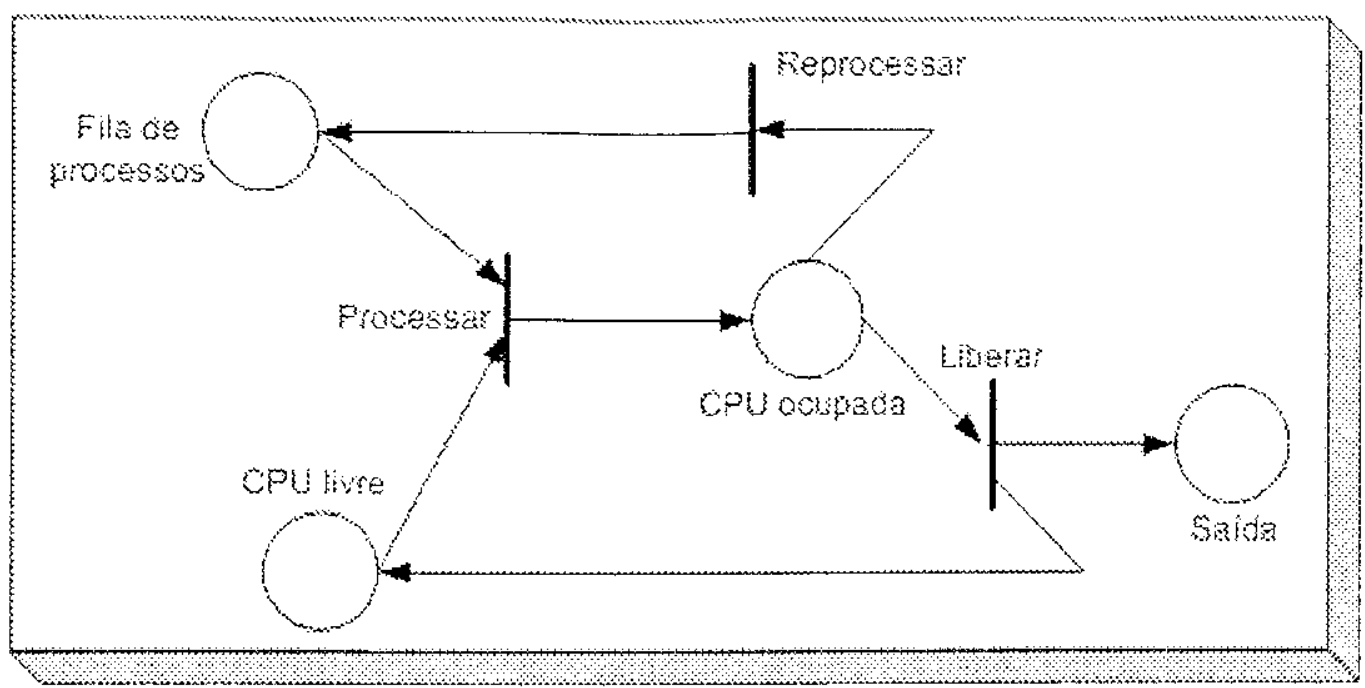

Figura 2.3: Una Rede de Petri Ilustrando Processos Competindo pelo Processador.

\section{Statecharts}

Statecharts é una extensão das máquinas de estado finito, que possibilita a representação de hierarquia, concorrència e comunicação entre os diversos estados de um determinado sistema (Harel, 1987). Essa técnica tem a finalidade de especificar sistemas reativos, ou seja, sistemas que devem reagir a estímulos externos e internos, nomalmente sub condiçoes críticas em relação ao tempo (Harel \& Politi, 1998).

A definição de statecharls é fundamentada em conjuntos de estados, eventos e condições primitivas, transiçoes e variáveis. A partir disso o modelador pode especificar os valores das variáveis do sistema em um certo instante. A idéia principal é seu uso na representação de sistemas complexos, onde os diagramas de estado apresentam deficiências. Sistenas complexos requerem uma estrutura de representaģão hierárquica (com agrupamento o refinamento de estados) e de concor rência, de mancira que seja facilmente visível o movimento através dos estados do sistema no decorrer do tempo. A Figura 2.4 apresenta o exemplo anteriormente expresso em redes de filas e de Petri, agora ilustrado om statecharts.

\subsubsection{Soluções para o Modelo}

Depois de definida a técnica de análise para a construção do modelo do sistema em estudo, chega-se ao momento de escolher a solução a ser dada. Existem, basicamente, duas técnicas para a resolução de modelos: analítica e por simulaşão. Ambas apresentam vantagens o desvantagens, dependentes do tipo de modelo a ser resolvido, o que é determinante para a escolha de uma delas. 


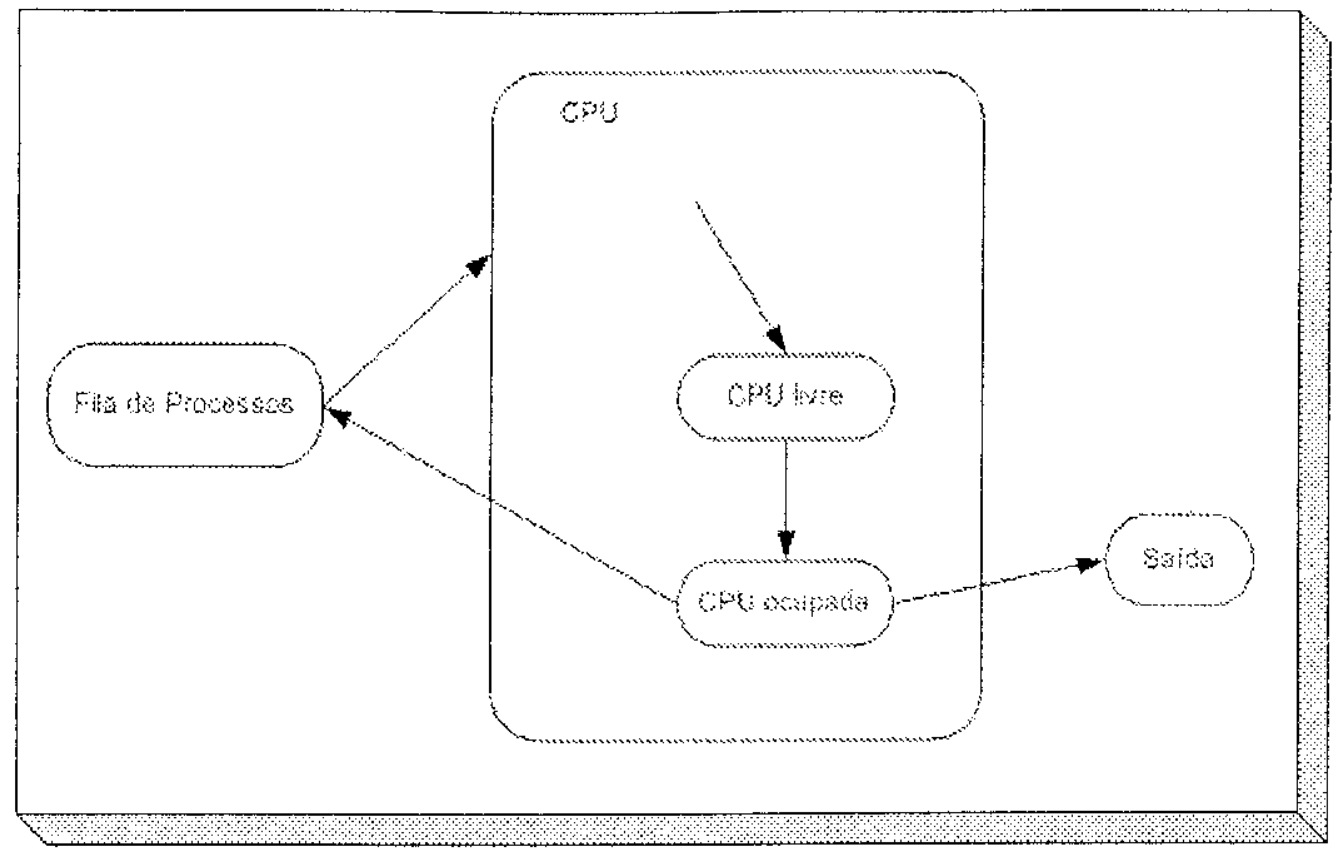

Figura 2.4: Processos Competindo por um Processador (statecharts).

\section{Solução Analítica}

Por ser o métudo mais rápido, a solução analítica é a preferida, mas nem sempre ‘ aplicável (Kleinrock, 1976), porque säo necessárias simplificaçoes no modelo para que este possa ser resolvido. Simplificaçoes nata mais são do que restrições impostas pela soluço analítica, que geralmente não correspondem ao verificado em sistemas reais. Apesar de ser $u$ mm método que propicia resultados expressivamente exatos, essas restrições podem levar a um modelo que não representa o sistema real de forma adequada, o que toma sen: sentido a utilização desse nodelo.

Para exemplificar a dificuldade imposta por essas simplificacoees, na soluçäo analítica de modelos baseados em redes de filas, não há como estabelecer prioridades nas disciplinas das filas. Dessa forma, todos os usuários são tratados de forma idêntica, o que inviabiliza. por exenplo, a representação de esquemas de prioridades presentes em servidores Web que presstam serviços de forma diferenciada. Anda existem várias outras restriçōes cono a possibilidade de flas infinitas, impossível em sistemas reais.

Vessas situaçôes em que a solução analítica apresenta dificuldados pode-se adotar a resolução por simulação.

\section{Simulação}

A possibilidade de simular o comportamento de um objeto (ou um sistema de objevs: constitui uma necessidade presente em diversas áreas do conhecimento. Se o modelo proposto para o sistema envolve uma gama de informaçōes e/ou exige que se façam algumas 


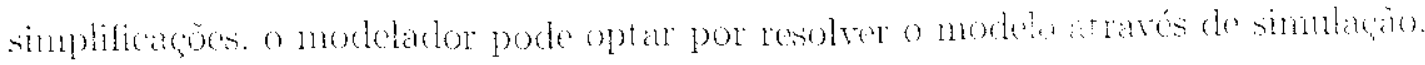

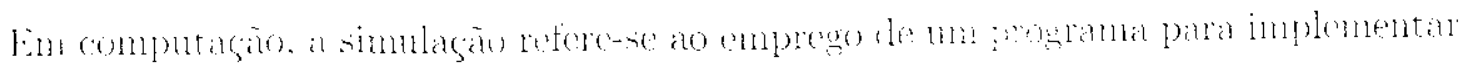

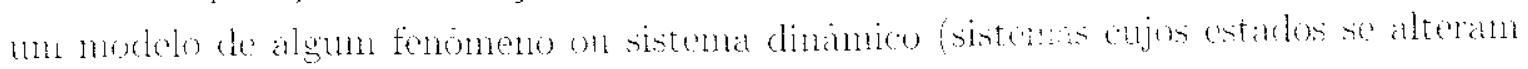
(om o tompo) (Orlandi. 1995).

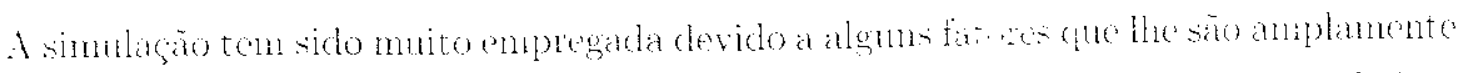

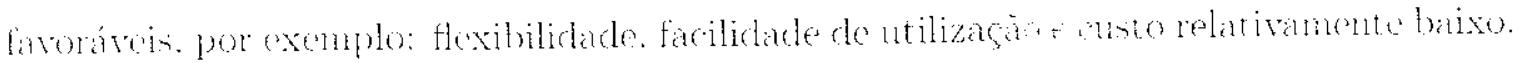

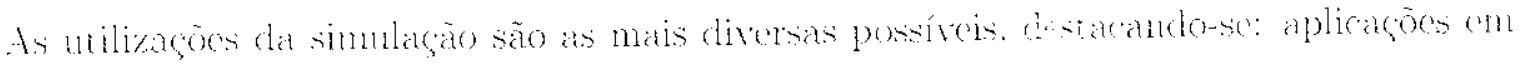

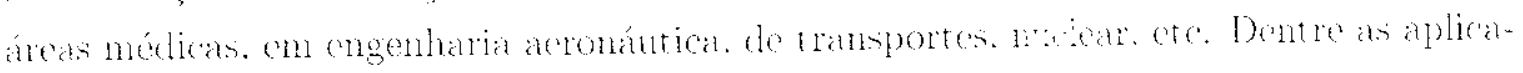

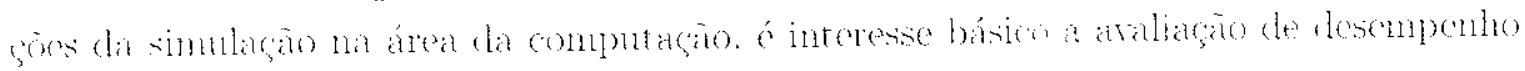

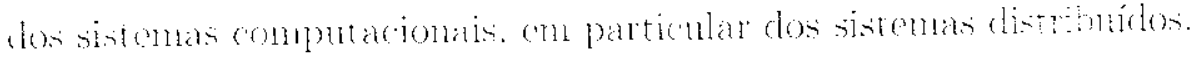

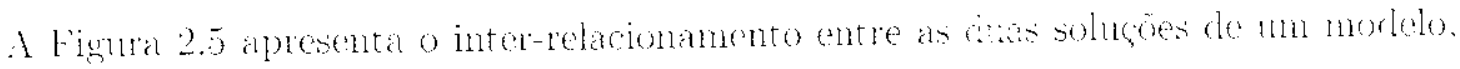

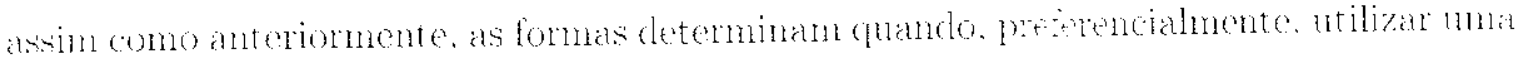
solsça cun detrimento da ontra.

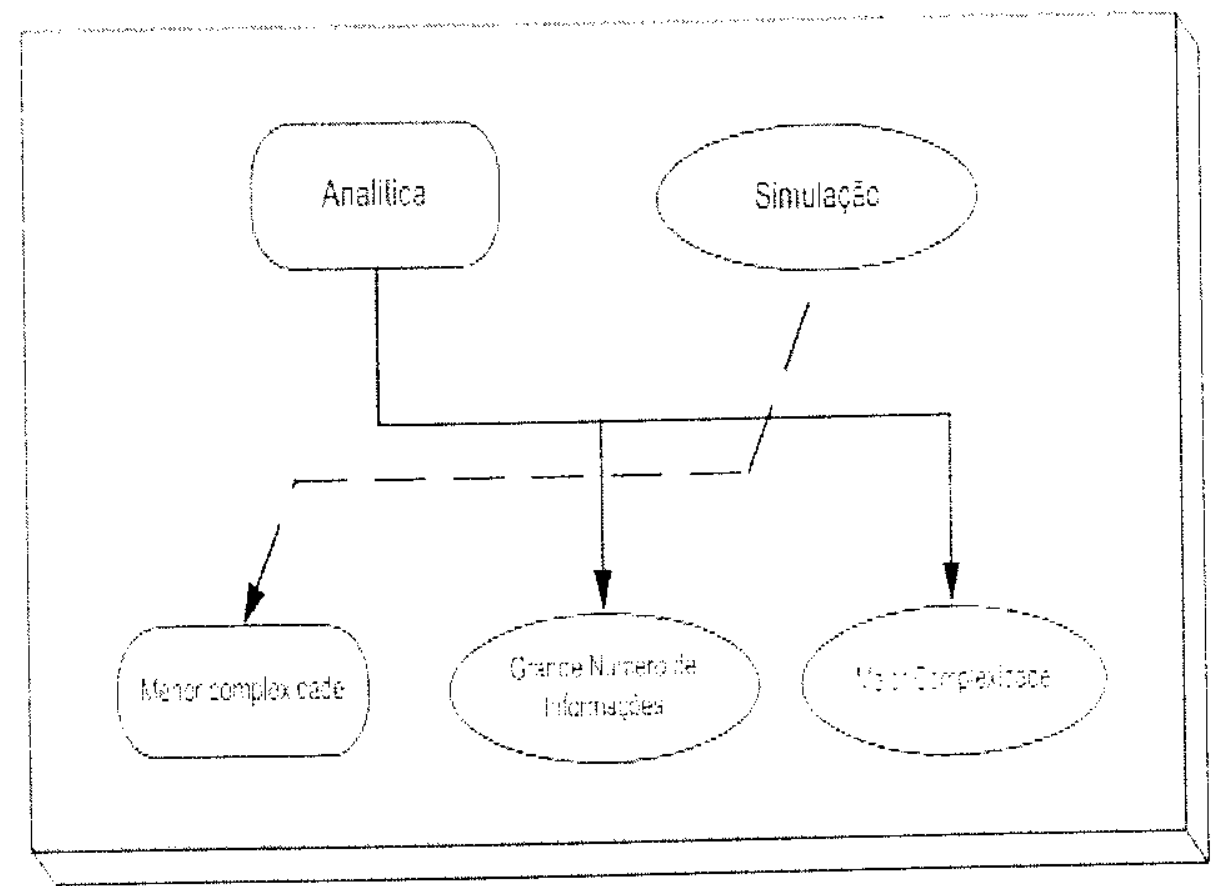

Figura 2.5: Soluço Preforencial para la: Mrorlelo.

\subsection{Considerações Finais}

A crolha de uma técnica para a análise de un sistema omputacional (distribuíclo on coutralizado) está diretamente relacionada ao estado de dot molvimento do sistema que se deseja avaliar. As técnicas de aferiça são bastante atratian para sistenat já existentes on en fase final de implementação. É pouco provável clit. wo atual estado ta arte dos ambintes computacionais. algún coma o risco de desenvere un sistema pata depois 
analisá-lo: nesse caso, técnicas de modelagem rlevem ser adotadas.

Outro aspecto a ser considerado após a escolha da técrica de modelagem é a solução do moctelo: analítica ou por simulação. Apesar da decisão ficar a critério do modelador, há pontos que devem ser considerados. O principal deles é relativo ao grau de complexidade do modelo a ser resolvido, isto é, para modelos menos complexos é mais recomendável a utilização de soluções analíticas, pois são situasóes que, normalmonte, admitem alguns tipos de restriçōos. Para modelos mais complexos, é mais reconendável a utilização de simulação. Ainda pode-se levar em consideração a quantidade de informaçōes que o modelo manipula. Para um número menos significativo de informaşues, a solução analítica é mais apropriada. Para modelos que manipulam una gama maior de informações, é mais reconendável o uso de simulas̃ão.

Para o caso particular de instituiçóes que precisam verificar o desempenho de seus servidores Web, a consideração a respeito da fase do desenvolvimento do sistema não é necessária - o sistema já existe e se encontra em funcionamento. Assim, as técnicas de aferiça (Protótipos, benchmarks, Coleta de Dados) podem ser empregadas diretamente. Embora seja uma técnica de aferição, os protótipos se aplicam melhor no caso de sistemas inexistentes on que se apresentam em fase de construção. Outra pussibilidade para esso caso é a utilização da Coleta de Dados. Como já visto, essa técnica é a que oferece os resultados mais precisos. Entretanto, ela também apresenta problemas. Lm ponto importante a se destacar é que, como os dados são coletados dirante a execução do sistema cada coleta apresenta um resultado diferente. Isso porqu a utilização real de um sistema, vista por um período de tempo, nunca se repete exatantrite da mesma forma. Com isso, a impossibilidade de se reproduzir as mediços pode se tornar um problema.

Por fim, a utilizarão de benchmarks representa mais uma maneina de so avaliar sistemas existentes e, como as outras, apresenta suas vantagens e desvantagens. Os benchmarks podem alcançar resultados bastante procisos e, por utilizar cargaz de trabalho definidas por meio de parâmetros fixos, a reprodução de seus resultados não é um problema. Wais um ponto a se destacar é que, para a Coleta de Dados, ainda é necessária a utilização de monitores, sejam eles de harduare ou softuare. Dependendo dos dados que se pretende coletar, obter esses monitores pode não ser trivial. Já os benchmahk se apresentam em dirersas ferramentas, algumas delas disponíveis publicamente e de fácil aquisição. 


\section{Capítulo 3}

\section{Visão Geral da Web}

\subsection{Introdução}

Em 1989, Tim Berners-Lee. físico ligado ao CERN (Europen Omanization for Nuclear Research), apresentou uma proposta para o gerenciamento das informaçöes geradas por aruela instituigão. Além de um melhor gerenciamento, houve uma preocupacăo em facilitar a colaboracão entre grandes grupos internacionais de? pesquisadores quo utilizaram documentos de tipos variados e em constante mutaço (Tanenbaum, 2002).

A idéia inicial da Web ("Horld-Wide-Web), consistia de unateia de informacoes que poderiam contex ligagöe's (relerencias) con outras informagues relacionatas. Posteriormente: cada ponto dessat teia receberia o none de página. As ligacoes tanbén conhecidats como links, poderiam ser criadas sem preonpacäo com qualquer tipo de organizasão préastabelecida, on scja, uma página poderia referenciar outra que poderia estar en qualquer lugar, conter qualquer tipo de infomagäe, etc. Cada informagäo poderia ser constituíla de texts, imagen, on até mesno de programas executáreis.

Depois de algum tempo passon-se a utilizar o termo hipertexto, que nada mais é do que texto con ligacöes para ontras informaçoes. Com esses documentos, as informaçoes pexterian ser "seguidas" apenas com cliques do mouse. O hipertexto é uma maneira de organizar documentos de forma em que fique mais simples encontrá-los.

A Web näo possui fronteiris no sentido de que um usuŕrio pode ver toda a informação contida nela, como um grande documento hipertexto. Não há a necessidade de saber onde a informação está armazenada. ou qualquer detalhe de sua formatação ou organizaçäo. Por trás dessa aparente simplicidade, a Web possui um conjunto de conceitus, protocolos e convençốes (seģão 3.3 ) que proporcionam. ao usuário, os recursos mencionadas anteriomente.

Finalmente, para a confeção das páginas, Bemers-Lee criou uma linguagem denominada HTML (W3C, 1999). Essa linguagem possibilitou a escrita de documentos em um 
modo padronizado, o que veio a facilitar a apresentagão das páginas por bromsers que constituem programas utilizados para se ter acesso aos documentos na Web.

\subsection{Infraestrutura}

Desdo o seu surgimento, a Web apresonton un creseinento espantoso, tornando-so rapidamente o serviço nuais utilizado na Interne. A Wub superou, em geração de tráfego nat Jntemet, servicos já tradicionais como FTP, Telnet e te-mail. Para muitos usuários. principalnento os leigos, a Wob é a própria Internet.

A Internet, por sua wa, foi concebida no final clos anve 60 , como um sistema peerto-pen. O objetivo da ARPANLT original era comparthar recursos do computagito ao redor dos Estados Lnidos. Os primetros hosts conecrados à ARPANET oram sistemas do computaça independentes e forara conectados näo em um esquema mestre/escravo ou cliente/servidor, mas como pares (jurs) culuialentes.

Servicos como $\mathrm{FTl}^{3}$, Tetnet a a lleb alteraran o conceito inicial da Internet, porque

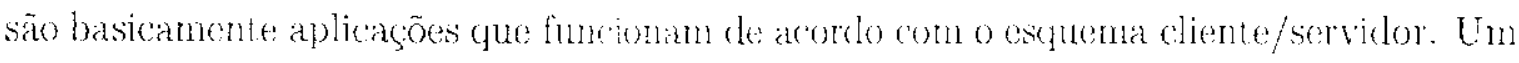
dionte Telnet precisa se concotar a um computador servidor: e un cliente FT' recebe e envia arquivos a $u$ servidor FTP.

A Web pode ser entendida como min giganteco sistema de hipertexto em escala glubal. A infrastrutura dos dados na Wé é basicamente um conjunto de docunentos, páginas, escritos em HTMI. As informagoes thentram-se em repositórios (servidores) espallartos ao redor do mundo e os usuários tên acsso a clas a partir dos brousers (clientos). Dessat Coma, a Web utiliza o esquema (itente/stervidor, assim como FTP e Telnet, sobre a infraestrutura da Internet.

O modelo de interação na Hab biscia-se an um paradigma do requisição/respostat. Assim, quando da utilização da Heb. o brouser - ou navegador - inicia uma conexão com o servidor, faz uma requisição recebe dados (resposta) e desconecta. O modelo é simples e pernite ao usuário navegar livemente para assistir vídeos, ouvir música, ler noticias, participar de jogos interativos e várias outras possibilidades. A tecnologia da Web foi concebida para funcionar em ambientes heterogêneos, considerando-se hardware e software. Para un servidor Web. é indiferente a plataforma en que o navegador está sendo exccutaklo e vice-versa; ele apenas retorna a informaşăo solicitada e o navegarlor se encarrega de apresentá-la ao usuário. Lm cliente näo precisa ter um enderego permanente; não precisa ter uma conexão contímia con at Internet; ele precisa apenas saber como fazer una pergunta e ouvir a resposta.

Na Web, particulamente, a portabilidade é garantida através da utilização de dois pałlöes em particular: 
- a linglizgem HTML: define um método para a confeção de págrinas. Permite ao editor do documento definir sua estrutura, formatação e estabelecer ligarcóces com untros documentos na theb. Os navegadores são capazes de ler um documento HTML, interpretáto e então gerar una apresentaçăo deste documento ao usuário.

- oprotocolo HTTl: a comunicaça entre os climtes (navegadores) es servidores é feitat utilizando-se o HTTP (scgăo 3.3.3) que funciona sobre outro protocolo conhecido corno TCP (seção 3.3.2).

\subsection{Protocolos}

Para que o processo de comunicagão nntre os diversos sistemas (handuate e sofluare) existemtes em rma rode do computadores seja possivel, é necestária a existênoia de um conjunto de regras e convensōes que permitam disciplinar a troca de informaçous. Fssas regras comuns constituem os chamados protocolos de comunicaşăo.

Diferentes empresas comecaran a desenvolver protocolos proprietários para fazer a

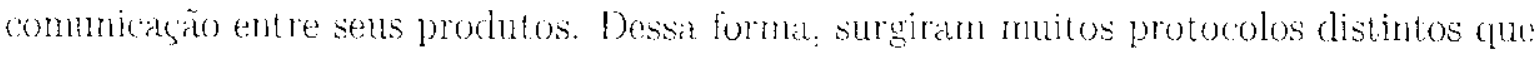
năo se comunicavam um com o outro. Vão tardou para que fosse percebida a necessidarles de um protocolo padrão, através do qual todos poderiam se comunicar.

O conjunto de protocolos TCI/IP veio ao encontro desse propósito e é atuahnente a maneira mais ut ilizada para a commicagäo en redes de computadores. Ltilizado já há un bom tempo nos EUA, o TCP/IP foi inplementado pelo DoD (Departoment of Dofense) com o fim de integrar seus computadores em uma única rede, a Internet.

O TCP/IP foi desenvolvido para permitir a interoporabilidade de serviços ontre computadores ligados a redes físicas bascadlas tm tenologias distintas. Lintre as tecnologias abtangidas inchuen-e: redes locais de diferentes tipos, concxós seriais ponto a ponto e redes X.25. O modoh admite a interligaç̃o direta ou indireta de um número arbitrário de redes distintas, e exige de uma rede participante o suporte para um serviço de entrega de pacotes. A partir dessa base, cria-se uma rede virtual utilizando um esquerna global de enderegrnmento (IP - seção 3.3.1) e oferecendo vários tipos de serviços: serviços orientados à conexão, utilizando TCP (seção 3.3.2), e serviços sem conexão, utilizando UDP.

\subsubsection{IP}

Os serviços Internet, orientados ou não à conexão, estão construíclos sobre um sistema de entrega de pacotes cuja unidade básica de transferência éo latagrama IP (Tanenbaum, 2002). ou simplesmente datagrama. O datagrama é dividido en cabeçallo e áréa de dados. O cabeçatho (Figura 3.1) possui uma parte fixa de 20-bytes e outra parte opcional de tamanho suriável. 


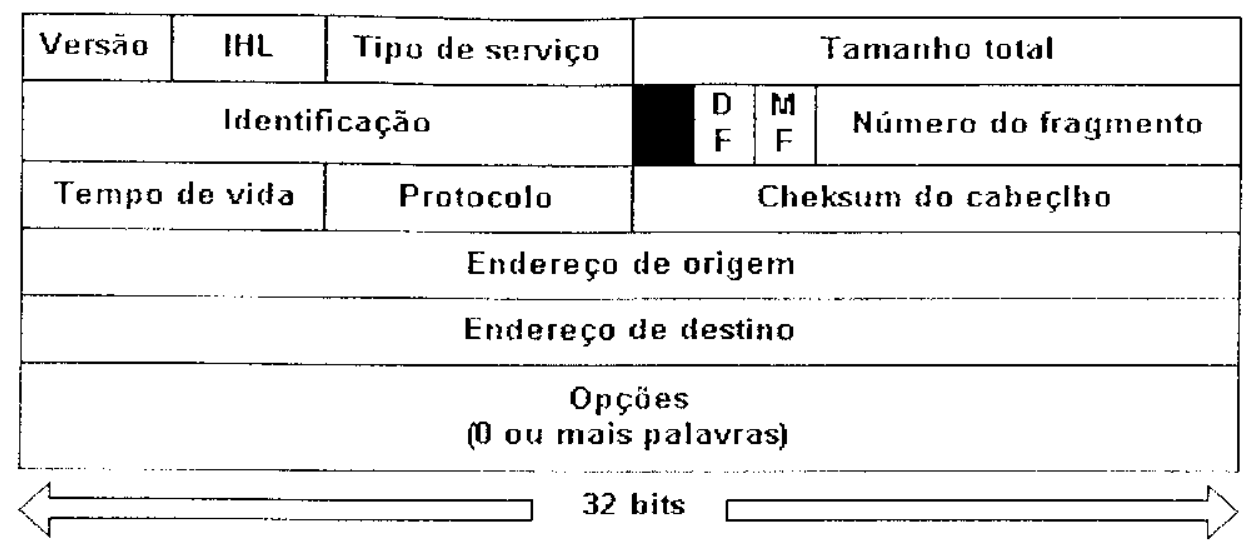

Figura 3.1: Cabecalho IP

O campo Versão indica a qual versão do protocolo o datagrama pertence. Pela indusão da versão em cada datagrama, é possível haver transiçoes entre versões que duren meses, até anos, com algumas utilizando a versão antiga e outras, a nova.

Cono o tamanho do cabeçalho não é constante, o campo IHL é usado para especifiear este tamanho em palavras de 32-bits.

O campo Tipo de serviço permite que o host indicue à sub-rede o tipo de serviço desojado. Várias combinaçóes de confiabilidade e velocidade são possíveis. Para a transmissãto de arquivos, por exemplo. uma transmissäo sem erros é mais importante do que uma transmissão rápida.

Tamanho total indica o tamanho total do datagrana - incluincto cabegalho e darlos. O tamanho máximo é de 65.535 bytes.

Jdentificação é necessário para permitir à mácquina destino determinar a qual datagrathir o fragmento recém chegado pertence.

En seguida há um campo. näo utilizado, cle um bit e mais dois campos, DF e MF: tambern do un bit. DF significa "rãa fragmenar" (Don't Fragmenl). Ele funciona como uma orem aos rotcartores para que não fragmentem o datagrama pois a máquina dostino não seria capaz de montá-lo novamente.

MF significa "mais fragmentos" (More Fragments). Todos os fragmentos, exceto o último, possuem esse bit setado (com valor 1). Isto é nocessário para saber quando todos os fragmentos do datagrama chegaram.

O campo Número do fragmento (Fragment offset), diz em que lugar do datagrama o fragmento se encaixa.

Tempo de vida, (Time to live), é um contador que limita o tempo de vida dos pacutes. Ele deve ser decrementado a cada hop (roteador por onde passa). Quando ele chega a zero, o pacote é descartado e um pacote de aviso é enviado a márquina de origem. 
Quando a canada de rede monta um datagrama completo ela precisa saber o que fazer com ele. O campo protocolo indica qual processo de transporte dar ao datagrama. TCP é uma possibilidade, mas LiDP e vários ontros também podem ser adotados.

O Checksum do cabeçalho, (Heuder checksum), é utilizado para a veriftcarão dos clados do cabegalho do parere.

Os campos Endereço de origem e Endereço de destino indican respectivamente o cuderego IP de origem e destino do pacote.

O campo Opções é utilizado en testes para a experintentaço de novas idólas. Sen tamanho é variável.

\section{Endereço IP}

Cada mácpuina (host) o roteador na Intemet tem um endereço IP. que codifica sou múmero de rede e número de host. A combinaçào é única: não existem duas máquinas con o mesmo IP. Os enderecos säo de 32 bits e utilizados nos campos Sotmee addecs.s e: Destination address dos pacotes.

Alguns enderecos possuem significado especial. como mostrado na Figura 3.2. () valor O significa "esta rede" ou "este host". O valor I é usado cono enderego de broudrast para referemiar todos os hosts de ma determinada rede.

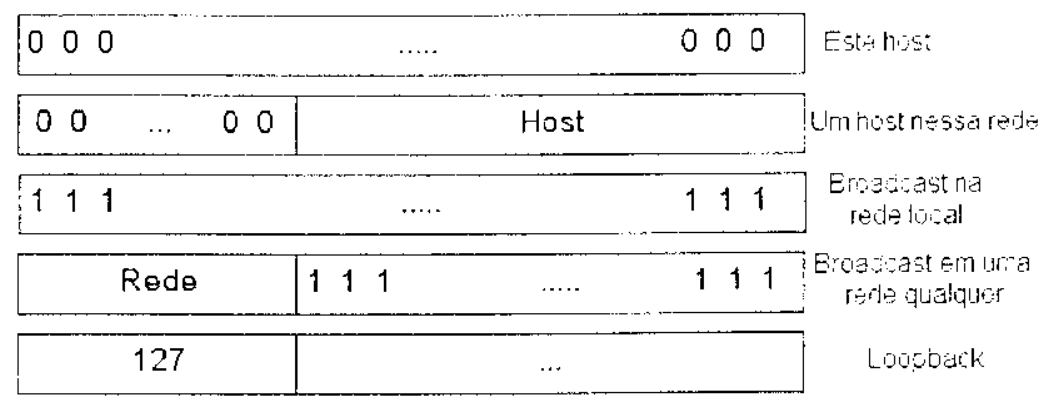

Figura 3.2: Enderegos IP especiais

O endereso IP 0.0.0.0 é usado pelos hosts em sua iniciaço e descartarto depois disso. Un IF com o valor o para rede referencia a rede atual. Esses enderesos permitem às náquinas referenciarem sua própria rede sem saber seu número. O lP consistindo apenás de 1 s permite broulcast na rede local. Lm endereço com un numero de rede apropriado e apenas $1 \mathrm{~s}$ no campo de host pernite à máquinas envarem pacotes en broadcast para redes em qualquer lugar da Internet. Finalmente. todos os enderecos da forma 127 .xx.yy.zz são reservados para testes de loopback. Pacotes enviados para esses endereços não são colocados na rede; eles säo processados localmente e tratados como pacotes vindos da rede. 


\section{$3.3 .2 \mathrm{TCP}$}

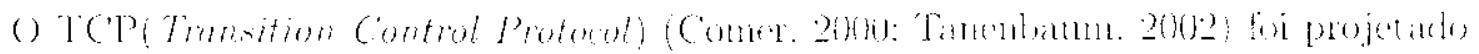

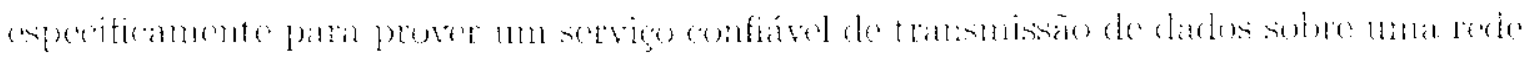
nàu confiável.

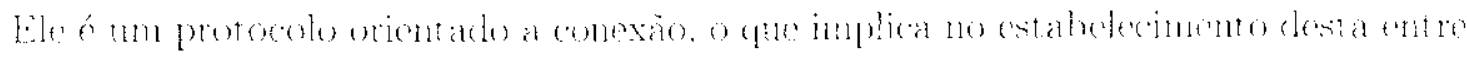

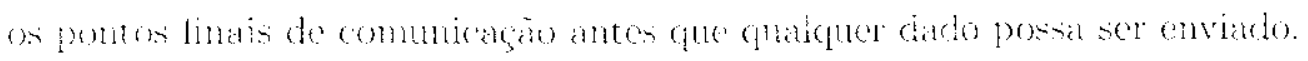

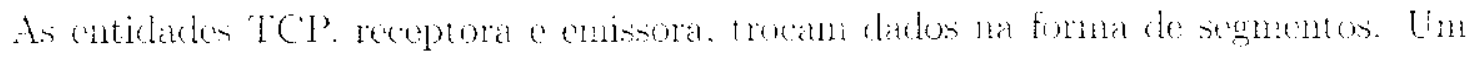

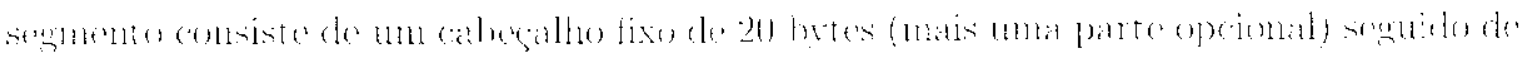

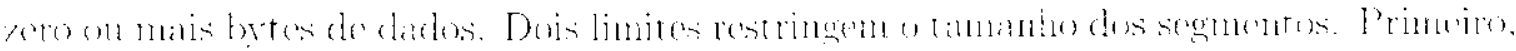

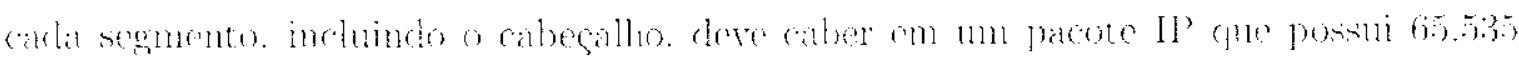

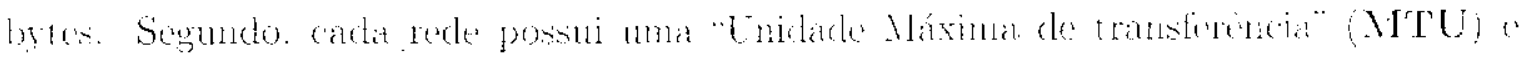

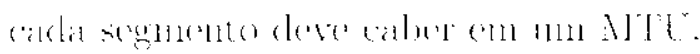

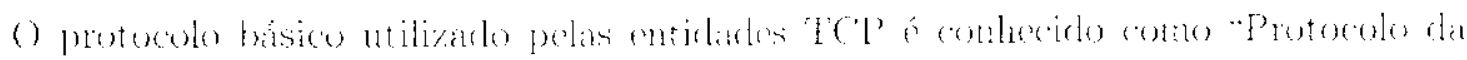

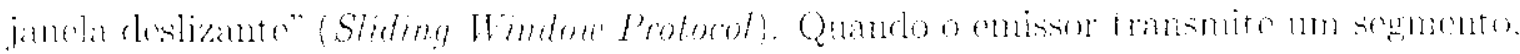

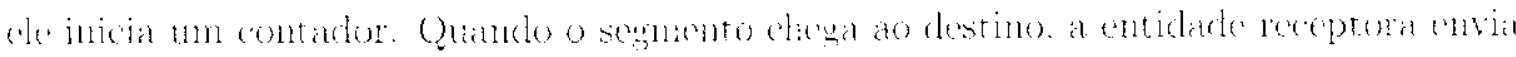

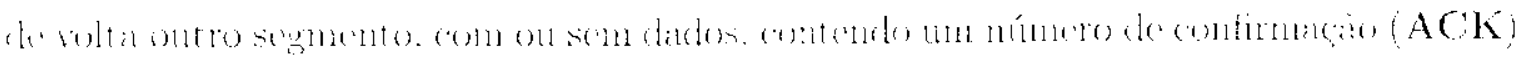

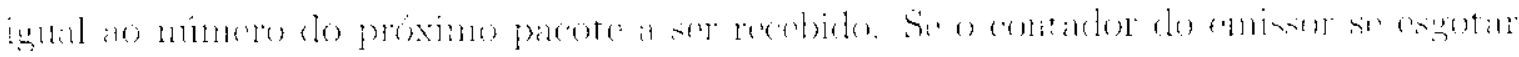

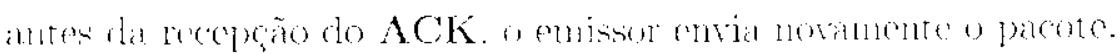

\section{Cabegalho TCP}

A Figna 3.3 mostra un segmento TCP. Cada segmento possti un caberallu que

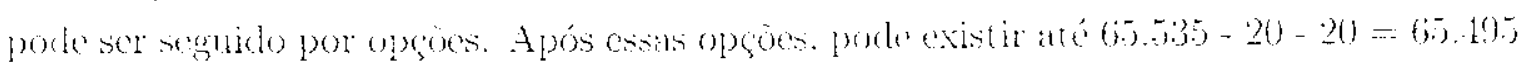

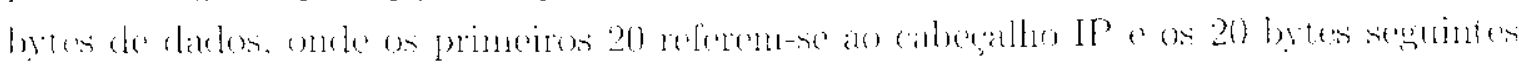
an cabegatho TCP.

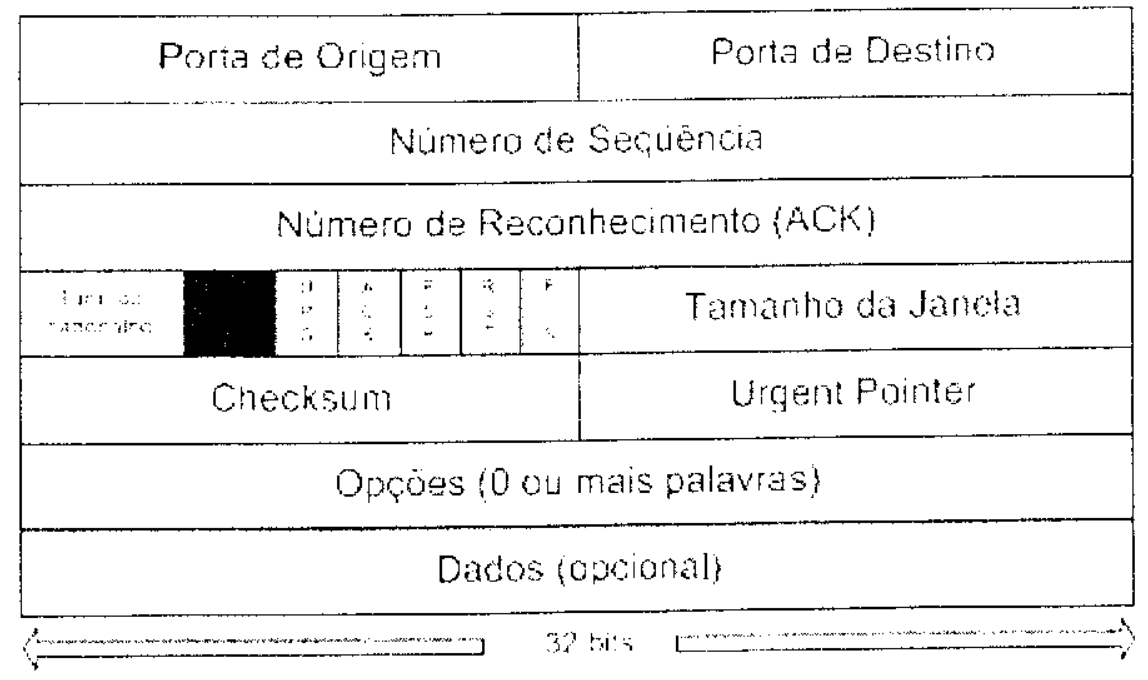

Figura 3.3: Cabegalho TC'P 
Os campes Porta de origem e Porta de destino identifican os ports finats da conexão.

Número de seqüência idenifica a posição do segmento cru toda a sinitencia e o Número de reconhecimento, (Acknowledgement number), indica o próxin segmento esperado.

Tamanho do cabeçalho indica o tamanho, um palavras de 32 bits, do cabegalho.

Na secuiencia aparecem seis fags de um bit. Vigent Pointer (URG) é isato para indicar onde os dados urgentes estão. ACK indica quando o Acknowldg ment number é válido. O campo PSH é utilizado para indicar ao receptor que entregue os dados à

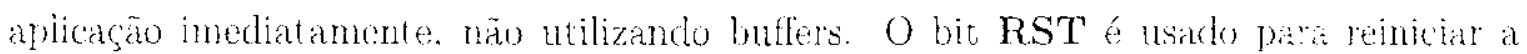
conexão que se tomon confusa devido a algun problema. SYN é usato para detabelecer conexôs. Uma requisição de conexão possui $\mathrm{SYN}=1$ e $\mathrm{ACK}=0$. O bit Fl. libera a conexão. Ele indica que o emissor não possui mais dados para enviar.

O contrule de fluxo no TCP é feito através de uma "janela deslizante" de tamanho

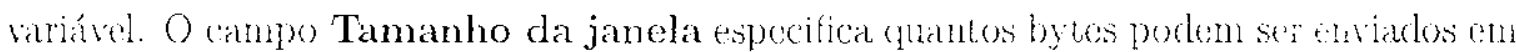
um segrnerito.

Checkem o utilizado para prover alta confiabilidade. Ele verifica o chegalho e os dados.

Finalmente, o campo Opções é utilizado para prover maneiras de adicionar funcionalidades extras näo existentes no cabegalho regular.

\subsubsection{HTTP}

O protocolo IITTP (Hypertext Thansfer Protocol) é o elemento que une cis partes quet

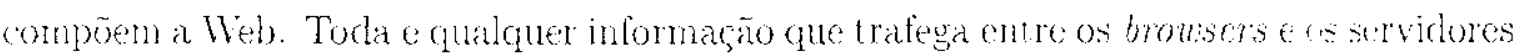
web o faz dentro de uma mensagem IITTP.

O IITTP, portanto, é o protocolo usado para fazer acesso aos objetos armazenados no servidor wob. Ele é um protocolo em nível de aplicasăo que assime a existincia de um servigo de transporte confiável, orientado à conexão, como o TCP. Lna transuão HTTP se desenrola segundo um mecanismo do tipo requisigão/resposta (request/rytoly), que será tratado com detalhes posteriormente. O HTTP é um protocolo do tipo statéss, ou sejat, o servidor não guarda nenhuma informação en relação ao estado dos chientes: se houver alguma falha na execução da tarefá é responsabilidade do cliente subneter ramamonte a transação, fomecendo todas as informaçôes necessárias para completá-la.

É importante destacar que embora - sob o ponto de vista do usuário - umra solicitação de página HTHL se resuma muitas vezes a apenas um clique do mouse. na verdacle: ela freqütentemente dá origem a várias solicitagoes HITP que são enviades do brouser para o servidor web (seguidas de suas respectivas respostas no sentido contrírio). Isso 


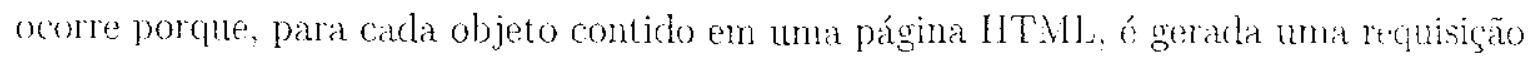
independente ao servidor. No protocolo HTTP 1.0, isso implica em estabelecer ma nova conexão ' $\mathrm{TCP}$ para cada objeto solicitado, o que pode levar a uma sobrecarga desn cessária no servidor ena rede.

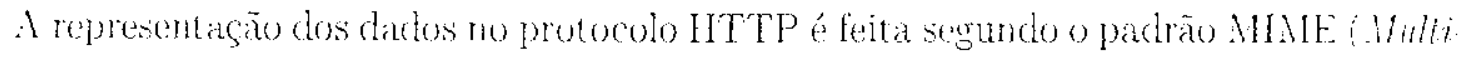
Purpose Internet Wail Entensions), definido na REC 1521 (Borenstein, 1993). Wunbém utilizado no protocolo SWTP para a codificação dos dados nas mensagens do correio tetrônico. Antes de iniciar uma transação, o browser e o servidor web geralnente rugocian os tipos de dados que serão trocados, o que também contribui para a sobrecarga inerente ao HTTP.

\section{Mensagens de Requisição e Resposta}

O HTTP define um formato padrão para as mensagens de requisicão e resposta. Uma reculisiça consiste tipicamente de una linha informando a ação a ser executadat no servidor, seguida de uma ou mais linhas de cabegalho (os parâmet ros) e do corpo da wereagem (opcional), como mostrado a seguir:

- Request line: Comtém o método IITTP invocado (a ação) a localizaçán do objeto no servidor o a versão do protocolo HTTP utilizada.

- Request hader: O cabegalho contém campos que o cliente pode utilizar para enviar informacoes ao servidor como. por exemplo, para informar os tipos de dados que ele écapar de aceitar, numa espécie de negociasão.

- Compo da mensagem: As vezes é urilizado quando o cliente precisa passer dados adicjonais ao servidor, como no caso do método POST.

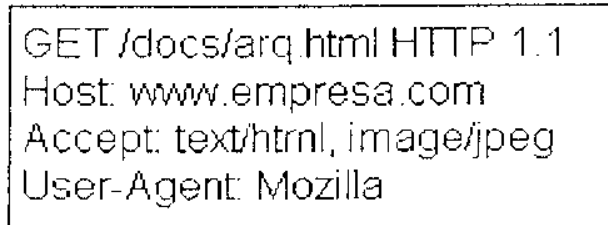

Figura 3.1: Exemplo de una requisiģa IITTP

No exemplo da Figura 3.4, o eliente solicita (GET) o arquivo/docs/arq.htnil do servidor www.empresa.com usando o protocolo HTTP 1.1. O campo Accept no cabecalho infoma que o cliente sabe como tratar texto em formato HTML (text/html) e imagens em formato JPEG (image/jpeg). O campo User-Agent informa ao servidor qual o tipo do brouser. 
Para as respostas, o HTTP detemina que as mensagens devem conter uma linha de status, seguida de um ou mais campos e do corpo da mensigen, precedido por uma linha on branco, como descrito a seguir:

- Response header: Contérn a versão do protocolo, o código de status e uma explicação do messmo.

- Request hender: Vários (ampos que informam as características do servictor e de objeto retomado para o cliente.

- Corpo da mensagem: Contém o objeto retomado, na maioria das vezes um documento HTMI.

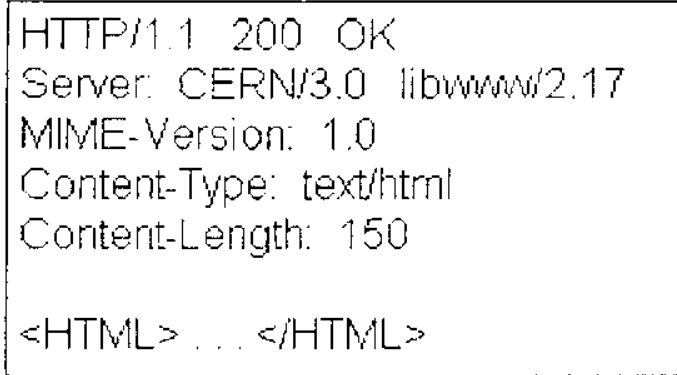

Figura 3.5: Fxemplo de umat resposta HTTP

A Figura 3.5 mostra um exemplo de uma resposta HTTP 1.1 válidia. O código 200 reporta que a requisiçäo foi bern-sucedida. O campo Server informa o tipo do servidor wel) (CERA 3.0) e o campo Content-Type diz que o objeto retornado és um documento HTMI, cujo tamanho é do 150 bytes (Content-Length). Finalmente, tem-se uma linha em branco e o documento propriantente dito.

\section{HTTP 1.0 e 1.1}

O protocolo HTTP 1.0, definido na RFC 19-5 (Berners-Lee et al., 1996), foi introduzido juntamente com a Web. em 1990. Nesta versão inicial, ele nada mais era que um nodo simples de recuperar diabs através da Internet. Con o crescimento da Web, surgiram novos requisitos e algumas de suas fraquezas foram aparecendo.

A primeira delas é que o HTTP 1.0 exige o estabelecimento de uma nova conexão TCP para cada objeto solicitado. No início, en que os documentos da Web eram constituídos basicamente de texto, isso não chogava a ser um problema, porém, atualmente, em que uma simples página HTMI, pode conter dezenas de pequenas imagens, isso tende a causar uma grande sobrecarga no trálego da Internet, bem como nos servidores. O protocolo HTTP 1.1, definido na RFC 2616 (Fielding et al. 1999) e padronizado em 1999 pelo W3C (World Wide Web Consortium). usa cono default o esquena de conexóes persistentes, 
que permite que uma mesma conexão TCP seja usada em várias transaçōes HTTP, o que 6 bem mais eficiente.

O IITTP 1.1 também permite fazer o pipelining de reculuisigoes. Neste caso, várias requisiçoes são enviadas em stuüiencia, sen aguardar pelas respostas. Isso é bastante útil, por exemplo, para recuperar as imagens de unia prigina, principalmente em ambientes que possuam uma alta latência päriz o estabelecimento de conexótes TCP.

Cltimamente, tem se disitminado o uso de caches na Web, como forma do diminir a latência no acesso aos servidores, bem como o tráfego na rede devido a transferências desnecessárias. En reconhecimento a isso, nesta nova versão do HTTP também foram inclúdos comandos específices para a manipulasano do caches, tanto pelos servidores (weh) e proxy) quanto pelos clientes.

\subsection{Caracterização de Carga da Web}

O desempenho de um sistenat distribúdo com muitos clientes, servidores e redes, depende em muito das características do sua carga. Assim, o primeiro passo em qualquer estudo de avaliação do desempenho é o entendimento e a caracterização de sua carga (Nenascé \& Almeida, 1998; Fonseca et al., 2003). A carga de um sistema pode ser definicla cono o conjunto de todas as entradas que recebe, durate un intervalo de tempo determinado; de seu ambiente. Por exemplo: considere um Banco do Dados (BD) observaco durante 1 hora onde ocorreram 70.000 transações. A cargd no BD durante aquela hora é o conjunto das 70.000 transaçoes e as características dessa carga são representadas por um conjunto de informaçós (tompo de CPU, nímero de operaçöes de $1 / O$, etc.) para rada uma das 70.000 transaçós.

Fica clara a difieuldade de lidar con cargas reais que possuam grande numero de elementos. Entretanto, para trabalhar com problemas práticos, é preciso reduzir a informax̧ão necessária para descrever a carga. Em outras pałavras, é necessário construir un modelo de carga cue contenha as características mais relevantes da carga real.

A escollat das características e parâmetros que irão descrever a carga depende do propósito do estudo. Se a intenção é o estudo da relação Custo/Benefício de se criar um "cache proxy" para um site, cntão as características podem ser a frequiência de referência a um documento, seu tamanho, etc. Entretanto, se o interesse está em determinar o impacto de una CPU mais veloz no tempo de resposta de un servidor Web, as informações utilizadas devem ser outras.

Ainda que alguns sistemas exijam um método específico para a caracterização de sua carga, há uma metodologia (Menascé \& Almeida, 1998) que pode ser utilizada, de maneira geral, na caracterização de qualquer tipo de carga (Calzarossa \& Serazzi, 1993; Arlitt., 1996; Vallamsetty, 2003). 


\subsubsection{Metodologia para a caracterização de carga}

\section{Escolha de um ponto do análise}

A carga global de un sistema distribuído é a combinação de diferentes cargas "vistas" por diferentes componentes do sistema. Para uma máquina cliente, en que um usuário manipula um browser; a carga apresentada são os cliques dados pelo usuário e as respostas vindas dos servidores Web. Já do ponto de vista do servidor; a carga constitui-se das recuisições HTTP que chegam dos clientes. Na visão da rede, a carga são os patotes que circulam por dela.

\section{Identificação dos componentes básicos}

Neste passo, são identificados os componentes básicos que compõem a carga. Transações e Requisiçōes são os componentes mais usuais. A escolha dos componentes depende tanto da natureza do sistema como do objetivo da caracterização. Em um servidor Web, por exemplo, a carga é composta das requisições que chegam dos clientes.

\section{Escolha dos parâmetros de caracterização}

Uma vez que os componentes tenham sido identificados, o próximo passo é escolher quais parâmetros caracterizam cada tipo de componente básico. Os parâmetros podem ser separados em dois grupos: um diz respeito à intensidade dia carga e o outro à demanda de servigo dos componentes. Em cada grupo pode-se obter as seguintes informasões:

- Intensidade da carga:

- taxa de chegada

- número de clientes e tempo de "pensar" (think time)

- número de processos ou threads em execução simultaneamente

- Demanda de serviço, especificada por k-tuplas $\left(D_{i 1}, D_{i 2}, \ldots, D_{i k}\right)$, onde k é o número de recursos considerados, e $D_{I J}$ é a demanda de serviço do componente I no recurso J. Por exemplo, a 2-tupla (CPU, I/O) da forma $(0,0095 \mathrm{~s}, 0,04 \mathrm{~s})$.

\section{Coleta de dados}

Este passo especifica valores para os parâmetros de cada componente do modelo. São geradas tuplas de caracterização de acordo com o número de componentes da carga. A coleta de dados inclui as seguintes tarefas: 
- Identificar os intervalos de tempo (time windows), que definem as sessões de medida. A observação contínua de um sistema durante dias ou semanass, permite ao analista captar os intervalos de tempo apropriados nos quais possa basear seus estudos.

- Monitorar e medir as atividades do sistema durante intervalos de tempo definidos.

- Dos dados coletados, definir valores para cada parâmetro de caracterização de cada componente da carga.

\section{Partiçāo da carga}

Cargas reais podem ser vistas como uma coleção de componentes heterogêneos. Em relação no nível de utilização de recursos, a requisição por um vídeo difere muito de uma requisição por um pequeno documento HTML. Por essa heterogeneidade, representar uma carga através de uma simples classe, significa perder tanto a representatividade da caracterizagão quanto o poder de previsão do modelo. Técnicas de partição são utilizadas para dividir a carga em classes, de forma que sejam formadas por componentes homogêneos. A seguir são detalhados alguns atributos para a partição de carga.

Utilização de recurso - O consumo de recursos por componente pode ser usado para quebrar a carga em classes. No caso da Web seria possível dividir as requisições HTTP segundo seu consumo esperado de CPU e I/O. A Tabela 3.1 mostra um exemplo de classes desse tipo.

\begin{tabular}{|c|c|c|c|}
\hline Transação & Freqüência & $\begin{array}{c}\text { Tempo máx. de CPU } \\
(\mathrm{ms})\end{array}$ & $\begin{array}{c}\text { Tempo máx. de I/O } \\
(\mathrm{ms})\end{array}$ \\
\hline \hline Trivial & $40 \%$ & 8 & 120 \\
Leve & $30 \%$ & 20 & 300 \\
Védia & $20 \%$ & 100 & 700 \\
Pesadà & $10 \%$ & 900 & 1200 \\
\hline
\end{tabular}

Tabela 3.1: Partição de carga baseada em utilização de recursos

Aplicaçōes - Uim agrupamento de acordo com a aplicação também pode ser aplicado. Se pretende-se estudar o tráfego na Internet por exemplo, pode-se quebrá-lo em classes como Web, telnet, FTP e outras.

Objetos - Pode-se dividir a carga de acordo com o tipo de objeto tratado pela aplicação. Na Web, encontram-se requisiçōes de objetos que vão desde simples texto ou páginas HTML a imagens, audio, vídeo, documentos formatados, páginas dinâmicas e outros. Uma requisição de uma página HTML de alguns poucos kibbytes impõe uma demanda sobre um servidor web que é muito diferente daquela originada, por exemplo, pelo download de um vídeo com alguns megabytes.

Origem geográfica - Devido aos atrasos presentes em redes de grandes dimensões (WANs), torna-se importante fazer uma distinção entre transações ou requisições que são 


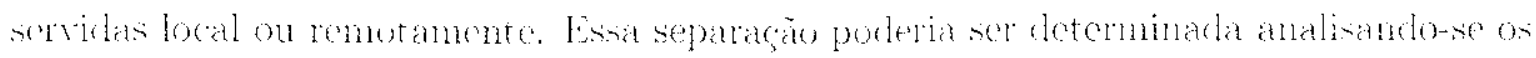
ervereges IP dos clientes.

\subsubsection{Cargas em rajadas}

Novas catracteristicas tem sido observadas on sistomas distribudos de grandes an-

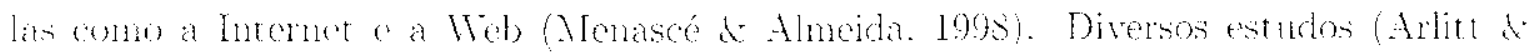
Willimison, 1996; Crovella \& Bestantos. 1997: Scheuemann et al. 1997) revelaram importantes propriedades do tráfego en redes. tal como anto-similaridade. novas politicas

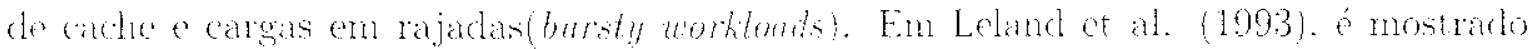

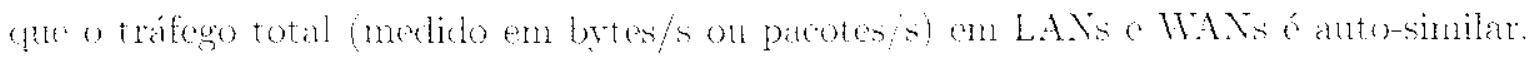
I Figura 3.6 plota um típico comportanento auto-inilat. De aconto cont (Crovellat 8 Bestarros, 1997). ats rajadas de tráfego são visíreis mesmo quando o int crvale de temupo

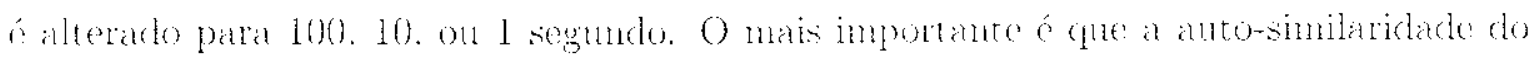

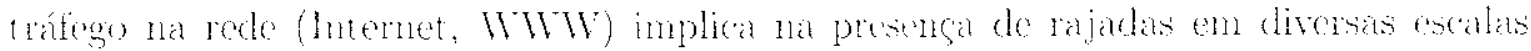
de tempo. Além disos. essa caracteristica tem un grande impacto no desenpenio de sistemas que funcionam em recle.

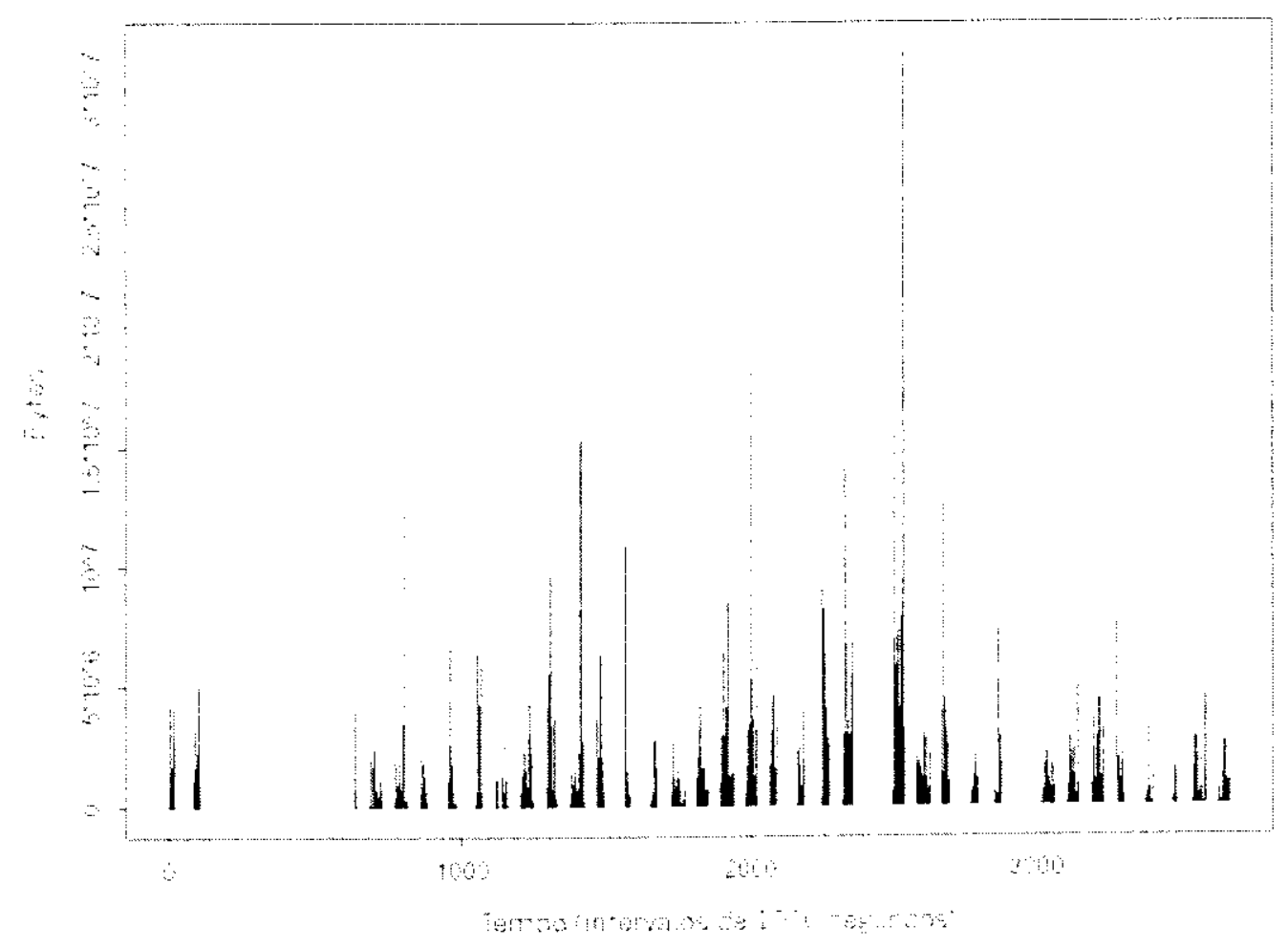

Figura 3.6: Tráfego dat Web em rajadas. (Crovella (t Bestavros. 1997)

Va Web. as requisiçoes HTTP são geradas por um grande número de clientes. Cada 
um desses clientes apresenta um "tempo de pensar" com grande variância. Além disso, o "tempo de pensar" de cada um não é independente; fatores como padrões comportamentais humanos e a publicagãa de conteúdos na Web de forma agendada causam uma grande correlasão entre as requisições geradas pelos clientes. Como resultado, o tráfego de requisições chega ao servidor em rajadas, e essa característica pode ser verificada em diversas escalas de observação (Crovella \& Bestavros, 1997) e com picos que excedem a taxa média em fatores de 8 a 10 vezes (Sterens, 1996). É inportante ressaltar que esses picos de requisiçoes podem exceder facilmente a capacidade do servidor, por isso a importância da inclusão dessa característica no estudo de scrvidores Web.

\subsection{Arquitetura de Servidores Web}

O software de um servidor Web, também conhecido como servidor HTTP, são prugramas que controlam o fluxo de entrada e saída de dados em um computador conectado a uma intranet ou à Internet. Basicamente, o softuare aguarda requisiçóes ITTP vindas de clientes na rede. O programa servidor estabelece a conexão entre cle e o cliente, envia o arquivo requisitado e retoma ao estado do espera. Com o propósito de melhorar o serviço, os servidores HTTP incorporaram diversas inovaçoes que aconteceram ao longo do tempo. Dentre essas inovaçoes pode-se destacar as estratégias de concorrência, que estão sempre em foco quando o assunto é desempenho ( $\mathrm{Hu}$ et al., 1997). De acordo com essas estratégias, os servidores podem ser classificados como (Hu et al, 1998):

\section{Iterativo}

A maneira mais simples de se implementar um servidor é não ter concorrência. Esse servidor simplesmente recebe cada requisiça e atende uma de cacla vez, respeitando a ordem: a primeira que chega é a primeira a ser atendida (FIFO). Esse tipo de servidor não funciona bern, exceto em casos de cargas muito baixas. Por isso ele é muito pouco utilizado atuahnente.

\section{Um processo por requisição}

A utilização da chamada de sistema fork(), para criar um processo novo a cada requisição recebida, é uma estratégia conum de concorrência em servidores Web. No entanto, essa estratégia não funciona bem em servidores com cargas altas porque a sobrecarga da criaçäo de novos processos prejudica o desempenho durante picos de requisições.

Existem várias técnicas para se minimizar essa sobrecarga. O servidor Apache (Apache Software Foundation, 2003), por exemplo, elimina o problema através de um conjunto de processos pré-inicializados (pre-forked). Para implementar esse esquema, o Apache 
inicializa um certo número de processos antes de receber qualquer requisiçâ. Quando una requisição HTTP chega, um processo dedicado é escalonado para seu atendimento. Essia estratégia alcanca bons resultados para cargas moderadas. Entretarto: durante cargas muito altas; a taxa de requisiços ultrapassa a quantidade de processos presentes no conjunto, quando a estratégia volta a funcionar como no início, um processo por requisição.

Além disso, servidores com múltiplos processos podem sofrer de mais uma sobrecargat, devido à constante troca de contexto. Por isso, os servidores recentes utilizam apenas um processo de acordo com uma arquitetura dirigida a eventos. Um servidor dese tipo usa outra chamada de sistema, select(), para aguardar eventos simultaneamente em todas as conexões que estão sendo manipuladas pelo servidor. Quando select() enrega um ou mais eventos, o servidor invoca manipuladores para cada conexão pronta.

\section{Uma thread por requisição}

Essa técnica é similar à anterior, exceto pelo fato do que são usadas thrends no lugar de processos. Para cada requisição recebida, uma nova thread é criada.

A estratégia que utiliza threads é mais eficionte do que a que utiliza processos, pois o custo para se criar uma nova thread é muito menor que o de se criar um nowo processo. Isso ocorre porque um processo filho requer uma cópia do espaço de enderesamento de seu processo pai, enquanto as threads compartilham um espaco de enderçamento com outras threads no mesmo processo.

\section{Thread pool}

Pode-se alcançar desempenhos melhores poden ser alcançados por meio da mudança do modelo de conjunto de processos para conjunto de threads. Nesse modelo thread pool, um conjunto de threads é criado na iniciação da máquina. Todas as threads fican blọqueadas no estado accept, aguardando requisiçôes dos clientes. Isso elimina a sobrecarga de criar una nova thread para atender cada nova requisição. Essa estratégia é urilizada pelo JAWS (J. Hu, 1998; Silva \& Kulesza, 2000).

Entretanto, nem sempre é possível um suporte eficiente para um grande poo! de threads. Por isso alguns servidores utilizam um sistema híbrido em que um pool de threads de tamanho moderado é multiplexado entre as diversas conexões, utilizando eventos para associálas às threads.

\section{Única thread}

Threads são uma boa escolha pois funcionam bem em plataformas multiprocessadas. Entretanto, para plataformas com uma única CPU, o uso de threads aumenta a sobrecarga 
devido a trocas de contexto e sincronização. Assim, a estratégia de um única thread funciona melhor. Um servidor com uma única thread difere de um interativo no fato de que ele manipula múltiplas requisições ao mesmo tempo. Essa estratégia é mais complicada para implementação devido à utilização de I/O assíncrona. O potencial, entretanto, são servidores mais rápidos para plataformas uniprocessadas.

\section{Cargas dinâmicas}

Tudo o que foi discutido acima assume requisiçoes a documentos estáticos. Entretanto, o protocolo HTTP dá suporte também a requisiçōes a documentos dinâmicos cujo conteúdo depende de parâmetros particulares e do tempo de chegada da requisição. Documentos dinâmicos são criados por programas auxiliares que são executados como processos separados. Para tornar mais fácil a construção desses programas auxiliares, foram definidos diversos padrões de interface como o CGI (CGI, 2002) e o FastCGI (FastCGI, 2002). A interface CGI cria um novo processo para manipular cada requisição a documento dinâmico e o FastCGI permite processos persistentes para o tratamento desse tipo de documento.

Há uma tendência para a construção de servidores Web que trabalhem de acordo com uma arquitetura onde um pequeno conjunto de processos implementa a funcionalidade do servidor. Há um processo principal responsável pelo atendimento de todos os documentos estáticos e os documentos dinâmicos são criados por processos auxiliares. Dessa forma, a sobrecarga devido à troca de contexto atinge o ponto ideal, pois fica reduzida ao absolutamente necessário.

\subsection{Considerações Finais}

Neste capítulo foi apresentado um panorama geral da Web que abordou inicialmente a infraestrutura da Internet e posteriormente os protocolos TCP/IP e HTTP. Nessa primeira parte foram apresentados o surgimento e o método de funcionamento da Web. O protocolo HTTP foi estudado com maior detalhe por ter grande importância no funcionamento e no comportamento da Web.

A caracterização da carga presente na Web foi apresentada através de uma metodologia de caracterização. Cada etapa foi discutida e um exemplo de aplicação prática na Web foi apresentado. Posteriormente foi discutida a importância que cargas auto-similares, que se apresentam em rajadas, possuem no estudo de sistemas distribuídos de grande escala como a Internet e a Web.

Finalmente foi feita uma discussão de algumas das arquiteturas para servidores Web existentes atualmente. Foram apresentados servidores Iterativos, que funcionam de maneira simples e sem qualquer tipo de concorrência; servidores com concorrência em nivel 
de processo que, por isso, apresentam sobrecarga devido à excessiva troca de contexto; e servidores que utilizam threads no lugar de processos e conseguem uma certa vantagem por exigir menos recursos da máquina.

A Web é um sistema distribuído que está em constante mutação. Assim, paradigmas e protocolos utilizados atualmente podem ser descartados em pouco tempo. As arquiteturas de servidores também se enquadram nesse esquema. Uma arquitetura que apresenta bom desempenho hoje, pode perder sua qualidade diante de um novo tipo de carga que se apresente na Web. 


\section{Capítulo 4}

\section{Benchmarks para Servidores Web}

\subsection{Introdução}

Como descrito no Capítulo 2, os benchmarks são programas utilizados para teste de software, hardware ou sistemas computacionais completos. Por se tratar de una técnica de alerição para avaliação de desemponho, ela é aplicável apenas em sistemas já cxistentes ou que estão en sua fase final de desenvolvimento; há ainda a preocupação em garantir à nâo interferência do benchmark no comportamento do sistema.

Devido ao crescimento e à importância alcançados pela Wob, os sistemas destinados a trabalhar nessa rede passaram a receber grande atenção. O clesempenho de servidores Web se tornou uma preocupação constante em todo sistema (que oferece serviços através da Wob. Administradores e desenvolvedores desses sistemas procuram respostas para perguntas como: Qual a taxa de transferência de dados alcançada pelo servidor? Quantas conexöes podem ser atendidas en um determinado intervalo de tempo? Qual a latência presente nesse servidor? A partir das respostas obtidas pode-se chegar a uma definiçāo de desempenho e capacidade alcançados pelos servidores. Com o intuito de auxiliar na obtencão das respostas citadas, foram propostos diversos benchmarks especializados em avaliação na Web (Tittel, 1996; Banga \& Druschel, 1999).

Quando se pretende avaliar o desempenho na Web, devent-se considerar três fatores principais: o usuário final que gera as requisições, a infraestrutura da rede que transporta os dados, e o servidor onde estão armazenadas as informações requisitadas.

Todos os benchmarks para Web disponíveis atualmente são, na verdade, benchmarks para servidores Web. Isso ocorre porque o adninistrador do servidor (webruaster) não é capaz de controlar as configuraçoes e comportamentos do cliente, nem a latênciá das redes às quais o servidor está conectado. Em outras palavras, toda a informaçāo a respeito de desempenho na Web é, realmente, apenas uma medida de quão bom é o atendimento que um servidor Wob pode dar a um conjunto de requisições. 
As características mais comuns desses servidores abordadas pelos benchmorks são:

- Latência de resposta: Tempo necessário para o reconhecimento e atendimento de uma requisição ITTP.

- Capacidade de atendimento a conexões: Núntero máximo de conexões pur unidade de tempo que o servidor porde manipular.

- Throughput do servidor: Quantidade de dados que o servitor pode, por unidate de tempo, enviar e receber.

Existem atualmente diversos benchmarks para a avaliagyäo de servidores Web disponíves na Internet. A seguir são descritos aqueles selecionados para a utilização neste trabalho.

\subsection{WebStone}

O WebStone é um benchmark configurável para servidores HTTP. Ele utiliza parấmetros de caracterização de carga e processos clientes para gerar tráfego HTTP com o intuito de sobrecarregar um servidor de diferentes maneiras (Trent \& Sake, 1995; Mindcraft, 2002). O WebStone foi desenvolvido para medir o throughput máximo e o tempo médio de respostia. Ele gora requisiçoes GET para documentos específicos no servidor Web e coleta diados de desempenho.

Composto de processos clientes e mestre, o WebStone trabalha de maneira distribuida. O processo mestre gera um número predefinido de processos clientes que, por sua vez, começam a gerar requisiçoes ao servidor. Quando todos os clientes terminam sua execurgão, o mestre recolhe os dados de clesempenho coletados pelos clientes e faz um relatório geral. O usuário pode definir tanto o tempo de duração do teste quanto o número de iterações executadas.

\subsubsection{Configuração}

\section{Instalaçāo}

O WebStone utiliza o mecanismo GNU padrão de instalação, ou seja, para instalá-lo é necessário a execução dos passos: configure; make; e make install. Nesse caso, entretanto, a instalação não ocorreu de forma tranqüila, pois houve problemas na compilação do código fonte. A definição de variáveis em alguns arquivos teve que ser alterada e tudo que fazia referência à API foi tirado do Makefile, pois essa parte da compilação necessita de arquivos adicionais. Como não havia o interesse em explorar essa característica nos testes, ela foi simplesmente extraída da ferramenta. 
A instalayăo refuer, além da compilação do código fonte, as seguintes configurações:

1. criação de uma conta de usuário específica para a utilização do WebStone.

O WebStone utiliza uma conta de usuário para executar comandos remotamente nas máquunas clientes. A partir desses comandos, o sistema webmaster controla a execução de cada sistema cliente.

2. edição dos arquivos que controlam os conandos-r (.rhosts $e$ /etc/hosts.equiv), para que o usuário criado possa ter acesso a todas as máquinas do teste.

É necessário acertar a configuração de cala máquina cliente para que estas aceitem a conexão do webmaster. Conexões feitas por meio de comandos-r säo normalmente bloqueadas por se tratar de uma potencial falha de segurança na rede. Nesse caso, as configuraçoes ficaram restritas às máquinas que foram utilizadas nos testes e, retornava-se a configuração ao normal ao fim do processo.

3. geração do conjunto do arquivos aressados no servider.

O WebStone pressupõe que os arquivos requisitados durante o teste existam no servidor, caso contrário, é indicado um erro e o teste é abortado. Por isso, o próprio bcrehmark disponibiliza um modo de criar um conjunto de arquivos. O comando "./webstone -genfiles" cria vários arquivos de diversos tamanhos, como file50k.html, por exemplo. Depois do criados, esses arquivos são transferidos para o servidor para serem acessados durante o teste.

Com isso, finaliza-se o processo de instalação da ferramenta que, como mencionado, apresentou dificuldades; algumas superadas facilmente, outras com dificuldade. Como ponto bastante positivo, pode-se destacar o fato de não ser nectssária a instalação em cada máquina que se pretendia utilizar no teste. Nessas máquinas, foi necessário apenas a execução do passo 2, com o objetivo de definir a configuração dos comandos-r.

\section{Execução}

Mesmo após a conclusão da instalação, o WebStone ainda não se apresenta en condi̧õos de execução. Antes disso, é neecessário fazer a configuração dos parâmetros que serão utilizados. Isto é feito através de dois arquivos: testbed e filelist.

A Tabela 4.1 ilustra o arquivo testbed utilizado em testes feitos durante o trabalho.

O primeiro conjunto de parâmetros significa que a execução será iniciada com 1 cliente e, por meio de um incremento de 50, seräo executadas 11 iterações, quando o número de clientes superará 550 finalizando o teste. Cada iteração é executada por 1 minutó e o teste como um todo será repetido 3 vezes. 


\begin{tabular}{|c|}
\hline $\begin{array}{l}\text { ITERATIONS }=" 3 " \\
\text { MINCLIENTS }=" 1 " \\
\text { MAXCLIENTS }=" 550 " \\
\text { CLIENTINCR }=" 50 " \\
\text { TIMEPERRI }=" 1 "\end{array}$ \\
\hline $\begin{array}{l}\text { SERVER }=" 1 \text { asdpe } 17 " \\
\text { PORINO=80 }\end{array}$ \\
\hline $\begin{array}{l}\mathrm{RCP}=\mathrm{rcp} \\
\mathrm{RSH}=\mathrm{rsh}\end{array}$ \\
\hline WEBDOCDIR=/usr/local/apache?/htdocs \\
\hline CIJENTS="lasdpc15": \\
\hline $\begin{array}{l}\text { CHENTACCOLN]=projeto } \\
\text { CLIENTPASSWORD=****** }\end{array}$ \\
\hline FIXED_RANDOM_SELD=true \\
\hline
\end{tabular}

Tabela 4.1: Parâmetros utilizados ma execução dos testes

O conjunto de parâmetros seguinte significa ques será testado um servidor chamado "lasdpcli" na porta 80 (a porta pode ser alterada para possibilitar a utilização de proxies na mesma máquina). A seguir são especificados os comandos utilizados pelo webmaster para acessar as máquinas clientes, rep e rsh, bem como o none da conta e a senha utilizadas nesse acesso. A entrada "WEBDOCDIR" define onde estão, no servidor, os arquivos requisitados pelos clientes.

Finalnente, são especificados os nomes - hostnames - das máquinas clientes. No caso ilustrado foi utilizada apenas 1 máquina. A quantidade de processos nessa máquina fica definida de forma implícita. Como dito, o teste será executado de 1 até 550 clientess. Empregando-se "duas" máquinas, cada uma executará de $1 / 2$ até 550/2 processos. Como não é possível dividir 1 processo entre duas máquinas, no primeiro passo é utilizado apenas 1 cliente. O Webmaster controla todo o teste utilizando a conta e senha definidas para executar comandos de forma remota nas máquinas clientes.

Uma vez terminada a configuração do testbed, passa-se a editar o filelist. A Tabela 4.2 ilustra um arquivo utilizado em testes feitos durante o trabalho.

$\begin{array}{lll}\text { /file500.html } & 350 & \# 500 \\ \text { /file5k.html } & 500 & \# 5125 \\ \text { /file50k.html } & 140 & \# 51250 \\ \text { /file500k.html } & 9 & \# 512500 \\ \text { /file5m.html } & 1 & \# 5248000\end{array}$

Tabela 4.2: Arquivo filelist usado nos testes. 
Na tabela há a definição de cinco arquivos diferentes. O número que segue o nomo do arquivo representa seu peso na distribuição. Todos os pesos são somados e a frequiência de cada arquivo é o seu peso dividido pelo peso total. No exemplo mostrado, a soma dos pesos é igual a 1.000. Dessa forma, o arquivo file500k: html será requisitado 350 de 1000 vezes. A última coluna, considerada um comentário pelo programa, mostra o tamanho de cada arquivo em bytes.

Terminada a configuração e definição dos parâmetros do teste, ele pode então, ser iniciado. O procedimento de teste é controlado em parte por shell scripts e em parte por programas. O script webstone controla o sistema como um todo, com opções para ajuda ao usuário, geração dos arquivos do servidor (genfiles), configuração do sistema e inicialização do teste de diversas maneiras. Essas opções são definidas acrescentando-se ao comando "./webstone", argumentos que podem definir a exccução do teste como "silenciosa", para depuração ou para coleta automática de resultados após o término do teste. A sinopse deste script é:

webstone [-help | -setup | -kill | -genfiles | -silent | -results]

Outro script, denominado rumbench, trata especificamente da excução do teste com o benchmark: Ele é chamado pelo script webstone para executar o trabalho de preparar, de acordo com os parâmetros, uma secuienencia de execuçoes do WebStone. Entende-se por sepuiêneia um conjunto de iteraçóes a ser executadas. Em todo teste realizado com - WebStone é nocessário especificar númoros mínimo e máximo de processos clientes, além de um incremento que será aplicado ao valor mínimo tantas vizes quantas forem necessárias para se atingir o valor máximo. Assim, uma iterarāo é executacla para cada diferente número de processos. Acima desse nível há iteraçōes do teste como um todo, isto é, há o procedimento de se atingir o valor máximo a partir do mínimo por meio de um número finito de passos, que pode ser repetido um número determinado de vezes.

Com os parâmetros definidos, o processo webmaster é invocado para executar o teste de fato. Esse programa apresenta a seguinte sinopse:

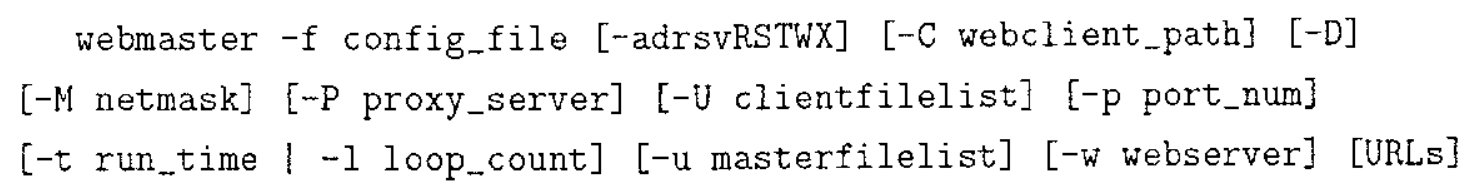

Cada opção caracteriza a execução do programa de uma forma particular. Nesse caso, as características são:

-C webclient_path: Localização do programa webclient nos sistemas clientes.

-D: Arquivo, nos sistemas clientes, para receber os dados de depuração. Padrão stderr. 
-M netmask: Valor a ser usildo como máscara de rede.

-P proxy_server: Nome do servidor proxy para o qual enviar as requisiçōes.

-R: Diz ao webclient para registrar todas as transações.

-S: Utiliza um valor fixo para a semente de números aleatórios que especificam qual URL será requisitada.

-T: Habilitil as instruçoes de trace.

-U URL_file: Lê as LRLs a serm requisitadas no arquivo "URL_file".

-W: Indica que o nome do servidor está no arquivo de configuração no sistema webmaster.

-X: Näo utilizar rexec() para inicializar os clientes. Em seu lugar, utilizar sleep() para permitir ao usuário inicializá-los manualmente.

-a: Imprime informarsoes de tempo para todos os clientes.

-d: Hábilita instruşōes de depuragão e trace.

-f config_file: Arquivo para especificaçäo de clientes. Deve haver uma linha para cadit sistema cliente; com a seguinte sintaxe:

$\langle c l i e n t$ host name> <login> <password> <number of webclients> [ $<$ Web server $\rangle]$

É perfeitamente possível utilizar o sistema webmaster também como cliente.

-l loop_count: Faz com que o filelist seja percorrido "loop_count" vezes, requisitando cada URL contida nesse arquivo.

-p portnum: Número da porta em gilu o servidor espera por requisições.

-s: Diz ao webclient para salvar todos os dados recebidos do servidor.

-t run_time: Duração do teste em minutos.

-u URL file: Arquivo contendo as URLs para o teste, no sistema webmaster.

-v: Habilita modo "verbose".

-w webserver: Nome do host onde está o servidor a ser testado. Se o nome comeģar com um dígito, webmaster o utiliza, juntamente com a máscara especificada, opção " M", para calcular o endereço IP do servidor, na mesma rede do cliente. Por exemplo, se o IP do sistema cliente é 168.10.2.14, a rede tem o valor padrão (255.255.255.0), e o servidor é 25 , então o endereço a ser usado é 168.10.2.25. 
Dessia forma, cada parâmetro acrescenta uma determinada característica ao teste. Independentemente dessas características; o programa sempre analisa toda a informação de configuração do teste, abre um socket para comunicação com os sistemas clientes que irão gerar á carga no servidor e entäo, através do comando rexec(), inicializa os processos webclient em cada um dos sistemas clientes.

O webclient, por sua vez, tem a seguinte sinopse:

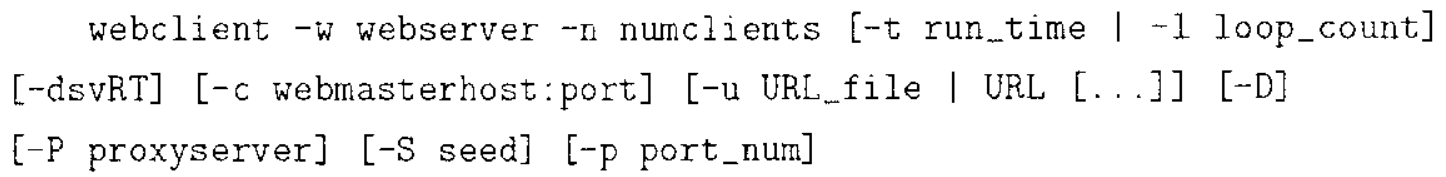

As opsões de definição da execução do programa são as seguintes:

-D: Envia os dados de depuraşão para stderr.

-P proxy_server: Envia requisiçōes à "proxy_server".

-R: Grava todas as transaçôes om arquivo.

-S sced: Usa a semente fornecida para inicializar o gerador de números aleatórios.

-T: Habilita as instrucōes de trace.

-c webmasterhost:port: Conecta ao sistema webmaster através da porta fornecida para trocar mensagens de controle e enviar resultados.

-d: Habilita as instrucoes de depuração e trace.

-1 loop_count: Faz com que o filelist scja percorrido "loop_count" vezes, requisitando cada URL contida nesse arquivo.

-p portnum: Número da porta em que o servidor espera por requisiçōes.

-s: Diz ao webclient para salvar todos os dados recebidos do servidor.

-t runt_time: Duração do teste em minutos.

-u URL_file: Arquivo contendo as URLs para o teste, no sistema cliente.

-v: Habilita modo "verbose".

-w webserver: Nome do host onde se encontra o servidor a ser testado.

Depois de verificar cada parâmetro, o processo webclient cria um número de instâncias de si mesmo, especificado cm testbed. Embora a parte cliente da execução do teste esteja sendo referenciada aqui como processo, essas instâncias portem ser tanto processos como threads. A tarefia básica desses processos ou threads, é enviar uma requisição HTTP e 
medir o tempo tomado para que ela seja atendida. Logo após o atendimento e registro de tempo, outra requisişão é feita.

Quando a cxecução termina, o clicnte relata seus resultados - o que podo acontecer de duas formas diferentes: se o programa está sendo executado de forma independente, "standalone", os resultados sāo escritos na saída padrão(stdout); so a execução está acontecendo sob o controle do webmaster, então espera-se até que este último "entre em contato" para receber os resultados.

Embora seja possível a execução dos programas webmaster e webclient sem a utilização de controladores como os seripls runbench e webstone; não é aconselhada, pois a execução do benchmark através da linha do conando torna-se muito complexa.

Ao final do teste, o procedimento padrão - isto é, se nầ loi especificado algum parâmetro que interfira nesse ponto - estabolece que os resultarlos obtidos cm cada iteração sejan armazenados no dirctório runs. O WebStone oferece ainda um mecanismo, o scrimt. wscollect, que formata esses resultados em 1 ma tabela unificada, tomando mais simples a sua visualização.

\subsubsection{Arquitetura}

O WebStone é um benchmark multi-processado e distribuído. A secã̃o anterior já exibiu alguns pontos de sua arquitetura que volta a ser abordada com mais detalhes nesta seção.

O procedimento de execução do WebStone ocorre da seguinte forma: runbench é executado em uma máquina (webmaster) para controlar o teste no nível mais alto. Este script criará então, na máquina atual, uma instância do processo webmaster que lê os arquivos de configuração e, baseado neles, cria $u$ comando a ser executado pelos clientes. Esses clientes, webclients, são então criados de forma remota em diversas máquinas e iniciam sua execução. Ao término da sua execução, cada cliente coleta os dados medidos e os passa ao processo central. Este último aguarda até que todos os clientes emitan seus resultados que são compilados em um relatório final. Nesse ponto, quando o controle volta a runbench, termina-se uma iteração. Se ficou especificado, através dos parâmetros, a execução de mais iteraçóes, todo o processo é repetido até se alcançar o final do teste como um todo. A Figura 4.1 ilustra a relação entre as diversas partes de um teste com o WebStone.

Em relação ao código fonte, a ferramenta apresenta un funcionamento confuso, apesar de: bem comentado. Isso porque em alguns pontos há implementaçoes com o intuito de permitir o uso de requisiçōes a páginas com vários arquivos - utilizando uma conexão para fazer várias requisições - mas, de forma geral, a ferramenta não permite esse tipo de funcionamento. São utilizadas ainda, diversas estruturas para a coleta de dados e estatísticas, o que acaba gerando confusão. Outro agravante desse ponto é o controle feito 


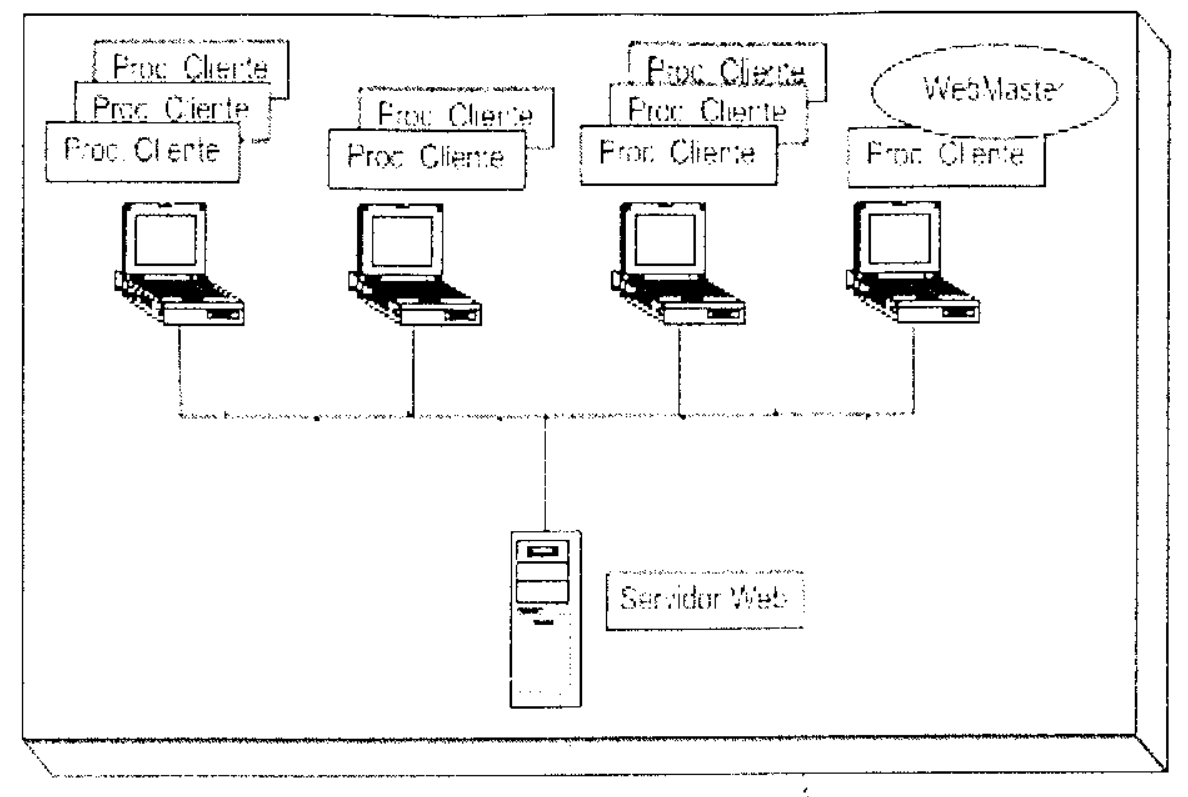

Figura t.1: Arquitenua do benchuark Wowstonc.

en parte por programas en código $C$. en parte por shell seripts. o que acaba gerando matis coufusios.

\subsubsection{Carga de trabalho}

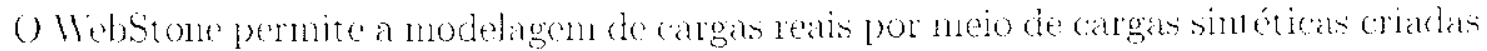

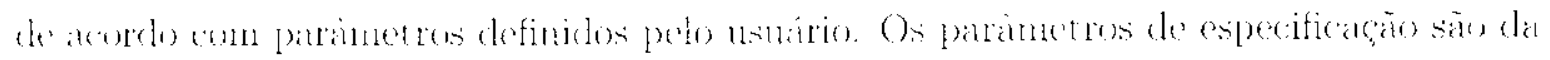
seginte format

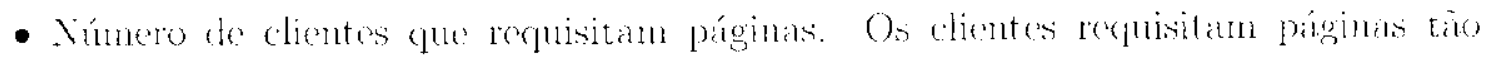

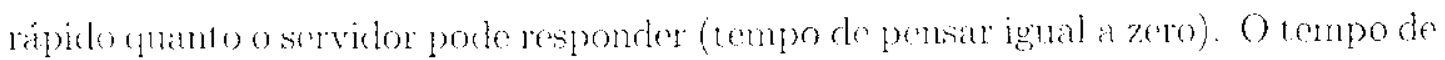
pensar (think time), nio pode ser representado em un carga gerada pelo Vhebstone.

- Tipo de pígina defindo pelo tamanho e frecuiencia de acesso. Cada página na combinaça possui un peso que indica a sma probabilidade de ser acescada.

- O múmero de páginas disponíveis no servidor.

- Yímero de máduiras clientes, onde os processos clientes säo cxecutados.

A definiçato desses parànetros é feita de acodo com o que foi mostrarlo na segrio 4.2.1, isto é através de arquivos de configuração. Alóm dos paranetros mostrados neste capítulo.

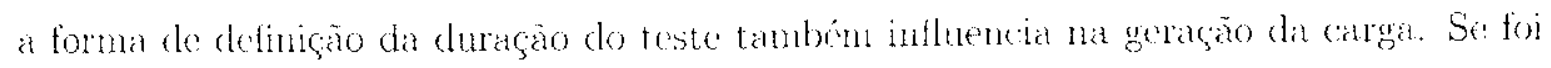

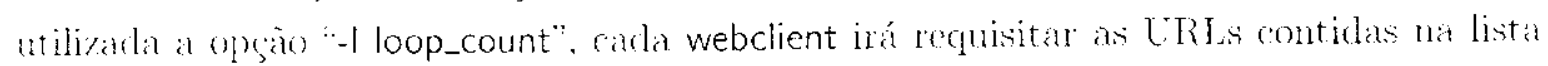
d" forma següncial. passando por toda a lista "loop_count" veres. quando o tester se: encerará. Mas se a definiça for feita através da opção "t run_time". os prucesios clientess

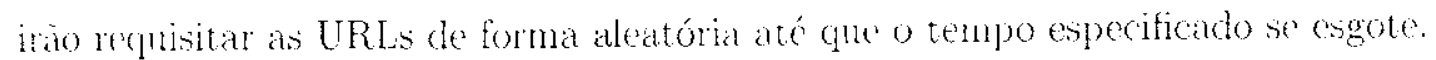




\subsubsection{Resultados apresentados pelo WebStone}

Os principais resultados produzidos pelo WebStone săo a latência e o throughput. Este último, medido em bytes por segundo, representa o número total de bytes recebirlos do servidor, dividido pelo tempo de teste. A primeira medes, do ponto de vista do usuário, o tempo necessário para a conclusão de uma requisição. A latência consiste de três componontes: conexão, tempo de resposta, e latência da rede devido a roteadores, modems coutros. O primeiro componente reflete o lempo necessário para estabelecer uma concxio, enquanto o segundo reflete o tempo tomado para completar a transferência dos dados, uma vez que a conexão tenha sido estabelecida.

A Tabela 4.3 ilustra os resultados obtidos pelo WebStone $\mathrm{em}$ um teste típico, isto é, utilizando valores paträo para os parâmetros. Várias iteraçóes são necessárias porque o Wehstone é un processo estocástico e. portanto, haverá variaçoes de execuçăo para execuräo, especialmente se o conjunto de arquivos do teste contiver arquivos grandes, on se o.servidor chegar a ficar sobrecarregado.

\begin{tabular}{|c|c|c|c|c|c|}
\hline $\begin{array}{c}\text { Número total } \\
\text { de Clientes }\end{array}$ & $\begin{array}{c}\text { Taxa } \\
\text { de Conexões } \\
\text { (conexões/s) }\end{array}$ & LLF & $\begin{array}{c}\text { Tempo médio } \\
\text { de resposta } \\
(\mathrm{s})\end{array}$ & $\begin{array}{c}\text { Nível } \\
\text { de Erros } \\
(\%)\end{array}$ & $\begin{array}{c}\text { Throughput } \\
\text { médio } \\
\text { (Mbit/s) }\end{array}$ \\
\hline \hline 1 & 936,7 & 0,99 & 0,001 & 0 & 10,39 \\
101 & 2060,5 & 50,84 & 0,025 & 0 & 88,55 \\
151 & 2060,15 & 98,72 & 0,018 & 0 & 88,83 \\
201 & 2061,65 & $1: 16,78$ & 0,071 & 0 & 88,9 \\
251 & 2065,37 & 196,96 & 0,095 & 0 & 89,06 \\
301 & 2071,25 & 239,17 & 0,115 & 0 & 89,31 \\
351 & 2063,48 & 290,13 & 0,141 & 0,3 & 88,98 \\
101 & 2069,13 & 306,88 & 0,148 & 0 & 89,22 \\
151 & 2063,33 & 313,52 & 0,166 & 0,57 & 88,97 \\
501 & 2062,68 & 404,31 & 0,196 & 0,7 & 88,94 \\
\hline
\end{tabular}

Tabela 4.3: Exemplo de resultados obtidos pelo WebStone

A métrica LL.F (Litle's Load Factor) é derivada da lei de Little (Menascé et al, 1994). Fla indica o grau de concorrência na execução das requisições, isto é, o múmero médio de conexões abertas no servidor Web cm um momento qualquer do teste. É tanbém uma indicaçäo de quanto tempo é gasto no processamento de requisiçōes - não em erros ou sobrecarga. Em condicones ideais, II.F deveria ser igual ao número de clientes, pois um número menor indica que o servidor está sobrecarregado e, por isso, algumas requisiçōes não estão sendo atendidas antes de seu tempo acabar (time out). Quando conexões comégam a ser descartadas, o nível de erros cresce, reafimando que o servidor não está conseguindo atender a todas as requisições recebidas. O número de erros pode ser um excelente indicador de como o servidor se comporta em caso de sobrecarga. 


\subsection{Httperf}

O httperf (Mosberger \&. Jin, 1998; Provos et al., 2000) é uma ferramenta constrúda para medir o desempenho de servidores Web. Fla pode utilizar o protocolo HTTP em suas versote 1.0 e 1.1, e oferecer ainda uma variedade de geradores de carga. Durante a execucão de um testc, são coletadas diversas métricas de desempenho que são compilarlas em um quadro de estatística no final da execução. A operação mais básica do httperfé gerar um número fixo de requisiçoes GET o medir quantas respostas foram recebidas do servidor e a que taxa essas respostas aconteceram.

É importante ressaltar que para se obter resultados corretos, torna-se necessário cxocutar, no máximo, um único processo do httperf por máquina cliente. Além disso, deve haver o menor número possível de processos executando no cliente e no servidor.

\subsubsection{Configuraçāo}

\section{Instalação}

O httperf, assim como o WebStono, utiliza o mecanisno GNU padrão de instalação. Dessa forma, para instalá-lo é necessária a execução dos seguintes passos: configure; make; e make install. Caso haja interesse en altorar valores padröes como os diretórios de instalação dos executáveis ou da documentaç̃̃o, podem-se passar op sões ao script configure. O httperf pode ainda ser compilado com suporte a SSL (secure sockets layer), mas para isso é necessário que o OpenSSL (wwwopensslorg) esteja instalado no sistema.

A instalaçäo do hutperf feita no presente trabaho ocorreu de forma tranquiila, sem grandes dificulades. Primeiro foi feito o dounloud do código fonte da ferramenta. O arquivo foi então descompactado no local desejado - nesse caso / usr/local/httperf - e finalmente os três passos citados acima foram executados. Todo esse procedimento foi executado em cada máquina que se pretendia utilizar como cliente.

\section{Execuçāo}

Und execução simples do httperf pode ser alcançada dà seguinte forma:

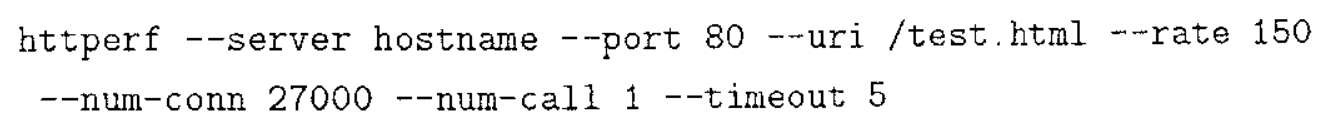

O comando faz com que o httperf utilize a máquina "hostname" como servidor Web, e é executado na porta 80 . A página requisitada é "/test html" e, nesse caso, a mesma página é requisitada repetidamente. A taxa de requisição é de 150 por segundo. O teste envolve a criação de 27.000 conexões TCP com cada uma gerando uma chamada HTTP 
(una chamada consiste em enviar uma requisicão e receber a correspondente resposta). A opção "timeout" informa o tempo em segundos que o cliente permanece esperando uma resposta do servidor. Se o "timeout" expirar, o benchmark considera que a chamaria falhou. Destaca-se que, com um total de 27.000 conexōes a uma taxa de 150 conexósis, u tempo total de teste será de 180 segundos: independentemente dà cargá que o scrvidor pode suportar.

No caso da utilização de diversas máquinas clientes, un conando desse tipo deve ser executado em cada máquina a ser utilizada. O httperl não possui un gerenciador central para o controle dos clientes. Teminada a execução do teste, diversas estatísticas sobre o desempenho do servidor são impressas por cada máquina cliente. Para se obter um relatório geral sobre a execuçäo é necessário juntar: manualmente, todos os relatórios gerados por cada uma dessas máquinias.

A forma de execuçâo descrita utiliza apenas algumas dis opcoes presentes no hrtperf. Para a obtengão de um teste mais completo podem-se utilizar mais parâmetros de configuração, tais como:

-- burst-length $=N$ : Especifica o tamanho das rajadas. Cada rajada consiste de $N^{r}$ chamadas ao servidor.

- -hog: Esta opção requisita o uso de quantas portas TCP forem necessírias. Sem esta opção, o httperf fica limitado ao uso das portas "efemeras" - ephemeral ports - (na laixa de 1021 a 5000). Esse limite pode se tomar rapidamente um gargato, por isso ó uma boa idéia a especificação dessa opgão. Além disso, éssa opsão deve ser especificada quando da utilizagão de servidores $N$ T, pois ela impede a incompatibilidade entre mácuinas L.VIX e NT.

$--h t t p$-version $=S$ : Especifica o valor do campo versão que deve ser incluído nas requisiçoes enviadas ao servidor. O valor padrão utilizado é "1.1". Essa opção pode ser definida como "1.0" para forgar a geração de requisiçóes HTTP/1.0. Definir essia opsão para qualquer valor diferente de " 1.0 " ou " 1.1 " pode resultar em um comportamento imprevisível.

-- period $=[D] T 1[T 2]:$ Fspecifica o intervalo de tempo entre a criação de conéxões ou sessões. O parâmetro $D$ especifica a distribuição desse tempo. Se omitido ou definido como "d", um período determinístico é usado como especificado pelo parâmetro $T 1$ em unidades de segundos. Se $D$ for definido como "e", uma distribuição exponencial, é usada como um tempo médio de $T 1$. Finalmente, se $D$ for definido como "u", uma distribuição uniforme sobre o intervalo $[T 1, T 2)$ é usada. Em todos os casos, um período igual a 0 resulta em conexöes/sessöes geradas seqüencialmente (uma nova conexão/sessão é criada imediatamente após o término da anterior).

--ssl: Indica que toda a comunicação feita entre o httperf e o servidor deve utilizar 
o protocolo SSL. Essa opção é disponibilizada apenas se a ferranenta for compilada com suporte a SSL.

- -wsess $=N 1, N 2, X$ : Forga a ulitizagão de sessoes ro lugar de requisicoes individuais. Lna sessão consiste em uma seqüercia de rajadas cspacadas pelo tempo de pensar do usuário. Cada rajada é constiturda por um número fixo $L$ de chamadas ao servidor ( $L$ a expecificado pela opgäo--burst-length). Essas chamadas são feitas dia seguinte forma: inicialmente, apenas uma chamata ó foitas assim que a respesta para essa primeira chamada for recebida, todas as chanadas restantes são feitas de forma concomrente. Essas últimas chanadas podem ser teitas em pipeline en uma só contexĩo persistente. ou de forma separarta om conexões individuais. A decisão sobre qual método será utilizado depericle da resposta à primeira chamada enviada pelo servidur. Se o cabeçalho da resposta contiver a linha "Connection: close", seráa utilizadas concoesos separadas. A opgäo especifica os seguintes parânetros: $N 1$ e o múmero total de sessóes a ser geradas, Ne é o mumero de chamadas por sessão e $X$ é o tempo de pensar: em scoundos, que separa rajadas consecutivas. Lim teste envolvendo sessões termina täo logo o múmero $V 1$ de sessöes tiver sido completado ou ter ocorrido alguma falha. Una sessão é considerata falha se alguma operação conticta nela tomar mais lempo do que o especificado pelas oproes - -timeout e - -think-timeout.

Todas as opgoes citadas representam apenas una parte do que é oferecido pela ferratmetentat. Elas foram moncionadas por terem sido consideradas mais importantes. O htoperf posini anda diversas opcóos para a obtenç̃o de testes mais específicos e dirigitos aos objetisus do usuário.

\subsubsection{Arquitetura}

Como mostrado na seçä anterior: o htpper trabalia com apenas un processo por mácinina. Fsse processo lé os paranotros da linha de comando, estabelece as características do teste e inicia sua execucão com a criação de uma thread. Não há nonhuma forma de controle centralizado. Na utilização de diversas máquinas chentes, cada uma trabalha de forma independente. Cabe ao usuário, ao final do teste, compilar os resulados de cadia máxuina em um documento único.

O softuare foi projetado tendo en vista os objetivos: ter bom desempenho e facilidade para futuras extensõos. O bom desempenho é alcançado pela implementatç̃o dat ferramenta em C, com bastante atenção aos trechos (to código referentes ao desempenho. Outro fator é o gerenciamento de timéul: para não depender de mecanismos do SO, o httperf implementou um mecanismo próprio: um instrumento leve e especializado que descarta as pesadas chanadas ao sistema (system calls). 


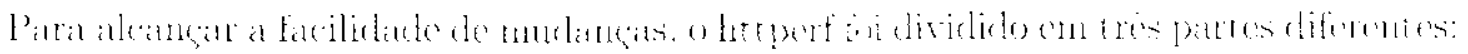

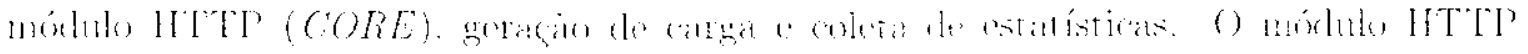

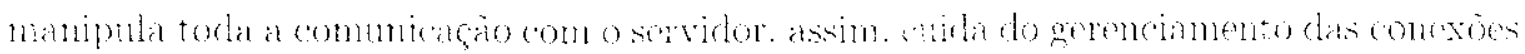

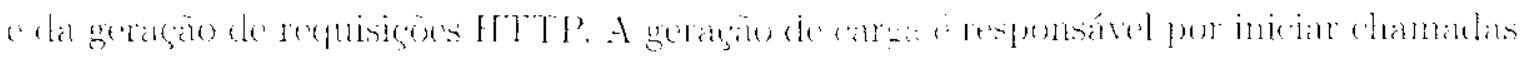

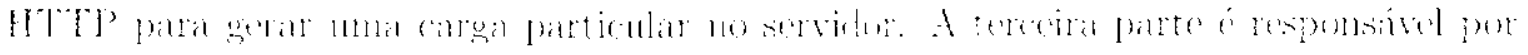

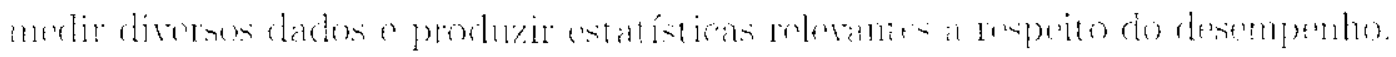

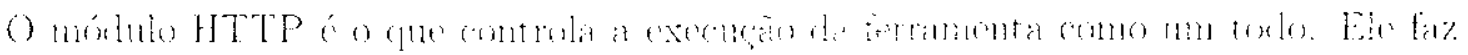

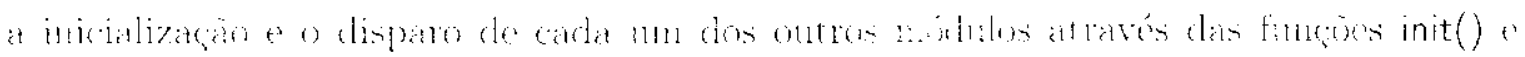

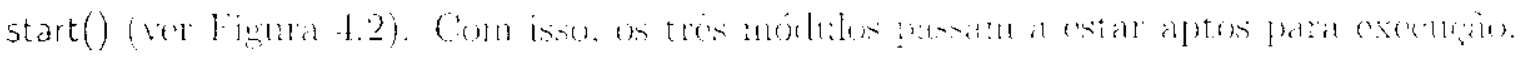

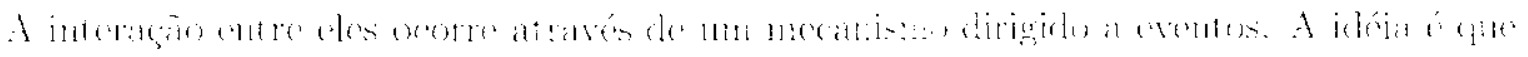

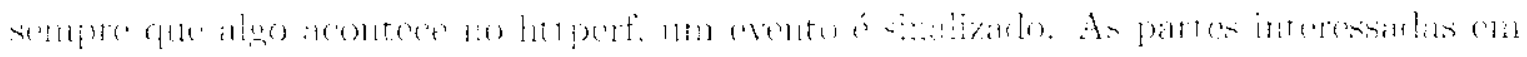

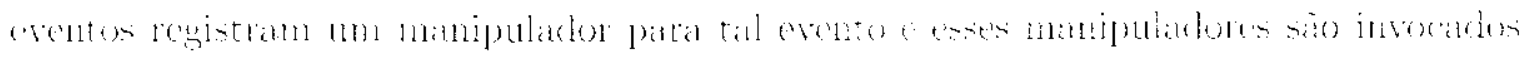

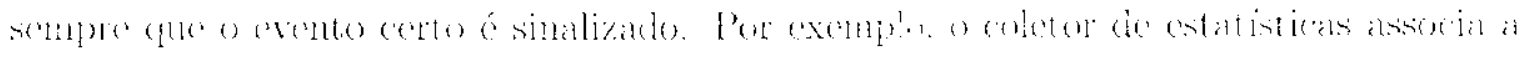

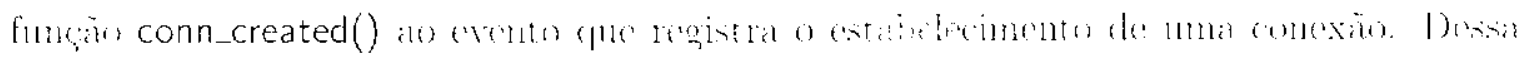

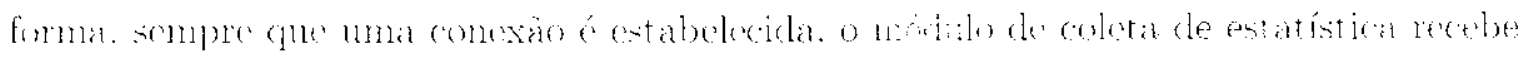

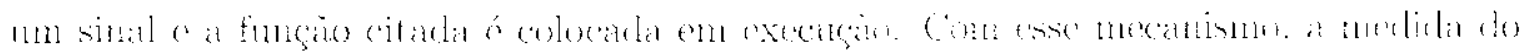

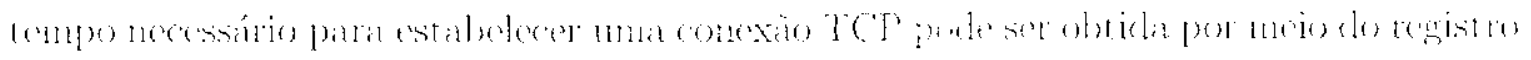

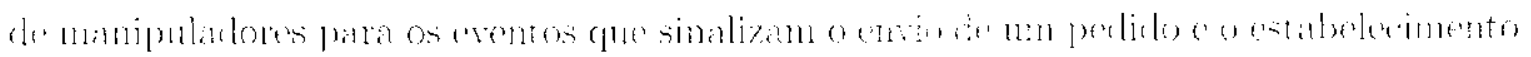

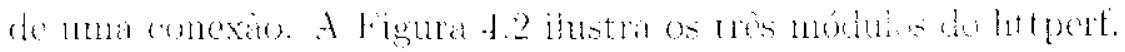

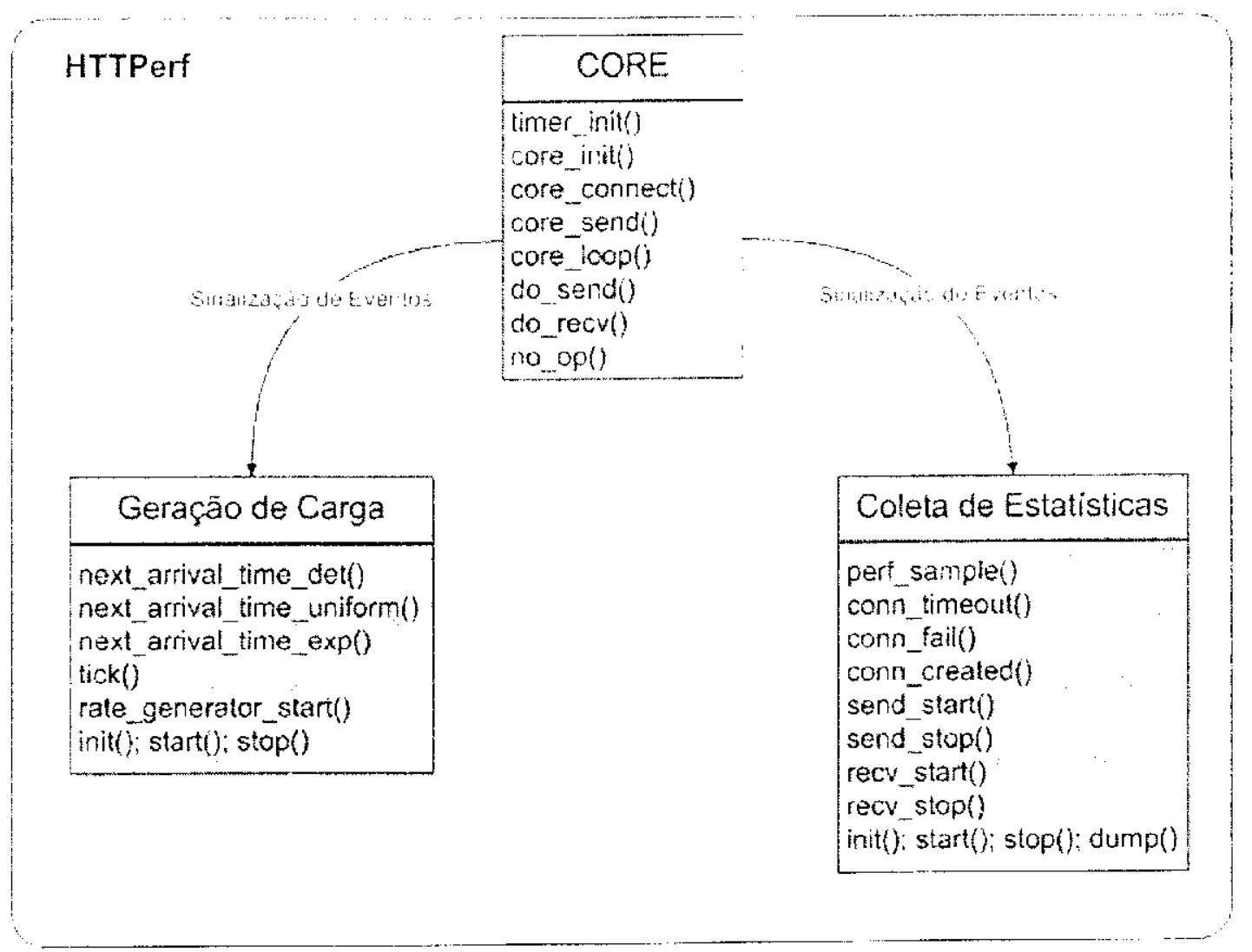

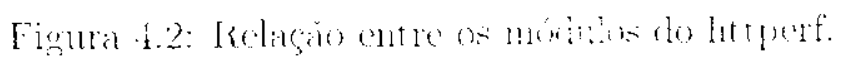


O código fonte proprianente dito encontra-se ben organizado con os arquivos pertencentes a cada móchulo do sistema separados em dirtórios distintos. No diretório principal residem os arquivos referentes ao módulo HTTP: ou CORE. responsável pelo controle geral do sistema. Há ainda dois subdiretórios, gen e stat, que correspondem respectiramente aos módulos de geraşão de carga e coleta de estatísticas. O nudo de funcionanento dirigido a eventos também facilita o entendimento de todo o meranismo da feramonta. De forma geral, o código do httperf contén comentários em uma quanticlade reduzida, mas ainda assin son entendimento se dá de manteila direta.

\subsubsection{Carga de trabalho}

O módulo HTTP dá suporte ao IYTTP 1.0 e 1.1 . Entre as caracteristicas mais inte-

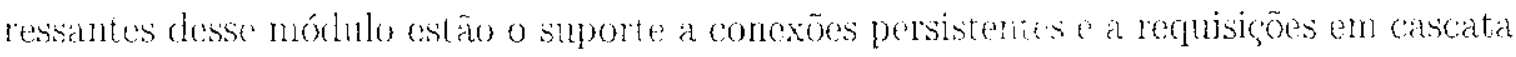
(pipelining).

A versão oficial do ht tuerf (Mosberger \&. Jin, 1998) dá suporte a dois tipos de geradores de carga: geradores de requisição e geradores de: LRL:

- Geração de requisiçōes: Há dois tipos de geradores de carga: o prineiro gera requisiçōes deterministicamente a uma taxa fixa. Cada requisição é usadia prara executar uma linha de comando especiticando o número de chamadas em cascata a sor execuladas. O número padrāo de chamadas em cascata é 1, o que reproduz o comportamento do HTTP 1.0 onde cada conicxão é usada para apents uma chamadia. O segundo tipo de gerador cria sessoes. também deteministicamente a uma taxa fixa. Cada sessão consiste em un número especificalo de chamadas em rajaklas.

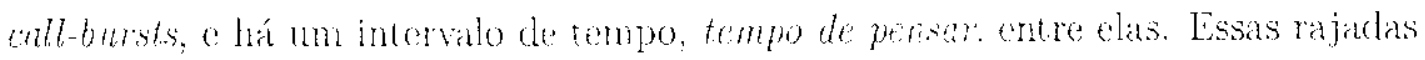
consistem em un número fixo de chamadas independentes. As chamadas em rajadas imitam o comportamento típico de um navegador. Olando o usuário seleciona uma pígina, o navegador primeiro requisita o arquivo ITTML e depois os objetos pertencentes à página.

- Geraçāo de URLs: Geradores desso t ipo crian una segiência desejada de URLs que devem sor acessadas no servidor. Geradores mais primitivos apenas especificavam a mesma URL repotidamente.

Outros geradores utilizam um conjunto fixo de CRLs. Com esses geradores, as páginas são assumidas como organizadas em uma árore tenária do diretórios (cada diretório possui até 10 arquivos ou subdiretórios) no servidor. Esses geradores são úteis, por exemplo, para induzir uma taxa de erros no (ache (cache miss) do servidor ent teste.

A definição desses parâmetros é feita de acordo com a forma mostrada na seção 4.3. L. Embora tenha sido citada apenas a grerargäo de carga de forma deteminística, o lutperf 
olerece anda os mótodos liniforme o Exponencial especificados por meio do parânetro "poriod =[D]TITT2".

\subsubsection{Resultados apresentados pelo httperf}

A Fignra 4.3 ihustra un resultado final típico de um teste realizado com o htperf. Primeiramente aparece a linha de comando utilizada para dar início à execução do programa e, eritão, os resultados propriamente ditos. Na linha de comando pode-se perceber a ent rada: "-wsesslog = 10000,5.000, sessoes. 05.txl". Exceto pela definiçio do nome de un arquivo este parâmetro funciona como a opção ". wsess" mencionada acima. O arquivo é utilizado para especificar como devem ser feitas as requisiçoes dentro de cada sessão. São definidos o número e a forma, sequenciahmente ou em pipeline, que as requisições devem ser feitass.

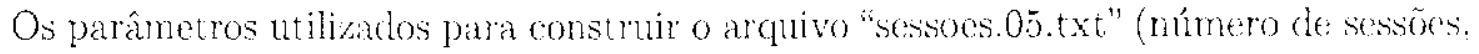
(plantidade de requisicon por sessão, tamanho dos arquivos requisitados), foram tirados do benchmark Surge (Cruvella et ol, 1999).

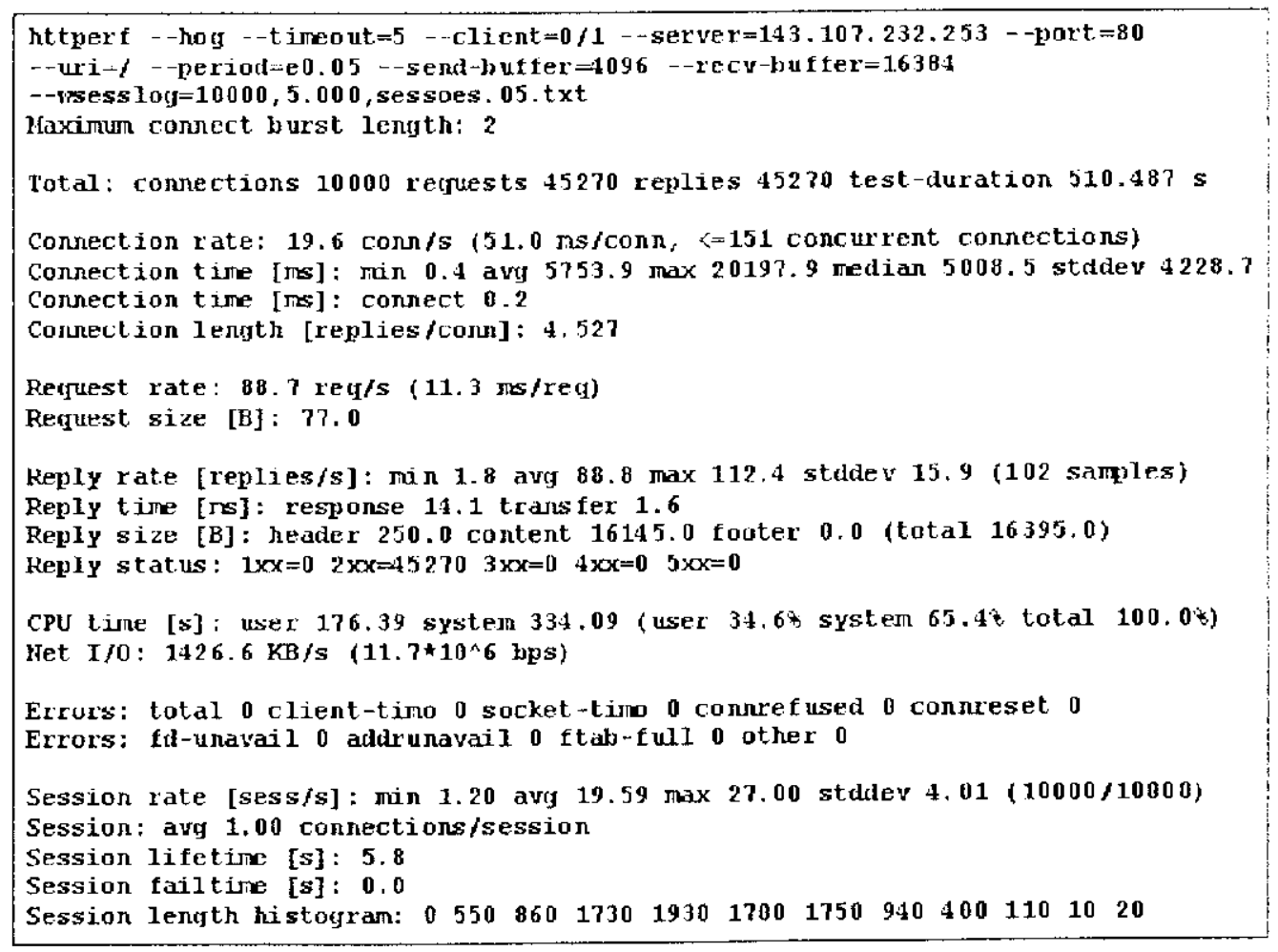

Figura 1.3: Estatísticas de desempenho obtidas pelo htperf.

Pode-se perceber seis grupos de estatísticas: resultados gerais ("Total"), resultados pertinentes a conexós ("Connection"), referentes a requisiçoes HTTP ("Request"), respostas recebidas do servidor("Reply"), utilizaça de CPC ("CPU") e rede ("Net $1 / O ")$ e, finatmente, um sumário de erros ("Errors"). 
- Total Section: Compila quantas conexöes TCP foram iniciadas pelo httperf, quantas requisiçoes ele enviou, quantas respostas foram recobidas e qual a duração total do teste. No exemplo acima, foram feitas 10000 conexões, que geraram 45270 requisiçōes e obtiveram esse nesmo número de respostas. O teste teve ma duração total de 510,487 segrundos.

- Connection Section: Exibe infurmaçoes relacionadas às contexoes TCT geradis pela ferramenta. Especificanente, a linha "Comection rate" mostra clue novas conexöes foram iniciadas a uma taxa de 19,6 conexões por segundo. Essa taxa corresponde a un período de 51 milisegundos por conexăo. O último valor na linha mostra que, no máximo. 151 conexões estavam abertas em un determinado instante.

A primeiria linha entitulada "Connetion time" mostra estatísticas para o tempo de vida das conexóes que ocorreram corretamente. O tempo de vida de uma conexão é o tempo entre a inicialização e o encerramento da conexão TCl' Una conexão é considerarta correta se teve pelo monos uma chamada completada corretamente. No exemplo ilustrado, a linha indica que o tempo de vida mínimo ("min") foi de 0,4 milisegundos, alóm de: fornecer valores também para a média("aıg"), o máximo, a mediana o dessio padrio.

A linha seguinte exibe o tempo médio tomado para estabelecer uma conexão. Apenas conexốs (ule ororreram com sucesso são levadas em contat. No extmplo, 0,2 milisegundos foram necessários, em média, para estabelecer una conexão.

Finalmente, "Connection length" dá o número médio de respostas recebidas cn cada conexão que obteve pelo menos uma resposta - no caso, o valor alcançado foi 1,527 respostas/conexão. Fsse número pode ser maior que 1,0 devido a conexöes persistentes.

- Request Section: "Request rate" mostra a taxa em que requisiçoes HTTP foram enitidas e o período a que essa taxa corresponde. No exemplo acina, a taxa de requisição foi de 88,7 por segundo, o que corresponde a 11,3 milisegundos por requisição. Para o caso da não utilização de conexões persistentes, os resultados nessa seção poden ser bastante parecidos, on até mesmo idênticos, aos encontrados na seção de conexões.

"Request size" apresenta o tamanho médio, em bytes, das requisiçōes HTTl. No exemplo, esse tamanho foi de 77 bytes.

- Reply Section: "Reply rate" exibe diversas estatísticas sobre a taxa de resposta. No exemplo, a taxa mínina de resposta("min") foi do 1,8 respostas por segundo, a média ("ang") de 88,8 respostas por segundo, e o máximo de 112.4. O número entré parênteses mostra que 102 amostras foram colhidas. O littperf coleta uma annostra de taxa, aproximadamente, a cada 5 segundos. 
A linha entitulada "Reply time" apresenta informaçōes sobre quanto tempo o servidor levou para responder e quanto tempo foi necessário para receber a respostia. No exemplo, foram gastos em média 14,1 milisegundos entre o envio do primeiro byte da requisição e o recebimento do primeiro byte da resposta. O tempo para transferir ou ler a resposta foi de 1,6 ms. Pode ocorrer de o tempo para transferência ser registrado como 0,0. Isso acontece, tipicamente, quando a resposta cabe em apenas um segmento TCP.

A linha seguinte: "Reply size", contém estatísticas sobre o tamanho médio das respostas. Especificamente, a linha lista o tamanho médio do cabegalho, do conteúdo e de rotapé("footers"). Por conveniência, a média do número total de bytes nas respostas também é dado, número entre parêtuteses. No exemplo, o tamanho total das respustas foi de 16395 bytes, em média.

A última linha é um histograma dos principais códigos de status recebidos do servidor. Fsses códigos são uma referência às classes de status utilizadas pelo protocolo HTTP. No exemplo, todas as respostas foram recebidas com o status "2xx", indicando que a operagão ocorrelu com sucesso.

- Miscellaneous Section: Essa seção comega com um sumário da utilização da CPU na máquina diente. No exemplo, a linha entitulada "CPU Time" mostra que 176,39 segundos foram gastos com execucão en modo usuário ("user"), 334.09 segundos pelo sistema ("system") e que isso corresponde a uma execuçāo de $34,6 \%$ em nodo usuário e $65,4 \%$ pelo sistema. A utilização total foi de $100 \%$, o que era esperado dado que o httperl exige muito processamento. Uma utilizaço total menor do cue $100 \%$ é sinal de que há processos competindo pelo processador e interferindo no teste.

"Net $1 / 0$ " fornece o throughput nédio da rede em kilobytes (1024 byles) e em megabits ( $10^{6}$ bits) por segundo. No exemplo; o uso médio da rede ficuu em 1426,6 kilobytes por segundo, e o número entre parênteses mostra que isso corresponde a 11,7 megabits por segundo. Essa banda de rede é medida com base no número de bytes enviados e recebidos nas conexões TCP. Em outras paliavras, não são levados em conta os cabeçalhos ou retransmissões TCP.

- Errors Section: A próxima sção contém estatísticas subre erros encontrados durante o teste. No exemplo, as duas linhas nomeadas "Errors" mostram que houve um total de 0 erros. Uma descrição de cada erro é apresentada a seguir:

- client-timo: Número de vezes que uma sessão, concxão ou chamada falhou devido a timeout.

- socket-timo: Número de vezes que uma conexão TCP falhou devido a um timeout em nível de socket (ETIMEDOUT). 
- connrefused: Vezes em que una conexão TCP falhou devido à recusa do servidor (FCONNREFUSED).

- connreset: Número de erros devido a um "RESET" vindo do servidor. Normalmente, un "RESET" ó recebido quando um cliente tenta enviar dados ao servidor que já encerrou à concxão.

- fd-unavail: Vezes en que o hutperl esgoton os descritores de arquivo (filt descriptors). Vesse caso o teste perde o significado porque o cliente foi sobrecarregato.

- addrunavail: Número de vezes em que o cliente esgotou os números de portas TCP (FADDRNOTAVAIL). Este erro nunca deve ocorrer, caso contrário, os rosultados devem ser descartados.

-- ftab-full: Vezes em que a tabela de descritores de arquivos do sistema esteve cheia. Novamentc, este erro não deve ocorrer.

- other: Registra a ocorrência de outros erros. Sempre que este contador for diferente de zoro, deve-se rastrear a causa real do erro.

Além desse conjunto de estatísticas, quando são utilizadas sessões durante o teste, o litperf imprime eladus a respeito dessas sessoes. lsso é o que pode ser visto como o último conjunto de estaristicas apresentado na Figura 4.3.

A linha "Session rate" mostra valores de mínimo, máximo, média e desvio padrão atingidos durante a execusāo do teste. Os números entre parênteses indicam quantas sessöes ocorreram com sucesso e quantas foram inicializalas. Na sequência, "Session" indica o tamanho módio das sessốes, medido em conexöes. No caso ilustrado, foi utilizadá apenas uma conexĩo por sessão.

"Session lifetime" mostra que foram gastos 5,8 segundos, em méclia, para completar uma sessão. O próximo valor, "Session failtime", fornece o tempo médio até que ocorra una falha en alguna sessão criada no teste. Como o total de erros foi zero, já mostrarbo anteriormente, esse valor também é 0,0.

A últina linha impressa como resultado do teste "Session longth histogram", é um histograma do número de respostas recebidas por cada sessão. No exemplo acima, nenhuma sessão terminou sem receber alguma resposta; 550 sessöes terminaram após receber uma respostid; 860 sessöos recheram 2 respostas e assim sucessivamente.

\subsection{Considerações finais}

A utilização de ferramentas para a avaliação de servidores Web deve ser feita com bastante cuidado, pois os resultados obtidos por meio desse tipo de benchmak podem tanto informar, como confundir os usuários a respeito da real capacidade do sisiema. Isso 
depende de como os resultados são interprelados. Antes de utilizar qualquer resultado, é necessário entender o sistema em estudo, os testes e, finalmente, os próprios resultados.

Apesar de serem citados vários benchmarks na introduçāo deste trabalho, no presente capítulo foram discutidos em detalhes apenas dois. Isto ocorreu porque uma das ferramentas, no caso o Surge, apresentou sérios problemas. Mesmo depois de se investir muito tempo em correçôes no código fonte e acertos na configuração de máquinas, o benchmark não funcionou como esperado. Assim, o que se utilizou da ferramenta foram apenas os parâmetros de caracterização de cargà que se mostraram muito interessantes. Já o SPECWeb foi descartado por se tratar de un softwart comercial, não estando assim, disponível publicamente.

Como pôde ser visto, os benchmarks descritos apresentam características bastante distintas, cada um com suas vantagens e desvartagens. O WebStone apresentou problemas na instalação e na execução. Foi necessário grande esforço para que essa ferramenta funcionasse de forma adequada. Além dos erros, o código tonte se apresentou bastante confuso, e foi diff́cil a identificação do modo de implementação de cada parte do algoritmo. Quanto à carga, o WebStone não permite a utilização de sessões, ou roquisiçōes en cascata, nem a representação do tempo de pensar dos usuários.

Como ponto positivo do WebStone, pode-se destacar o fato de este ser distribuído, ou seja: para a utilização de várias máquinas não săo necessárias diversas instalaçöos. No entanto, há a necessidade de configuração de cada uma dessas máquinas para que elas possam receber conexões através da rede. Outros pontos positivos são a existência de um mecanismo antomatizado para criar os arquivos que serão requisitados ao servidor e a presença de uma configuração (filelist e tcstbed) pré-determinada que pode ser utilizada em um teste tão logo a ferranenta esteja instalada.

Já o httperf se mostrou mais fácil de se instalar e executar. Apresentou também um cúdigo mais legível e fácil de se entcnder, conseqüentemente, mais propício a receber as altcraçōes propostas. Em relação à geração de carga, há a possibilidade de modelar o tompo de pensar dos usuários e utilizar o protocolo HTTP em suá versão 1.1, possibilitando o uso de chamadas en cascata(pipeline). Nesse quesito, o httperf apresenta uma desvantagem por não oferecer um conjunto de arquivos pré-definidos para a utilização em testes.

Outro fato bastante importante é a quantidade e a qualidade da documentação disponível. Nesse ponto, o httperf se saiu muito melhor do que o WebStone, pois este disponibiliza um material que gera confusão, por misturar diferentes versöes da ferramenta. Já o httperf mostrou, dentre outros documentos, um manual (manpage) bastante completo, contendo detalhes a respeito da implementação e do mecanismo de funcionamento da ferramenta.

Por fin, os dois benchmarks apresentam seus resultados de forma muito distinta, o 
que pode tornar difícil a comparaçäo direta entre eles. O httperf não utiliza o conceito de: clientes, assim, não faz sentido comparar por exemplo, o throughput de 101 clientes no WebStone - 88,83 Mbits/s - com o throughput obtido pelo httperf - 11,7 Mbits/s.

A Tabela 4.4 apresenta, de forma sucinta, um comparativo entre o htperf o o WebStone.

\begin{tabular}{|c|c|c|}
\hline & WebStone & httperf \\
\hline Documentação & $\begin{array}{l}\text { Apresenta-se en boa quantidade mas } \\
\text { bastante confusa, com partes que fa- } \\
\text { zem referência à versão } 2.0 \text { e outrà à } \\
\text { versäo } 2.5 \text { da ferramenta }\end{array}$ & $\begin{array}{l}\text { Apresenta-so em menor quantidade } \\
\text { porém, de forma mais técnica o sem } \\
\text { confusóes. }\end{array}$ \\
\hline Instalação & $\begin{array}{l}\text { Bastante complicada, sendo necessá- } \\
\text { rias correçoes no código fonte. Fntre- } \\
\text { tanto, a instalação é feita em apenas } \\
\text { uma máquina. }\end{array}$ & $\begin{array}{l}\text { Ocorreu sem problemas. Só foi no- } \\
\text { cessária a instalaçăo em todas as má- } \\
\text { quinas que se pretendia utilizar nos } \\
\text { experimentos. }\end{array}$ \\
\hline Execisão & $\begin{array}{l}\text { Ocorre de forma tranqüila. Há va- } \\
\text { lores já definidos para seren aplica- } \\
\text { dos em testes parträo. É necessário } \\
\text { apenas executar o script que controla } \\
\text { todo o teste. A utilização de diversas } \\
\text { máquinas chicntes ó trivial. }\end{array}$ & $\begin{array}{l}\text { Não há nenhuma definição padräo. } \\
\text { É necessário, antes de: turlo, buscar } \\
\text { parâmetros para definir o teste a ser } \\
\text { realizado. Se mais de una máquina } \\
\text { cliente for utilizada, o usuário deve } \\
\text { inicializar o teste em cada uma des- } \\
\text { Sas máquinas. }\end{array}$ \\
\hline $\begin{array}{l}\text { Carga de Tra- } \\
\text { balho }\end{array}$ & $\begin{array}{l}\text { Menos flexível pois utilizat apenas o } \\
\text { HTTP 1.0; não utiliza o conceito de } \\
\text { sessoes; não permite requisiçós em } \\
\text { cascata. Como vantagem, possibilita } \\
\text { a representacão de usuários por meio } \\
\text { de processos; ou scja, é possível defi- } \\
\text { nir testes com } 100500 \text { ou } 1000 \text { clien- } \\
\text { tes, por exemplo. }\end{array}$ & $\begin{array}{l}\text { Mais Flexível. Pode-se utilizar o } \\
\text { HTTP nas versóes } 1.0 \text { e } 1.1 \text { permi- } \\
\text { tindo assim a utilizacão do requi- } \\
\text { siçoes em pipeline juntamente con } \\
\text { sessōes. F́ possível ainda representar } \\
\text { o think time, e apresenta uma forma } \\
\text { "primitiva" para se utilizar logs. En- } \\
\text { tretanto, não é possível definir um } \\
\text { número específico de usuários. }\end{array}$ \\
\hline Resultados & $\begin{array}{l}\text { Säo apresentados do forma clara e } \\
\text { simplificada, devido à existência de } \\
\text { um tratamento feito aos dados cole- } \\
\text { tados. Os resultados de diversos cli- } \\
\text { entes são compilados em uma única } \\
\text { tabela automaticamentc. Pode-se ve- } \\
\text { rificar o resultado por número de pro- } \\
\text { cessos clientes. }\end{array}$ & $\begin{array}{l}\text { São apresentados por cada máquina } \\
\text { cliente. Para se obter o resultado ge- } \\
\text { ral do teste é necessário compilá-los } \\
\text { manualmonte. Não é possível verifi- } \\
\text { car o resultado por cliento mas ape- } \\
\text { nas por teste. }\end{array}$ \\
\hline
\end{tabular}

Tabela 4.4: Quadro comparativo entre o WebStone e o hitperf 


\section{Capítulo 5}

\section{Modificações no Httperf}

\subsection{Introdução}

O capítulo 4 expôs os benchmarks WebStone e httperf, destacando características do cada um deles e terminando com uma breve comparação entre os dois softwares. Como pôtle ser visto, o httperf se mostrou mais propício a receber as implementaçoes planejadas neste trabalho.

A melhoria de cargas de trabalho geradas por um benchmark pode ser obtida de diversas formas, dentre elas, pode-se destacar a pesquisa por novos parâmetros em cargas reais: execução de testes distribuídos - com várias máquinas clientes para alcançar maiores cargas - e mudanças no sistema operacional das máquinas clientes. Esta última opgão traz benefícios no que diz respeito à minimização de gargalos existentes no S.O como: troca de contexto em excesso e número máximo de descritores de arquivos abertos. Entretanto, essa opģăo se mostra bastanto complexa pois não são todus os S.O.s que permitem alteraçoes em seu modo de funcionamento e quando permitem, isso ocorre de forma bastante complexa. A segunda opção, sem dúvida, acrescenta funcionalidades à ferramentà e facilita o trabalho do usuário que pretende executar testes de forma distribuída. No cntanto, em casos como o httperf, mesmo sem esta funcionalidade e com un pouco nlais de trabaIho, o usuário pode conseguir testes distribuídos. A primeira opção, de se utilizar novos parâmetros de caracterizaçāo traz o seguinte problema: Como conseguir estes parâmetros novos? Ao mesmo tempo, ela traz a vantagem de que, uma vez executada a implementasão, novas cargas podem sor conseguidas por meio de noros parâmetros e não por moio de novas implementaçōes. Uma boa resposta para a pergunta colocada são us logs de servidores web, pois eles posstiem informaçōes a respeito de tudo o que foi presenciado pelo servidor em um determinado período de tempo. Assim. a partir da interpretação do $\log$ pode-se reproduzir aquela carga registrada.

A inclusão da capacidade de leitura de log no httpetf pode parecer, num primeiro momento, redundante, pois esse benchmark já possui uma maneira para fazer isto. En- 
tretanto, a forma como isso é feito não é eficiente. Primeiro é necessário que o usuário transforme um arquivo de $\log$, retirando praticamente todos os campos de cada registro, para que este possua apenas o nome das LRLs presentes nesse arquivo. Com o arquivo construído, é necessário ainda criar e transferir para o servidor, todos os arquivos (URLs) que serão requisitados. A pós todo esse processo, o teste poderá, finalmente, ser inicializado fazendo com que o httperf percorra o arquivo de URLs de forma seqüencial, requisitando objeto por objeto.

Com a utilização da fermamenta implementada neste trabalho, a tarefa se torna mais simples. É necessário apenas o log. no formato padrão CLF, que o resto é executado automaticameite. A ferramenta trabalha o log, gera um histograma, cria todos os arquivos (URLs) representativos, e provê uma forma de o httperf ter acesso ao histograma no momento do teste. Com isso, o benchrnark nāo apenas pereorre um arquivo de formá secuïencial, mas uiliza una representação da distribuição dos tamanhos dos objetos presentes no log tratado.

O algoritmo implementado pode ser dividido em três fases que funcionam basicamente da seguinte forma:

1. Análise do log. A primeira fase consiste de uma análise de todo o log, com o objetivo de retirar os registros que se encontram com erro. Os registros considerados corretos são então convertidos para um formato mais simples.

2. Geração do histograma. O log convertido é todo colocado em uma estrutura, na memória. Com a estrutura gerada, monta-se o histograma que consiste de uma função de distribução acumulada do tamanho dos arquivos presentes no log. Cada faixat desse histograma possui um tamanho de arquivo associado e um poso que indica a sua "participação" em relação ao total.

3. Geração dos arquivos. A geração do histograma engloba a associação de um arquivo para cada faixa existente. Esses arquivos ainda nāo existem, precisam ser geralos. Isto é feito nesta última fase, completando assim, todo o tratamento do $\log$.

Ao final da utilização da ferramenta, o usuário possui um histograma representativo daquele log tratado, podendo inicializar o httperf com o conjunto de parâmetros corretos para executar o teste.

\subsection{Logs de servidores web}

Os logs constituem uma dentre várias maneiras de se medir o tráfego na Web (Arlitt \& Williamson. 1996; Krishnamurthy \& Rexford, 2001). Esses logs, ou rastros, podem 
ser coletados nos servidores, em proxies ou nos próprios clientes. Nesté trabalho serão utilizados apenas logs registrados por servidores.

Lim servidor Wob nom malmente gera um log como parte do processamento dos pedidos do cliente. Cada entrada no log corresponde a um pedido HTTP' tratado pelo servidor, incluindo informaçōes sobre o cliente solicitante, o horário do pedido e as mensagens de pedido e resposta.

A maioria dos servidores Web realiza o logging (registro om log) por padräo. Vo ontanto, na prática, os rastros do servidor não oferecem informaçoes muito detalhadas. Isso ocorre porque quanto maior o número de informaçóes registradas, maior será a sobrecarga no servidor. Por isso, nomalmente são registradas apenas informaçoes como o endorego do cliente, método do pedirlo, URh do pediclo, código de resposta e tamanho do arquivo requisitado.

Fnbora nenhum padrão formal dite os formatos do log, a maioria das implementasões segute normas informais para os dados que devem ser registrados. Um tipo de log bastante utilizado é o Common Log Format (CLF) descrito à seguir.

\section{Common Log Format - CLF}

Cada entrada en un log CLF consiste de sete campos, listados na Tabelia 5.1 e descritos abaixo.

\begin{tabular}{|l|l|}
\hline Campo & Significado \\
\hline \hline Remote Host & Nome de host ou endereso IP' do cliente solicitante \\
Remote Identity & Conta associada à conexäo na máquina do cliente \\
Authenticated User & Nome fornecido pelo usuário para autenticação \\
Time & Data e hora associada com o pedido \\
Request & Método de pedido, URL do pedido e versão do protocolo \\
Response Code & Código de resposta HTTP com trôs dígitos \\
Content Length & Número de bytes associados com a resposta \\
\hline
\end{tabular}

Tabela 5.1: Campos presentes em um log CLF

- Remote Host: Registra o nome, ou o endereço IP: da máquina cliente. O endereço IP pode ser registrado, diretamente, através do socket HTTP. O registro de nomes, no entanto, requer una consulta a un servidor DNS para obter este nome através do endereço IP. A conversão de IP en nome fied normalmente desativada por aumentar significativamente o tempo de atendimento da requisiçáio.

- Remote Identity: Indica o proprictário, na máquina cliente, associado à conexāo TCP. Novamente, a obtenção desse dado implica em consultas a hosts remotos que demoram para responder ou nem respondem. Assim, a maioria dos servidores Web não utiliza esse campo. 
- Authenticated User: Nome de usiário fornceido no cabeçalho HTTP para autenticação pelo servidor. Se o servidor não utiliza informações de autenticação, esse campo não é registrado.

- Time: Registra a hora do pedido na granularidade de um segundo.

- Request: Corresponde à primeira linha do cabesalho HTTP cue contém o método do pedido, URI do pedido e a versāo do protocolo.

- Response Code: Código de resposta de três dígitos, com 200 para umia resposta correta e 1011 para LRI não encontrada, dentre uulros.

- Content Length: Indica o numero de bytes associados à resposta. Para respostas com código 404 ou 304, esse tanlanho é igual a 0 pois nenhum conteúdo é rotornado.

A Figura 5.1 ilustra parte de um log en formato C.LF. Pode-se perceber os sete campos cm cada un desses registros, sendo o segundo e o terceiro campos iguais a "-", pois o servidor não registrou essas informaçōes.

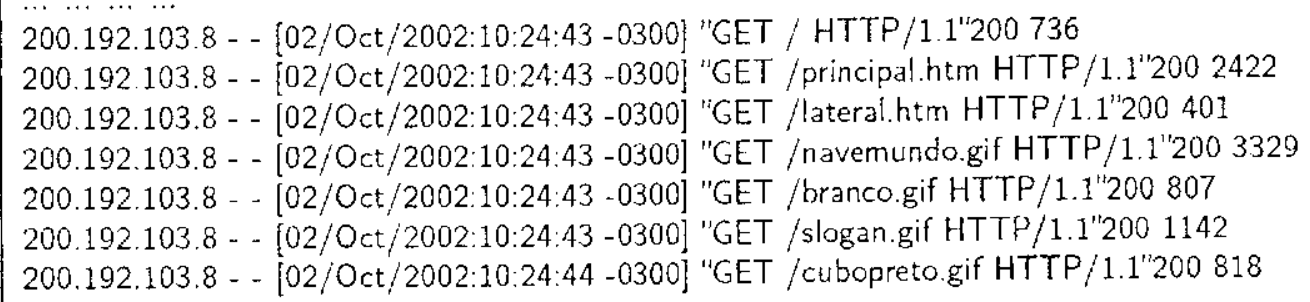

Figura 5.1: Exemplo de um log en formato CLF

No presente trabalho foram utilizados três logs distintos. Cada um deles é descrito em detalhes nas próximas seçōes.

\subsection{1 log do site da Copa do Mundo de 1998}

A Copa do Mundo de 1998 foi realizada na França durante o período de 10 de junho a 12 de julho. O site construído possibilitava aos ustários acessar diversos serviços como resultarlos de jogos em tempo real, estatísticas sobre jogadores, história dos times e estádios, além de uma grande quantidade de imagens e sons. Para suportar o trálego esperado durante o evento foi construída uma estrutura com 30 servidores, distribuídos em 4 localizações diferentes, uma na França e três nos Estados Unidos.

Os logs foram coletados inicialmente no formato CLF e, posteriormente, convertidos para um formato binário por razões de espaço de armazenamento. Seus registros representam a atividade de todos os servidores Web no período observado, entre 30 de abril e 
26 de julho de 1998 , alcançando um total de cerra de 1.3 bilhão de registros. A base de dados encontra-se dividida em arquivos de 7 milhoes de revistros cada, correspondendo a partes de un dia de coleta. Neste trabalho, foi urilizada uma parte dessas de cada vez.

En relação à carga registrada pelo log; pode-se afirmar que a grande maioria das requisiçoes uson o método GET $(99,88 \%$ ) para obtenção dos dados, seguido por um pequeno percentual de métodos HEAD $(0,1 \%)$ e POST $(0,02 \%)$. Analisando, em seguida, os códigos de resposta checou-se que a maioria das requisiçós resultou em sucesso (código 200). O segundo código de resposta mais comum foi o 304(not-modified). Pôde-se perceber, ainda, uma pequena quantidade de acessos que resultaram em erro, código de resposta igual a 404 (file not found).

A Tabela 5.2 mostra uma divisão das respostas por tipo de arquivo requisitado pelo usuário. Ela revela que quase todos os clientes $(98.01 \%)$ fizeram requisiçoes a arquivos cm IITML ou imagens. Das requisigôos restantes, o tipo mais freqüente foi o do arquivos cm Java. Tanto as ruquisiçōes a audio e vídeo, como as de natureza dinâmica, representaram uma parcela ínfima do total. Em relagão à quantidade de bytes transferidos, houve um predominio de arquivos em HTMI sobre as imagens. Isso se deveu, om parte, pelo fato de os arquivos HTML serem maiores do que as imagens; om média; alóm disso, muitas requisiçoes de imagens resultaram em respostas sem dados, do tipo Nol Modifud, ou seja, o arquivo, por não ser modificado com frequiência, não precisou ser enviado novamente pelo servidor. Nota-se também que os arquivos comprimidos, embora respondam por uma parcela muito pequena dos acessos, compreenderam um valor significatio, $20 \%$, do total de bytes transferidos. A discrepância entre a porcentagem de requisições a arquivos comprimidos e a porcentagem de dados transferidos por estas requisições é uma indicação dos efeitos que grandes arquivos porlem causar na carga de um servidor Web e de uma rede.

\begin{tabular}{|l|r|r|}
\hline $\begin{array}{l}\text { Tipo de } \\
\text { Arquivo }\end{array}$ & $\begin{array}{r}\text { \% de } \\
\text { requisiçōes }\end{array}$ & $\begin{array}{c}\text { \% de dados } \\
\text { transferidos }\end{array}$ \\
\hline \hline HTML & 9,85 & 38,60 \\
Imagens & 88,16 & 35,02 \\
Audio & 0,02 & 0,10 \\
Vídeo & 0,00 & 0,82 \\
Compr. & 0,08 & 20,33 \\
Java & 0,82 & 0,83 \\
Dinâmicos & 0,02 & 0,38 \\
Outros & 1,05 & 3,92 \\
\hline \hline Total & 100,00 & 100,00 \\
\hline
\end{tabular}

Tabela 5.2: Tipos de arquivos requisitarlos - Copa do Mundo 


\subsection{2 $\log$ do site Navemundo}

Navemundo é um portal que disponibiliza a seus usuários, informaçōes diversas como Emprego, Saúde, Tecnologia, Negócios e Música. Essc portal concentra diversos canais de informação que respondem a seus usuários através de domínios como www redenegocios. com.br, www aforja.com.br e o próprio www navemundo. com.br. Redenegúcios está relacionado a economia e mercado, oferece um serviço de assessoria e provê informaçous como cotaçōes, tarifas públicas, investimentos e empresas. Aforja concentra informaçös relacionadas a música, tais como notícias a respeito de bandas, entrevistas c críticas sobre discos e shows.

A estrutura montada para hospedar o portal e seus domínios constitui-se de dois servidores - um para atendimento aos usuários e outro para auditoria dos domínios existentes.

O $\log$ foi coletado no formato $\mathrm{CLF}^{7}$, com seils registros representando a atividade do servidor Web no período observado entre 28 de setembro e 05 de outubro de 2003 , alcançando um total de cerca de 885.640 registros.

Em relação à carga, pode-se dizer que a grande maioria das requisições usou o método GET (99,82\%) para obtenção dos dados, seguido por um pequeno percentual de métodos HEAD $(0,01 \%)$ e POST $(0,15 \%)$. Analisando, em seguida, os códigos de resposta notonse que a maioria das requisições resultou em sucesso (código 200). O segundo código de resposta mais comum foi o 304 (not-modified). Pôde-se perceber ainda uma pequena quantidade de acessos que resultaram em erro, código de resposta igual a 404 (fle not found).

A Tabela 5.3 mostra uma divisão las respostas por tipo de arquivo requisitado pelo usuário. Ela mostra que a grande maioria dos clientes $(89,2 \%)$ fizeram requisiçoes a arquivos en HTMI, ou imagens. Das requisiçoes restantes, o tipo mais freqüente foi o de requisições dinânicas. Em relaçăo à quantidade de bytes transferidos, houve um predomínio de arquivos em IITML sobre as imagens. Isso se deveu, em parte, pelo fato de os arquivos IITML sercm maiores do que as imagens, em média; além disso, muitas requisições de imagens resultaram em respostas sem dados, do tipo Nol Modified, ou seja, o arquivo, por não ser modificado com frequência, não precisou ser enviado novamente pelo servidor. Nota-se também que as requisições dinâmicas compreenderanı un valor significativo, $8,6 \%$, do total de bytes transferidos.

\subsection{3 log de testes com o WebStone}

Durante o andamento do presente trabalho, foram executados diversos testes e experimentos com os benchmarks mencionados. O servidor Web Apache, estava presente em todas as execuções, e como é padrão neste servidor, foram registrados logs desses experimentos. 


\begin{tabular}{|l|r|r|}
\hline $\begin{array}{c}\text { Tipo de } \\
\text { Arquivo }\end{array}$ & $\begin{array}{r}\text { \% de } \\
\text { requisiçōes }\end{array}$ & $\begin{array}{c}\text { \% de dados } \\
\text { transferidos }\end{array}$ \\
\hline \hline HTML & 21,96 & 52,23 \\
Imagens & 67,24 & 34,18 \\
Audio & 0,0 & 0,0 \\
Video & 0,0 & 0,0 \\
Compr. & 0,02 & 1,54 \\
Dinâmicos & 6,70 & 8,64 \\
Outros & 4,06 & 3,38 \\
\hline \hline Total & 100,00 & 100,00 \\
\hline
\end{tabular}

Tabela 5.3: Tipos de arquivos requisitados - Navemundo

Como un dos objetivos deste trabalho é utilizar diferentes logs para testar servidores, optou-se por utilizar lambém esses logs regisurados durante os experimentos. A coletiz ocorrou após a execução de testes com o WebStone em que foram utilizadas quatro máquinas - três clientes e um servidor. O arquivo final apresentou mais de 230.000 rogistros. Em relação à carga, diferentenente dos logs já mencionados, este apresenta, em sura totalidade, requisiçoes do tipo GFT; nenhuma requisição errada - que tenha retomado com código 404; apenas requisições estáticas e nenhum ítem de tamanho 0.

Embora este $\log$ não represente uma situação real, ele tem sua validade no que diz. respeito a comparações entre os resultados obtidos para esse caso especial e os casos citados acima.

\subsection{Implementação}

A implementação da nova característica do benchmork foi alcançada através da construsâa de una ferramenta de tratamento de logs e da modificasão do httperl para que este fosse capaz de utilizar o resultado gerado pela ferramenta.

De acordo com a geração do carga do httperf, abordada no Capítulo 4, a inclusão do novo parâmetro acarretou na criação de uma nova forma de definir a URL que deve ser requisitada. A nova forma foi intitulada "uri_histogram" e definida como mostra a Figura 5.2 .

O algoritmo ilustrado na Figura 5.2 funciona da seguinte forma: Primeiro, fase de inicialização, o arquivo contendo o histograma é lido e mapeado na memória como um vetor. Esse vetor é montado de forma que cada posição dentro dele represente uma faxixa do histograma, e ainda apresente o nome do arquivo associado a essa faixa.

Com o vetor na memória, a definição da URL é feita através de um número aleatório, gerado de acordo com uma distribuição uniforme no intervalo de 0 a 1 . Verifica-se, entāo, em qual posição do vetor esse número se encaixa, retornando assim, o arquivo associado 


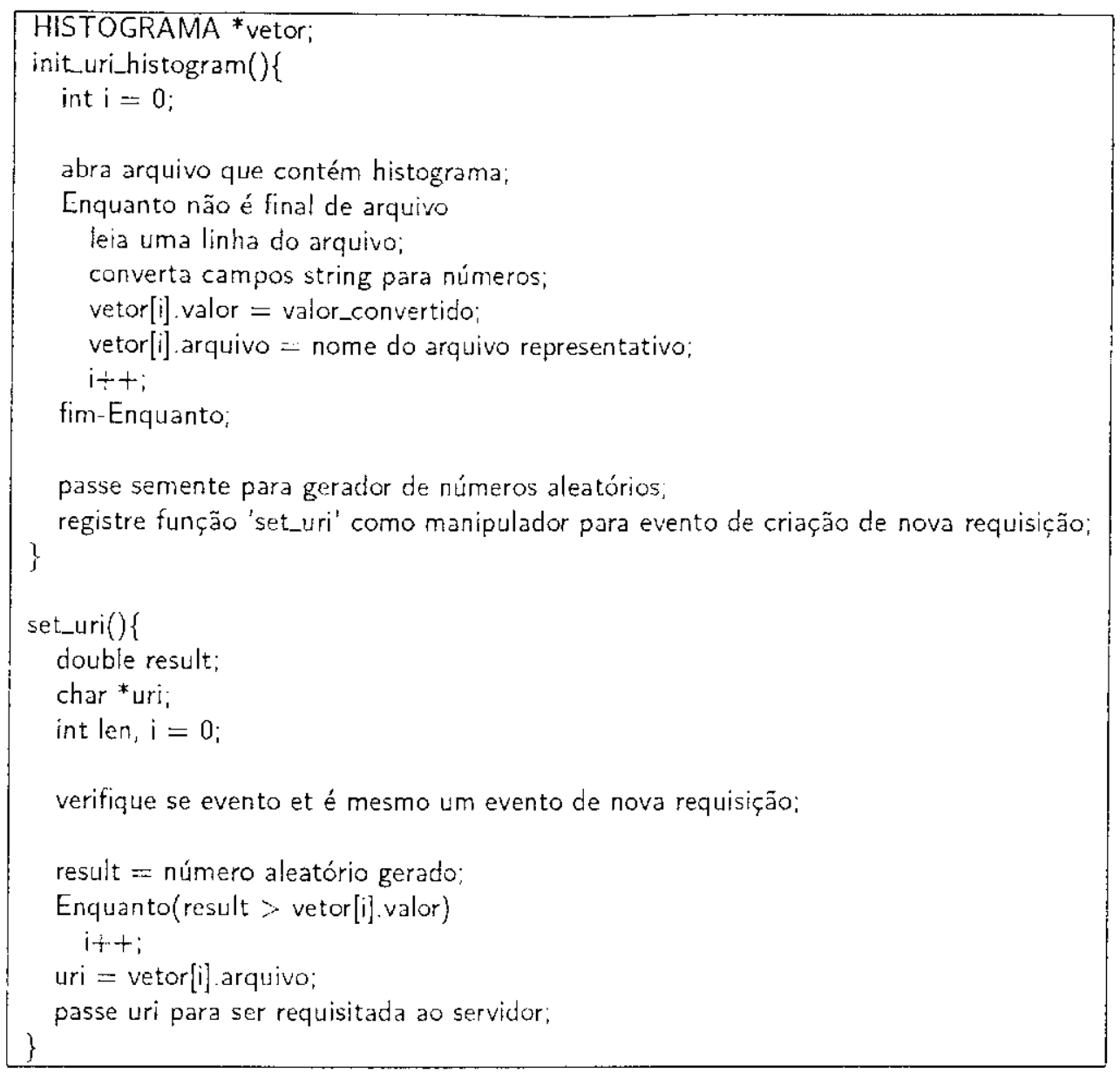

Figura 5.2: Algoritmo acrescentado ao httperf

àquela posição ou faixa. Esse arquivo é o que será requisitado ao servidor.

Além das modificaçóes no httperf. o tratamento do logs ainda exigiu a criação de uma ferramenta que. como mencionado, pode ser considerada em três tempos, a saber: Análise do Log. Construção do Histograma e Geração dos Arquivos.

\subsubsection{Análise do log}

Neste monento o log é lido pela primeira vez, em seu furmato inicial, contendo, possivelmente, diversos erros e registros defeituosos. Cabe a essa parte da ferramenta verificar se cada registro do log atende ao padrão especificado abaixo:

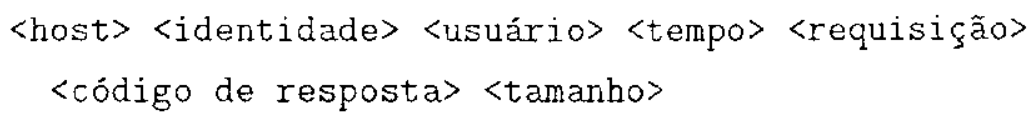

Dessa forma, cada entrada do log possui um nome de host ou endereço IP do cliente (host); uma conta associadla à conexão na máquina do cliente (identidade); o nome fornecido pelo usuário para autenticação (usuário); a data/hora associada com o pedido 
(tempo); o método do pedido, LRL do pedido e versão do protocolo (requisição); código de resposta HTTP com très dígitos (código de resposta); e, finalmente, o número de bytes associados à resposta (tamanho).

É considerado defeituoso todo registro que nāo possuir algum desses campos ou que possua um campo com formato diferente do esperado. Como por exemplo, un campo de tamanho com formato não numérico, ou um código de resposta fora do intervalo que vai de 100 a 599 . Todos os registros defeituosos são ignorados.

Os registros restantes são então convertidos para um formato mais simples, descartando os campos "identidade" e "usuário". Alén disso, o campo "tempo" é convertido para o formato de segundos desde as 00:00:00 de 1/1/1970.

Assim, o "novo" log criado através do tratamento e conversão iniciais, fica como formato:

$\langle$ host $\rangle\langle$ tempo $\rangle\langle$ requisição $\rangle\langle$ código de resposta $\rangle\langle$ tamanho

Um último ponto a se considerar durante esta fase é o registro das requisições com maior e monor tamanhos. Esses valores servirão de base para a criação do histograma na próxima fase.

\subsubsection{Construção do histograma}

Cada registro do log, convertido e sem erros, é agora lido e colocado em uma estrutura, definida como VFTOR, na memória. Esse VETOR (será discutido mais detalhadamente lla próxima seção) constitui-se de uma lista de listas. onde os registros säo separados por faixas, de acordo com o valor do seus campos "tamanho".

Com o VETOR todo montado, a construsão do histograma é obtida, basicamente, com o mapeamento dessa estrutura de uma nova forma. Isso ocorre porque o histograma utiliza faixas de tamanhos de arquivos, assim como no VETOR. A diferença aqui está no fato de que na estrutura está presente cada registro do log, já no histograna, as faixas possuem "apenas" um valor representativo em relação to total.

Essa nova forma de representação do VETOR é concretizada por una nova estrutura, que é utilizada para representar o histograma. Fssa estrutura constitui-se de um vetor de faixas, tendo cada faixa dois campos, arquivo e peso, que armazenam respectivamente o nome do arquivo representativo da faixa e a sua representação, en relação ao total, no $\log$.

O peso de cada faixa é obtido através da divisāo do número de registros que caíram naquela faixa pelo número total de registros em todo o log. Esses pesos são então somados de forma a se obter uma função de probabilidade acumulada, que é o próprio histograłrna. A Figura 5.3 mostra um exemplo. 


\section{Copa do Mundo}

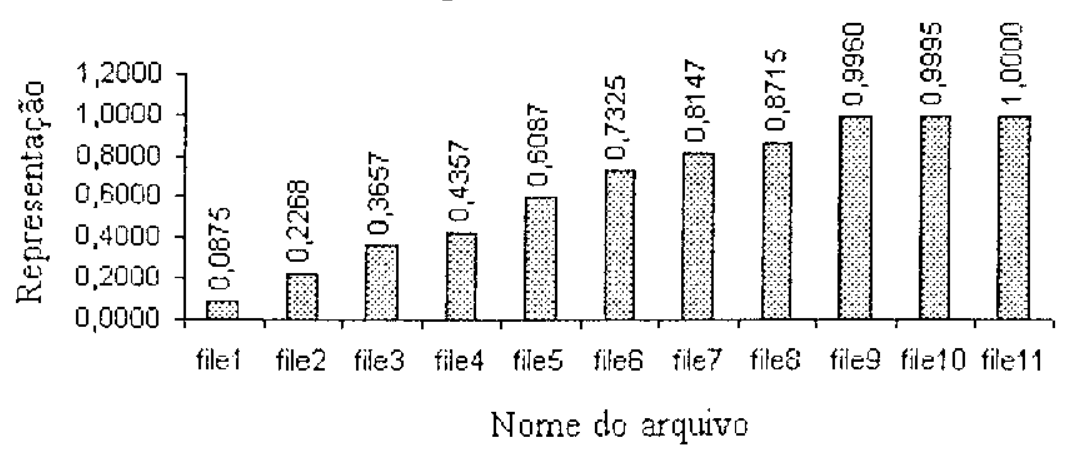

Figura 5.3: Ilistogrania criado a partir do log da Copa do Mundo

Por fim, o histograma é gravado em um arquivo para que possa ser utilizado pelo httperf no momento do teste.

\section{Estrutura Vetor}

A necessidade de se trabalhar com os registros do log de forma ágil, tornou necessário manter csses registros em memória. Como a intenção principal é dividir todo o log en faixas, quanto mais próximo disso a estrutura se apresentar, molhor.

Assim, as estruturas ilustradas na Figura 5.4 foram criadas para o armazenamento das informaçōes desejadas. Posteriormente foram definidas as regras de tratamento de cada uma delas.

REQ contém os dados de cada registro presente no log, incluindo todos os campos do registro mencionados acima. Cada NO possui uma estrutura RFQ e mais algumas informações de controle. Os NOs são arranjados em LISTAs; que possuem ainda a quantidade de elementos presentes nela e funções de manipulação. Toda LISTA está associada a um INDICE. No INDICE há um valor superior que estabelece quais os registros que entram en sua LISTA. Todos os INDICEs, por sua vez, são organizados en una lista controlada pela estrutura VETOR. A Figura 5.4 apresenta urra visão completa da estrutura.

A construção do VETOR inicia-se pelo estabelecimento de quantas faixas serã̃o criadas no histograma. O número de faixas estabelece o número inicial de índices. Cada índice possui um valor agregado, chamado valor superior, que varia do menor ao maior tamanho de requisiça presentes no log (registrados na primeira fase). Com isso, se os valores menor e maior fossem respectivamente 0 e 100 , e fossem criadas 2 faixas, por exemplo, seriam criados dois índices com valores superiores iguais a 50 e 100 . Assiml, quando os registros fossem incluídos no VETOR, todos que possuíssem tamanho menor que 50 ficariam na lista associada ao primeiro INDICE, e os de tamanho entre 50 e 100, estariam no scgundo INDICE. 
Indices

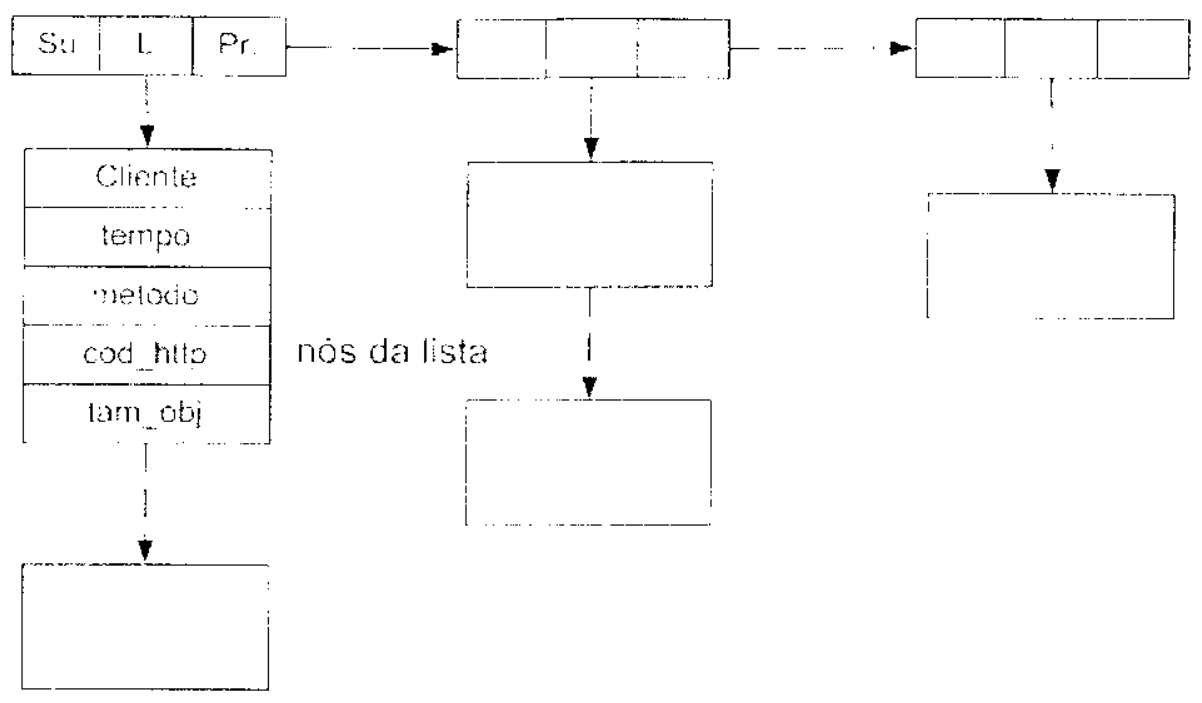

Figura 5.4: Fstmutum VETOTi.

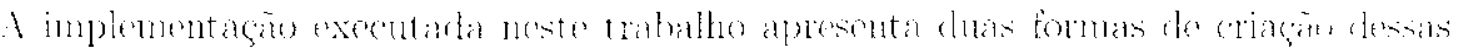

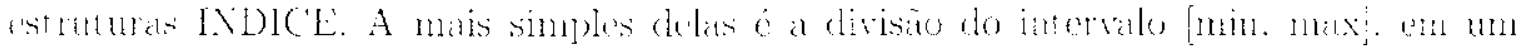

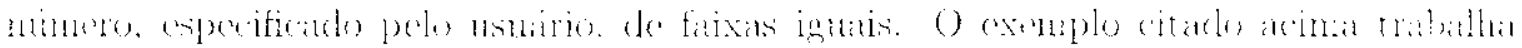
desint lomatit.

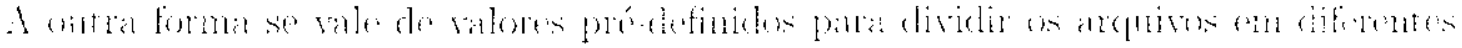

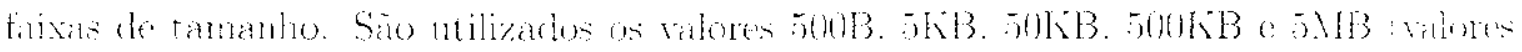

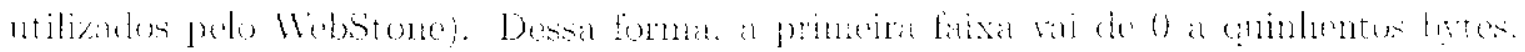

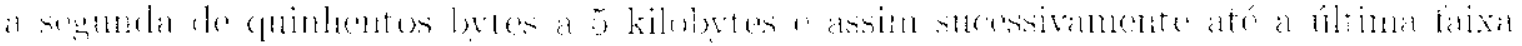

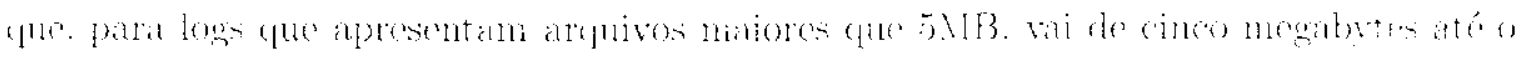
tamantue do mator arquivo.

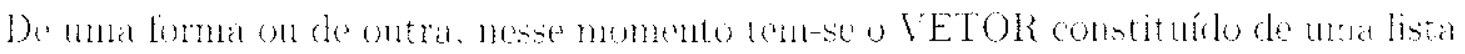

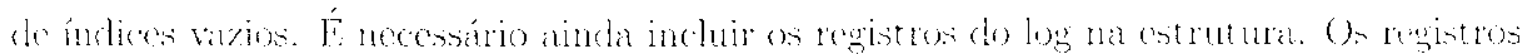

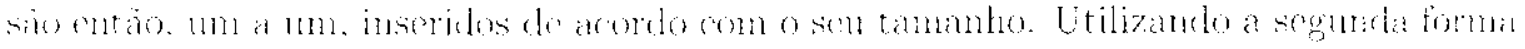

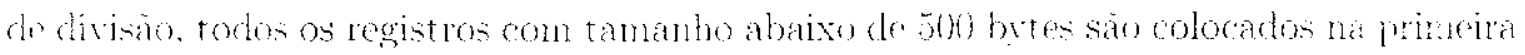

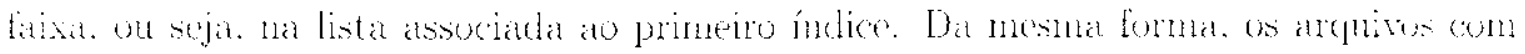

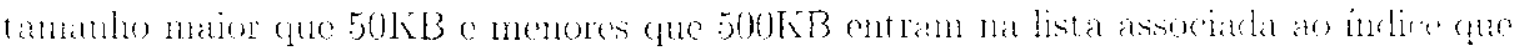
perimi valor superior ignal a $500 \mathrm{~KB}$.

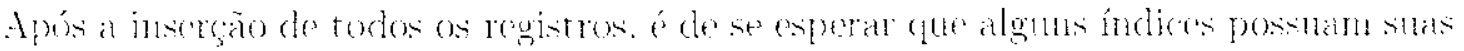
listas naiores que a lista de outros. On ato mesno indices completanente vazios. Para

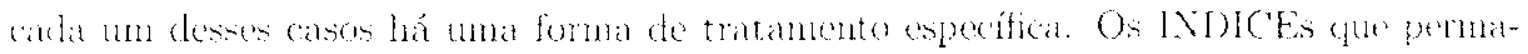

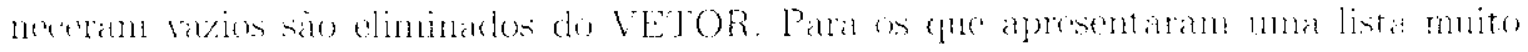

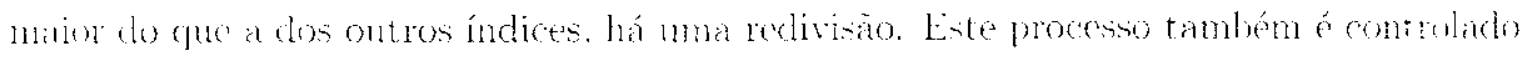

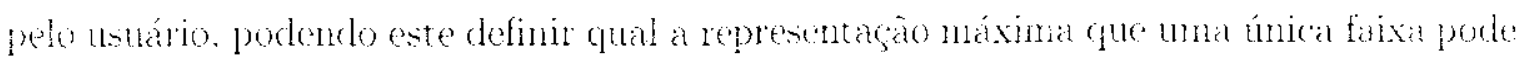


alcançar. Se o usúrio definir, por exemplo, que nảo quer faxas com representação maior do que 20\%, após a inserção dos registros. os nós IXDICE que estiverern acima de $20 \%$ serão redivididos, até que se alcance o valor desejado.

\subsubsection{Geração dos arquivos}

Durante a construção do histograma. foi associado a cada faixa, um arquivo representativo. Como mencionado, esse arquivo é a CRL què será requisitada ao servidor durante o teste. Como esses arquivos ainda nõo existem, eit's precisam ser gerados.

Cacla faixa possui dois valores delimitantes. I'm valor inforior e um valor superior. Como a URL deve representar essa faixa. foi escolbido como tamanho do arquivo, o valor médio entre esses dois valores.

Com o tamanho definido, săo criados arquiros e estes preenchidos com caracteres até que se alcance o tamimho desejado. Ou seja, sâno crados arquivos texto, com o tamanho determinado pela faixa a que pertence. O fato de serem criarlos arquiros texto, mesmo quando os logs apresentam imagens, vídeos e outros tipos de dados, näo influencia nos resultados pois para o objetivo do trabatho, o mad: impontanté é o tamanho e náa o tipo de arquiso tratado. Apenas trata-se tudo cono bits

Posteriormento esses arquivos deven ser transieridos para o servidor, para que este possa responder às requisiçoes dos clientes.

\subsection{Testes e experimentos}

Como disculido no decorrer desta dissertasão, os benchmarks para servidores Web năo apresentam alguns pontos importantes na guregno de cargas utilizadas durante os testes. Com isso, a tentativa de se alcançar uma carga o mais próximo do real possível é sempre um problema. O presente Capítulo apresenon. com maiores detalhes, uma forma de alcungar cargas que, se anda näo säo ideais, apresentan-so nais perto desse oljetivo do que as cargas já oferecidas pelas ferramentas mencionadas.

Nos ítens seguintes são apresentados diversos experimentos onde procurou-se avaliar os resultados obtidos com o benchmark modificado. O fato mais importante não são "apenas" os resultados, mas a forma utilizada para so chegar até eles, o que garante ma maior validiale dos dados.

\subsubsection{Plataforma utilizada para realização dos experimentos}

Tanto a implementação como os experimentos apresentados neste Capítulo foram realizados em uma redo de computadores pessoats em que toclos utilizavam o sistema ope- 
racional Linux. Mais precisamente, foi utilizadia a distribuiçäo RedHat (Red IJat, 2003), com o kemel 2.4.7. A Tabela 5.4 apresenta mais informaçōes sobre a configuração das máquinas utilizadas. Em todos os experimentos realizados, as máquinas utilizadas foram isoladas. sendo assim o tráfego existente na rede devido apenas à execução do próprio experinento.

\begin{tabular}{|l|l|r|r|}
\hline Máquina & Processador & Memória & Interface de Rede \\
\hline I.asdpc14 & AMD Duron 1,2GHz & $256 \mathrm{MB}$ & $100 \mathrm{Mb}$ \\
Lasdpc15 & Pentiun IV 2GHz & $256 \mathrm{MB}$ & $100 \mathrm{Mb}$ \\
Iasdpe17 & AMD Athlon XP 2GHz & $256 \mathrm{MB}$ & $100 \mathrm{Mb}$ \\
\hline
\end{tabular}

Tabeda 5.4: Mácuninas utilizalas para execugão dos experimentos

Em relaçào aos softuares utilizadus, optou-se por utilizar o servidor Web Apache (versão 2.0): por ser a última versäo do sorvidor http mais utilizado atualmonto; o o hutperf modificado, una vez que este é o principal objeto de estudo do trabalho.

\subsubsection{Descrição dos experimentos}

Dèido à criação de uma noxa ferramenta, tornou-se necessário executar, primeirnmernte. una série de testes para verificar sou funcionamento. Assim, foram ratates diversus logs com esta ferramenta, dentre eles, os já mencionados em maiores doualhes. Para cada log tratado foram obtidos, como resultado, un arquivo com caracteristicas específicas do log: um histograma e um arquivo representativo para cada faixa do histograma.

Após o leste te validação da ferranenta, de posse clos histogramas a arquivos gerados, deu-se inicio aos testes envolvendo o httperf e o servidor hit tip.

En cada teste foram utilizadas inicialmente apenas duas máquinas, o servidor e um cliente. Posteriormente observou-se que a mudança de um para dois clientes causara mudanças significativas nos resultados, mas que, no entanto, a utilização de três cliontess não acrescentava muito em relação a dois. A única alteração era a chegada mais rápida ao ponto do saturação do servidor; isto é, os erros de timeout reconhecidos pelos clientes aumentava rapidamente. Por jsso a maioria dos testes foram realizados com a utilização de 3 máquinas - un servidor e dois clientes. Em relação au núnero de processos, como explicado no Capítulo 4. execuçôes do httperf utilizam apenas 1 processo por máquina.

O objetivo principal a ser alcançado com os experimentos é a verificação de como será o comportamento do benchmark trabalhando de acordo com o novo método implementado, isto é como a nova carga de traballo influencia nus testes.

Valendo-se dos parànetros disponibilizarlos pelo hittperf, descritos na seção 4.3.1 os testes realizados foram definidos da seguinte forma parliu-se de uma taxa de 100 requisiçöes por segundo que era então incrementada para 200, 300,400, e assim sucessivamente 
até se atingir 1000 requisições por segundo, quando passou-se a incrementar o número de. requisiçoes com 200 unidades até se alcançar o máximo de 1400 requisições por segando. Dessa forma, os testes realizados com cada log consistia de 12 passos (100 a $1400 \mathrm{rec} / \mathrm{s}$ ).

As outras variantes nos experimentos são o histograma utilizado e os arquivos requisitados ao servidor. Estes pontos dependem do log em uso no momento, ou seja, quando utilizanclo-se o log da Copa do Mundo, por exemplo, o histograma referente a este log era passado ao httperf e os arquivos possíveis de serem requisitados eram copiados para o servidor. A seguir são apresentados os resultados obtidos.

\subsubsection{Resultados}

Os gráficos seguintes ilustram os resultados obtidos através do tratamento dos dilerentes logs, pela ferramenta construída.

A diferencra mais aparente entre os resultados, notada a primeira vista, é aquela que cliz respeito ao número de classes obticlas. No caso do WebStone, como foram utilizaclos cinco arquivos diferentes durante os testes que originaram o log, era esperado que o resultado tambóm apresentasse cinco classes. Para os outros dois casos, que representam o comportamento de servidores reais, o múmero de classes foi maior pois estes logs apresentam maior diversidade de arquivos, desde pequenas imagens até videos, além do respostas do tipo 404 e 304 que não aconteceram no caso do WebStone.

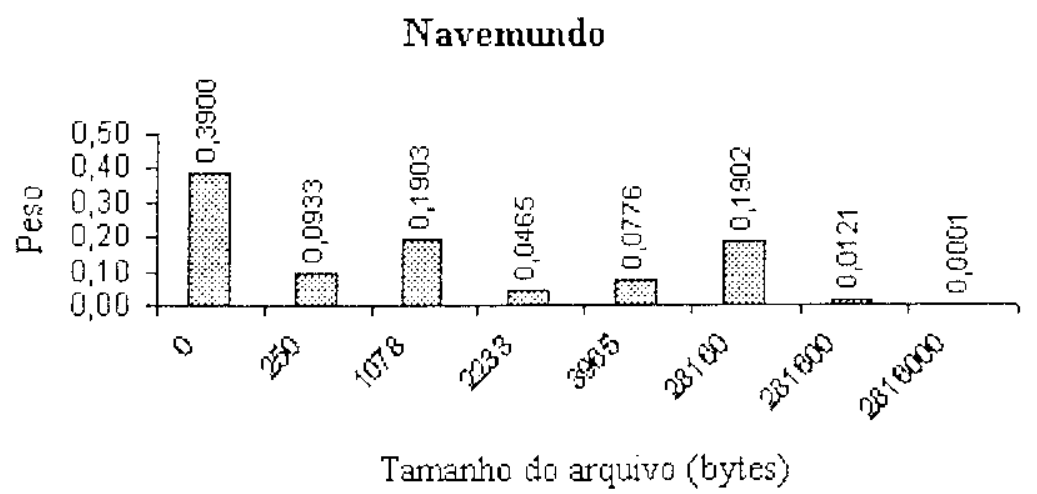

Figura 5.5: Distribuição de arquivos - $\log$ Naremundo

O gráfico da Figura 5.5 mostra que $39 \%$ das requisigoes registradas, retornaram com campo de tamanho igual a 0 . Como explicado isso so deve ao fato de existirem requisições que retornam con códigos 304 e 401. E a classe que representa os arquivos de maior tamanho, isto é, de aproximadamente $2 \mathrm{MB}$, aparece apenas com um peso insignificante em relação ao total.

No caso da Figura 5.6 pode-se perceber a existência de 11 classes, sendo a mais "contemplada", aquela cujos arquivos possuem um tamanho entre 934 e 1367 bytes. É ilustrado 


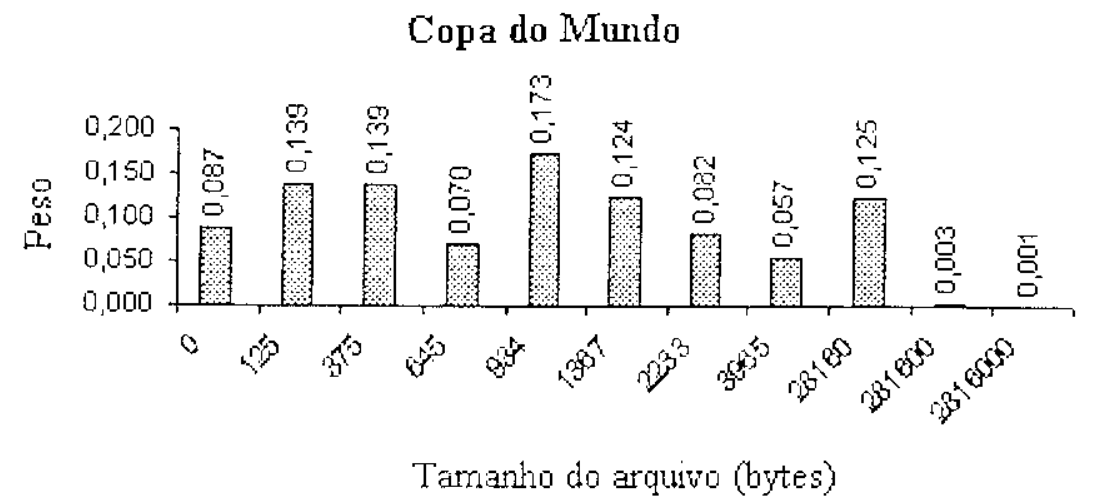

Figura 5.6: Distribuição de arquivos - log Copa do Nundo

ainda cue quase $9 \%$ das requisiçós registradas, retomaram com campo de tamanho ignal a 0 , e que os arquivos de tamanho maior que $2 \mathrm{MB}$ representaram menos de $1 \%$.

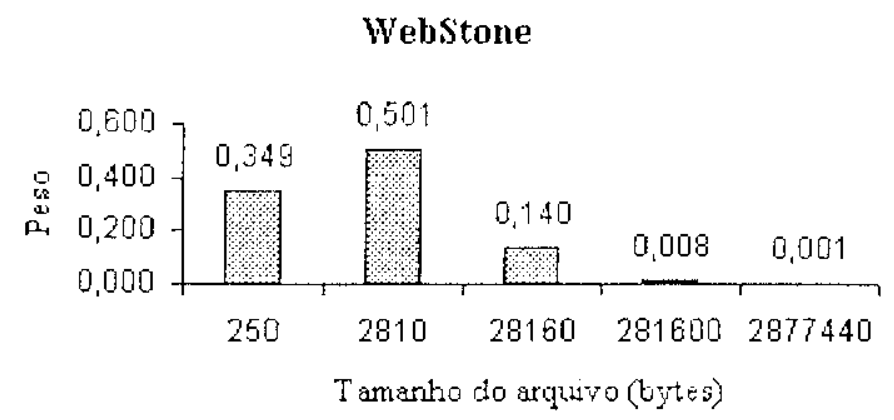

Figura 5.7: Distribuição de arquivos - $\log$ WebStone

Un fato importante a ser notado no gráfico da Figura 5.7 é a incxistência de uma classe para arquivos de tamanho 0. Isso ocorreu porque no teste não foram feitas requisiçoes com "GET condicional", o que possibilitaria um cóligo de retorno igual a 304, e todos os arquivos requisitados existiam no servidor, o que impossibilita o retorno do erros do tipo 404 . Outro ponto a ser destacado é a maior concentragão das faixas, em relaçáo aos outros logs, presente neste caso. Além de possuir menos classes, o que justifica, em parte. a presença de classes do: maior peso, cada faixa é representada por um único arquivo, tomancio assim a variância igual 0. Dessa forma, fica impossível redividir as faixas para gerar mais classes.

Fm relação aos três gráficos de distribuição de arquivos, vale ressaltar que em todos os casos: os arquivos de $2 \mathrm{~KB}$ ou menos representaram algo em tomo de $80 \%$, o que reforça a observação de que a carga na Web é constituída de arquivos pequenos. Além disso, a presença de classes com grande peso en relação ao total: se deve ao algoritmo utilizado para redivisão. Este algoritno, como explicado para o log WebStone, nada pode fazer no caso de classes que apresentam pequena, ou nemhuma, variância entre seus objetos. 
$\Lambda$ distribuiçăo de arquivos, representada pelas figuras já citadas, constitui um passo intermediário em todo o algoritmo desenvolvido. Isto porque o que é realmente utilizado nos testes são as representações ilustradas nas Figuras 5.8, 5.9, e 5.10, onde cada uma mostra uma função de distribuição acumulada. Essa função estabolece az probabilidade de: um arguivo ser requisitado durante a execugăo do experimento.

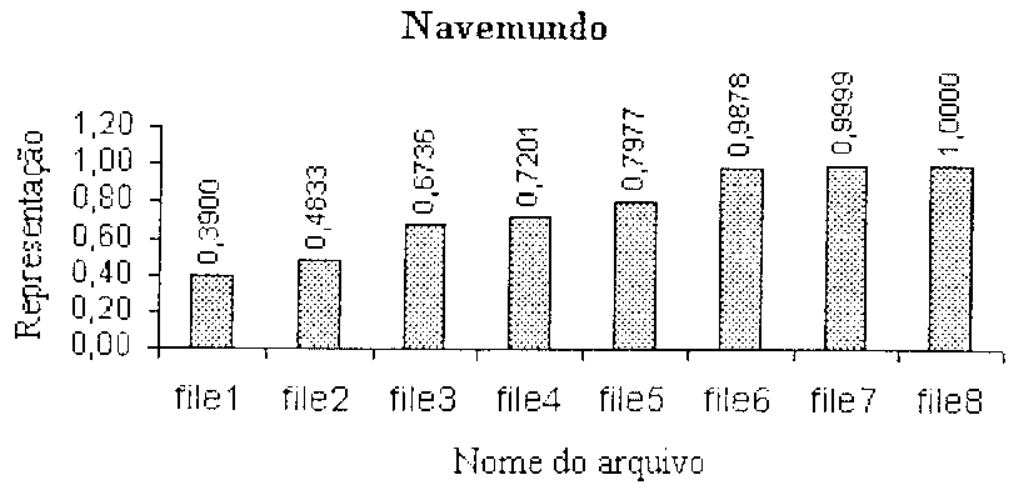

Figuma 5.8: Histograma para o log Navemundo

Na Figura 5.8, pode-se porceber que o arquivo "filel", será requisitado em $39 \%$ das oportunidades. Relacionando as Figuras 5.5 e 5.8, verifica-se que o arquivo "file1" representa a classe de arquivos de tamanho 0. Já a segunda classe, de arcuivivos com tamanho entre 250 e 1078 bytes, identificada pelo arquivo "file2", será contemplada em, aproximadamente: $10 \%(0,4833-0,39)$ das oportunidades.

\section{Copa do Mundo}

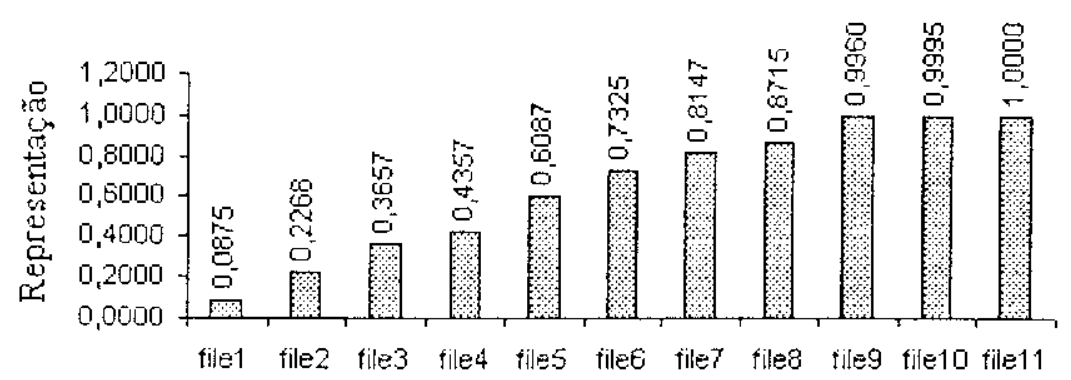

Nome do arquivo

Figura 5.9: IIstograma para o log Copa do Mundo

As Figuras 5.9 e j.10, apresentam gráficos bastante distintos, tanto pelo número de classes existentes, quanto pela representação de cada uma dessas classes. O tratamento do log da Copa do Mundo gerou mais faixas, cada uma com pequena representaçăo, enquanto que no caso do WebStone houve uma grande concentração, existindo uma faixa com representação acima de $50 \%$, "file 2 ". Como mencionado acima, isso ocorreu devido a 


\section{Webstone}

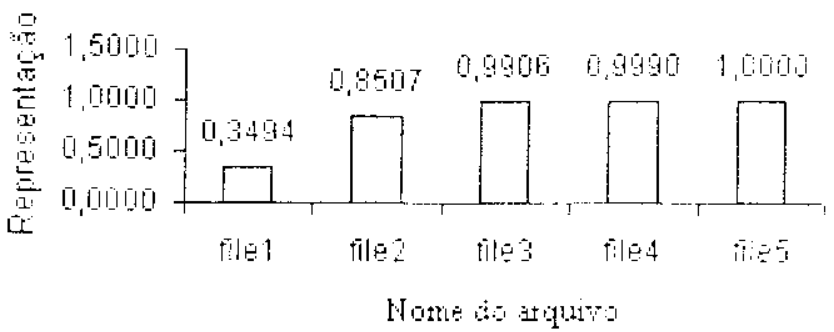

Figura 5. 10: Histergamal parat o loge Websionit

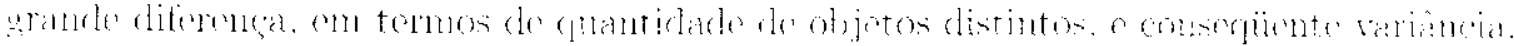
aprecutala pelos loge em entestán.

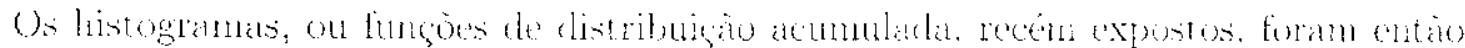

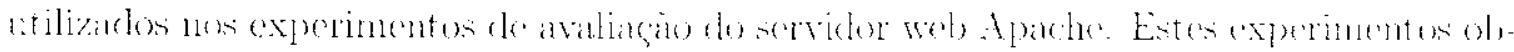

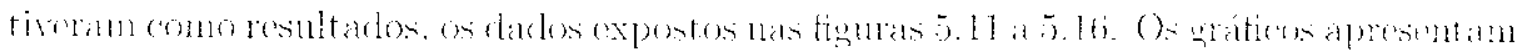

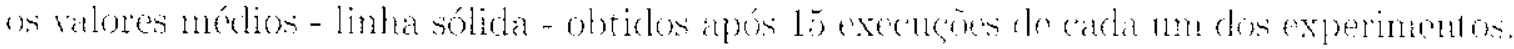

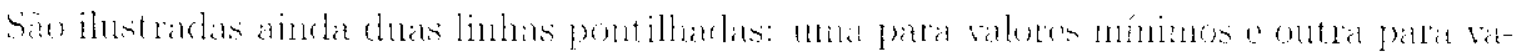

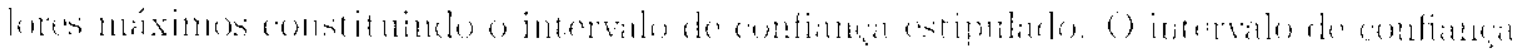

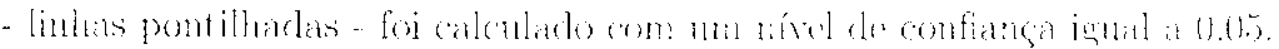

Navemundo

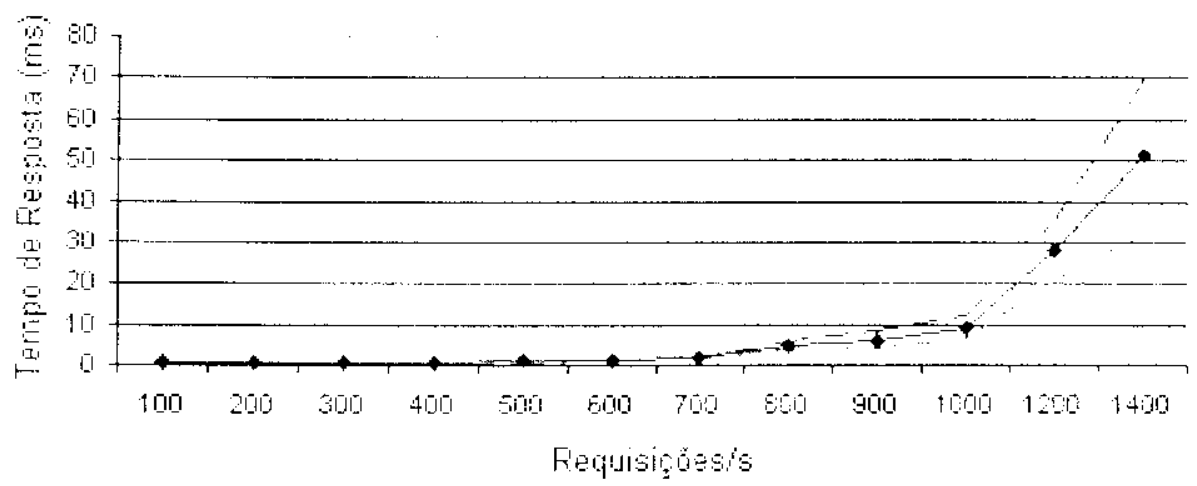

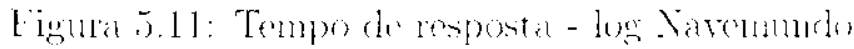

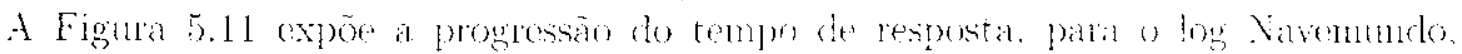
alcancarlo pelo servidor durante o teste. Os valores apretendetos reprenentam o intervalo

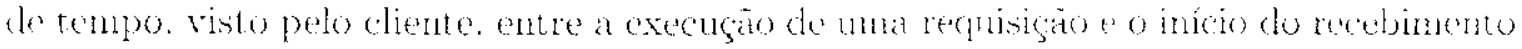

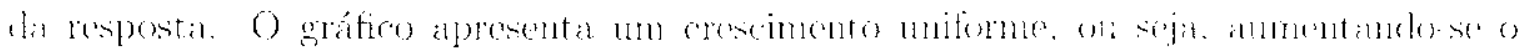

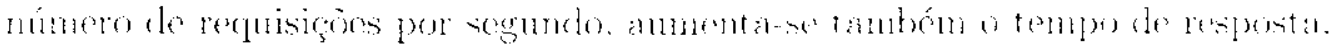

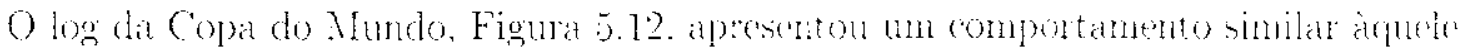




\section{Copa do Mundo}

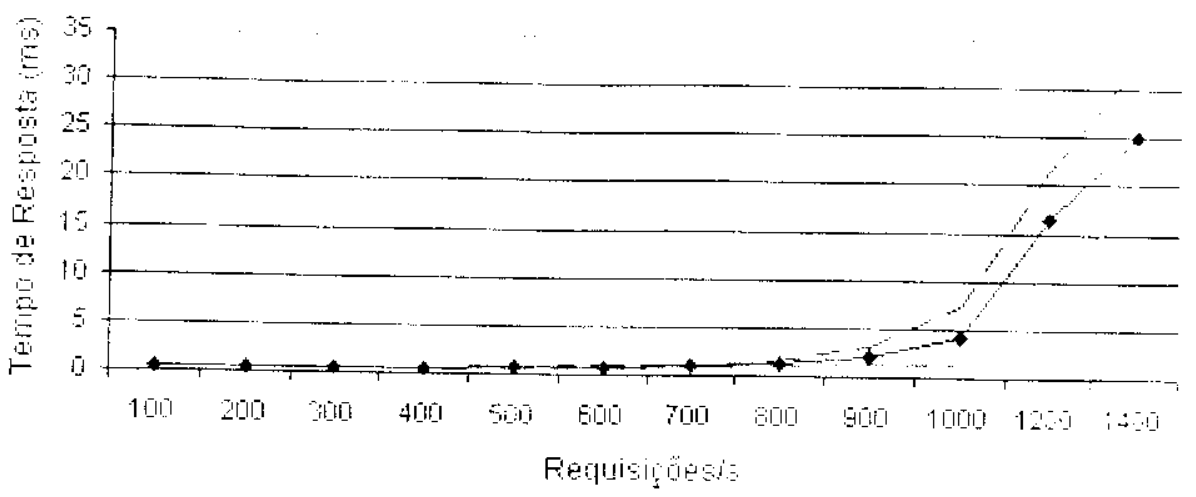

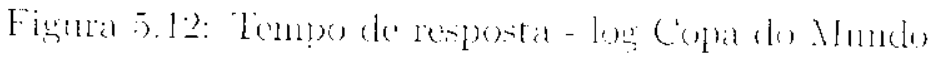

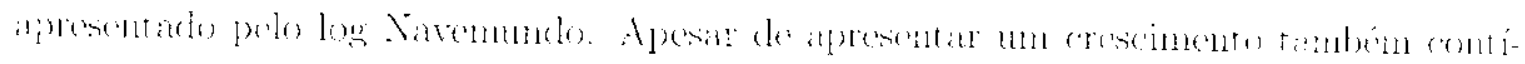

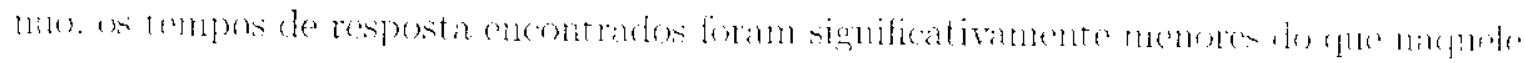

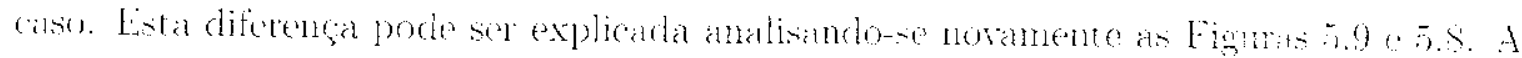

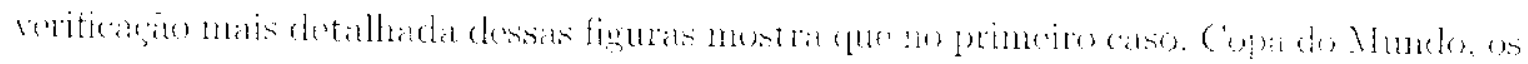

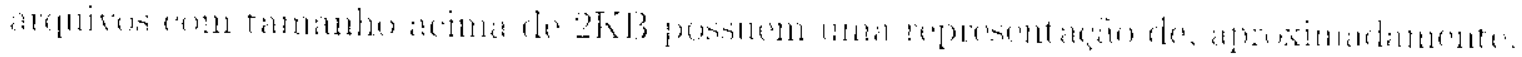

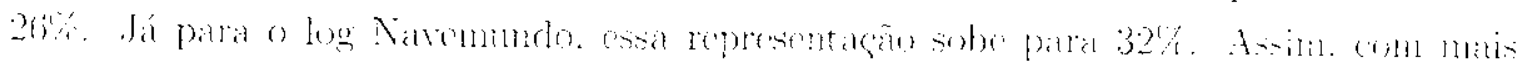

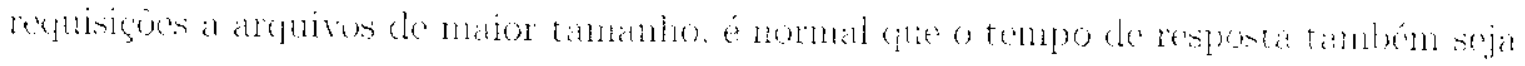
mitim.

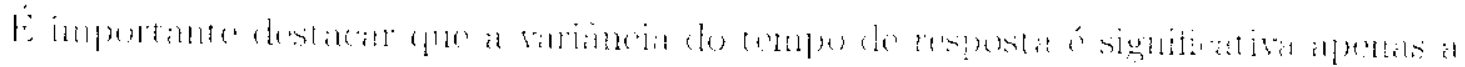

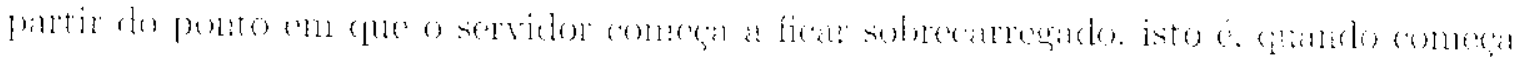

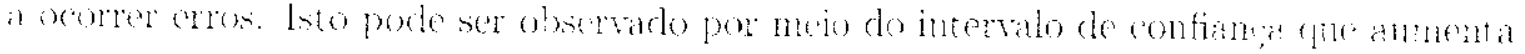

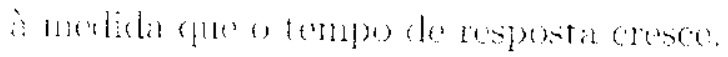

\section{WebStone}

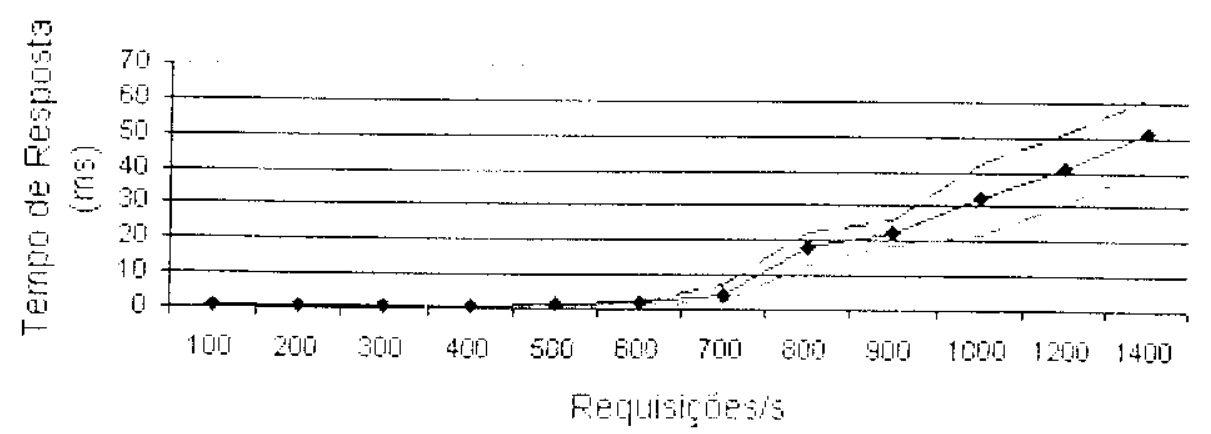

L'igura 5.13: Tempo de resposta - log Nenstone:

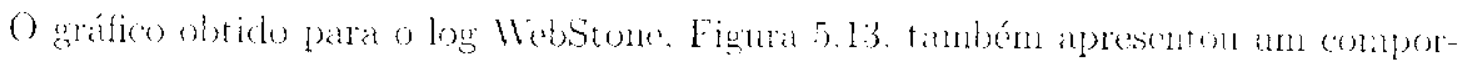

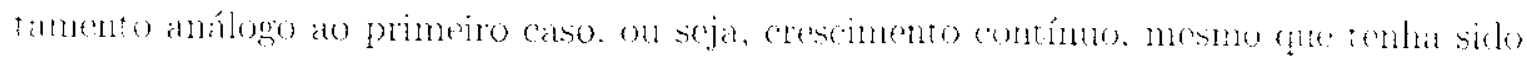




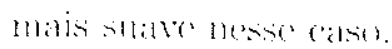

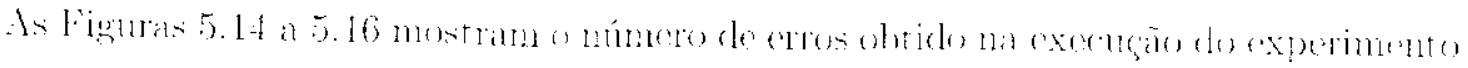

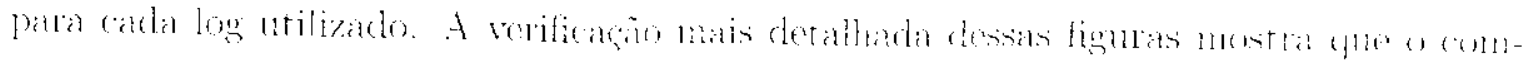

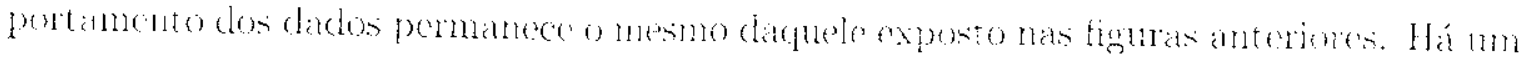

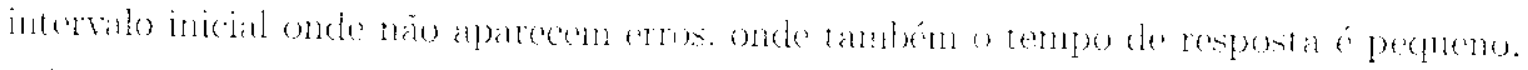

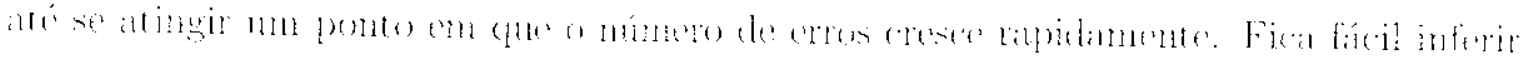

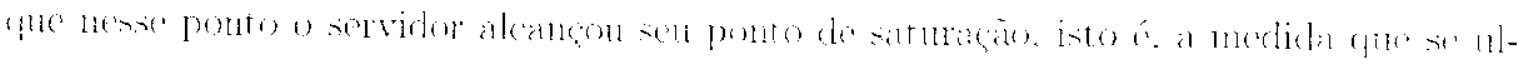

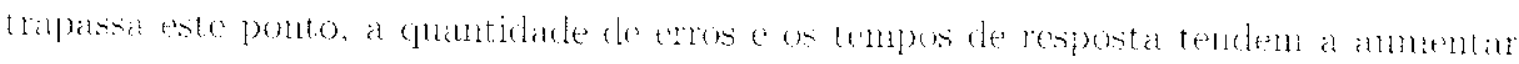
diasticaterthe.

\section{Navemundo}

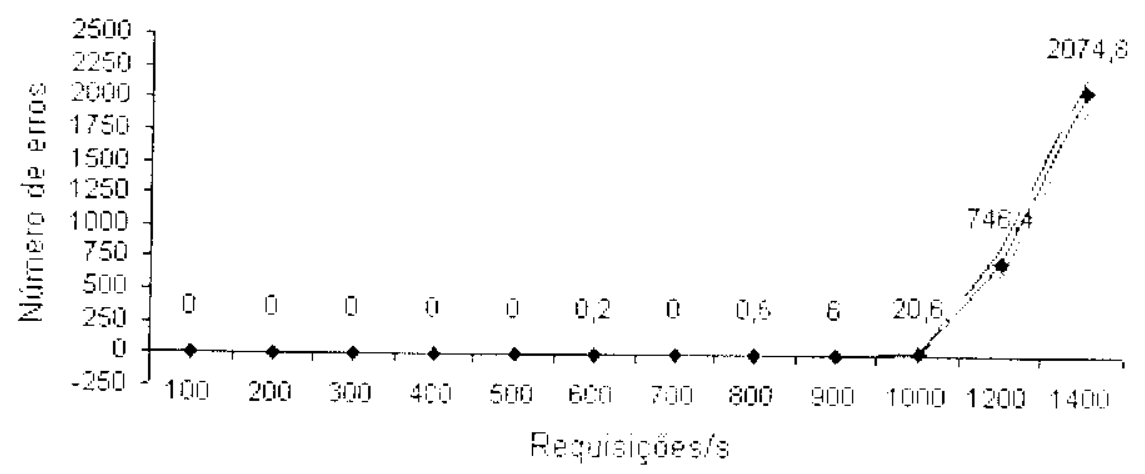

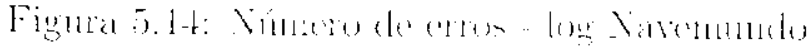

\section{Copa do Mundo}

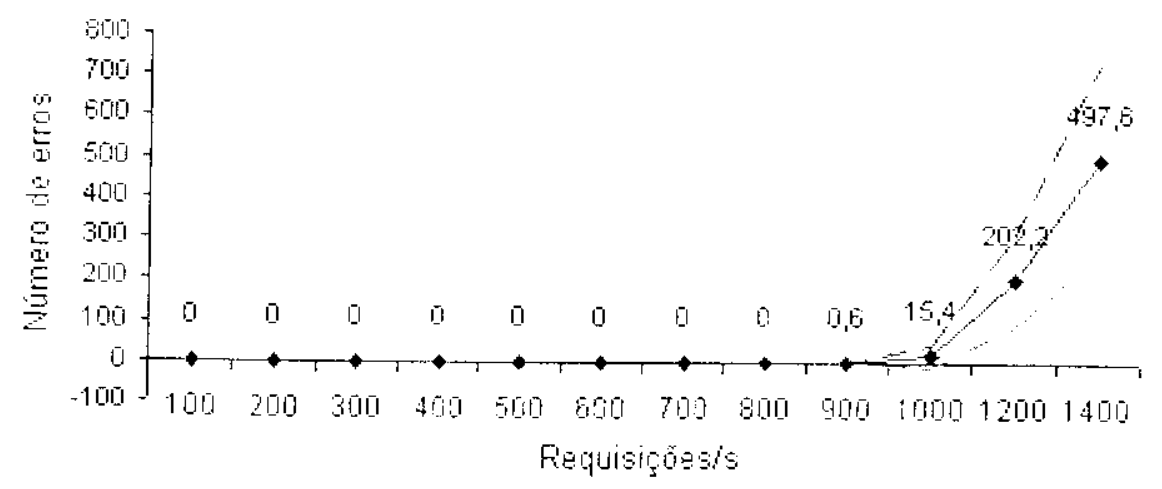

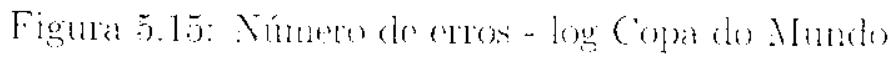

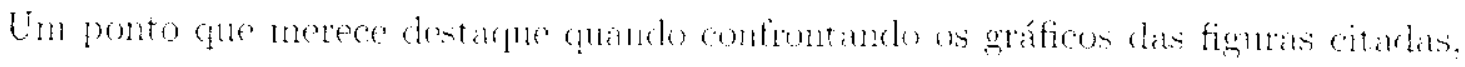

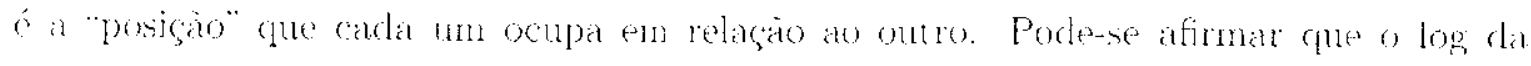

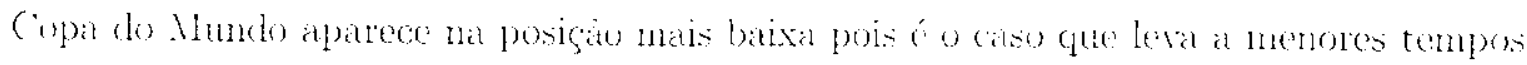

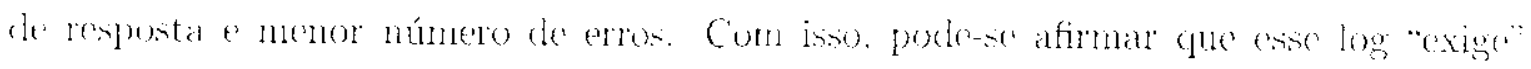




\section{WebStone}

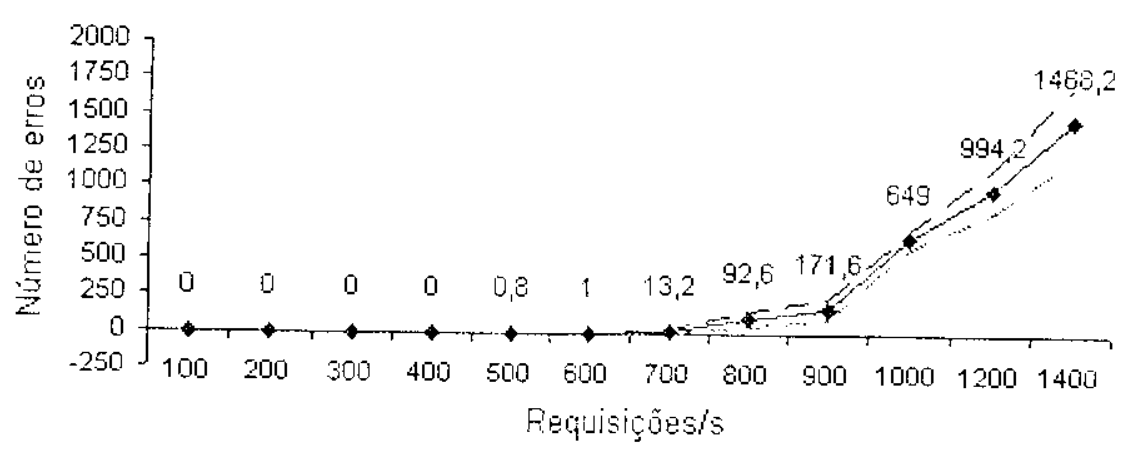

Figura 5.16: Número de erros - $\log$ Webstone

menos du servidor. Nas posições superiores aparecem. respectivamente, os logs WebStone e Natemundo. Sondo assim, o que gera mais carga no servidor, levando este a alcançat maiores tempos de resposta é o log Navemundo.

\subsection{Considerações finais}

A utilização de benchmarks representa un papel de considerável importância na avaliagà de servidores Web. Fstas ferramentä poden disponibilizar informaçoes, de formas variadas, em relação ao desempenho do sistema en avaliagão. No entanto, a forma como utilizar essas ferramentas - que parâmetros usar. por quanto tempo executar - pode $s: r$ vista como un obstáculo.

Na tentativa de facilitar o trabalho do usuário, alguns benchmarks, como o WebStone (seça 4.2), oferecem configuraçoes prontas para serem utilizadas en testes padrãu. Assin, o usuário precisaria se preocupar com a configuração do benchmark apenas em testes específicos.

Com esse mesmo objetivo é que foran desenvolvidas a ferramenta e as alteraçös no hutperf descritas neste Capítulo. Para conseguir parâmetros de configuração confiáveis, optou-se por utilizar logs de servidores como ponto de partida. Dessa forma, trabalhando com logs previamente coletados, foi possível a obtenção de valures próximos do real.

Tendo a ferramenta e o "novo" httperf implementados e prontos para execução, tornouse necessário fazer suas validaçoes. Isto foi feito através dos experimentos descritos na seção 5.4 .

Além de servirem para validação da ferramenta e diss implementações incorporadas ao benchmark, os resultados apresentados e discutidos confirmam que a utilização de logs em experimentos para avaliaçăo de servidures Web é viável e bastante atrativa. Variando-se 
o log utilizado, é possivvel obter, senn matores complicacones, cargas com as mais diferentes características.

Se as implementaçōes descritas não existissm e fosse utilizado o hutperf "original" para se obter os resultados mostrados na seçăo 5.4.3, o usuário precisaria, antes de tudo. definir luma carga de trabalho similar àuela utilizada para trabalhar. Isto poderia ser feito como no Capítulo 4, onde foram utilizados paránetros do Surge para definir una carga de trabalio para o hteperf. To entanto, isso năo elimina a necessidade de o usuário fazer, manualmente, todo o tratamento dos dados o extracaio desses parâmetros. Além disiso. se a intenga for executar diversos testes, com diferentes cargas, o problema co maior pois todo o trabalho deve ser refeito para cada carga clistinta. 


\section{Capítulo 6}

\section{Conclusões e Trabalhos Futuros}

\subsection{Considerações finais}

O trabaho discutido nosta dissertaçäo abordou aspectos envolvendo o estudo to benchmurts para servidores Web com o intuito de identificar características importantes, presentes en sistemas reais; mas que não cram consideradas por essas fermamentas. Foi apresentada ainda a seleção to uma das ferramenta cue recehen. por meio de implementaços, uma nova característica a ser utilizada en futuras avaliaçóes. Para o desenvolvimento de todo esse processo, houve a necessidade de realizar estudos e avaliaçoes visando escolher uma ferramenta que fosse mais adequada aos requisitos do trabahlo. De forma mais específica. foram abordados os temas Avaliarão de Desempenho (Capítulo 2), Web (Capítulo 3) e Benchmark:s para servidores Web (Capítulo 4).

Após esses estudos, constalon-se a adequabilidade da ferramenta httperf para receber as novas características, o também a importancia da interpretaşăo do logs para extraço (le) parânetros de teste.

Como já visto, os logs são, normalmente, arquivos de grande tamanho. Por isso, a slla utilização direta na ferramenta, durante a execução de experimentos, é inviável. Este fato justificou a criação de uma ferramenta à parte, capaz de analisar o log, coletar as informações requeridas e gerar uma forma mais fácil, o répida, de acessar essas in formações durante os testes. Esta forma mais "fácil" foi obticla através de histogramas que representavam a distribuição, da característica escolhida, emi todo o log. Assim, de forma geral, foi construída uma ferramenta que trabalhava o log e gerava histogramas. Estes eram então passados a httperf para serem utilizados na geração de carga de trabalho em experimentos de avaliação de servidores. Os detalhes envolvendo a implementacão da nova ferramenta e as mudanças feitas no httperf foram apresentados no Capítulo 5.

Ainda no Capítulo 5, podem ser vistos os resultados alcançados en experimentos feitos con o "novo" httperf. Esses resultados mostraram que a utilizaçăo de logs em experimentos para avaliação de servidores Web é bastante viável e atrativa. Com este procedinento, 
fle fácil obter diferentes cargas para testes. Fe necessário, apenas, corbeguir um log com as curaterísticas desejadas que o restante do trabalho executado pelos sofunures.

\subsection{Contribuições deste trabalho}

O desenvolvimento de una nova mantira para se alcançar cargas de trabahtho nais próxinas do real, com o intuito de avaliar servidores web, constitui uma das principatis contribuiçoss. una vez que o método empregado neste trabalho não tem sido explorado pelas ferramentas disponiveis atualmente. De forma geral, outras contribuiçoes relevantes são:

- Estabelecimento de conhecimento a respeito dos benchmarks utilizados pois como mencionalo qulando da discussão dos mesmos, algumas dessas ferramentas possullem documentagrão incompleta e, às vezes, até incoerente. Além de ter havido a necessidarle da corregão do código fonte en alguns casos. Assim, cote trabalho oferece. no mínimo, uma fonte de referência bastante ampla. servindo também como mom mamal de utilizaça para os benchmarks tratados.

- Construsão de uma ferramenta independente utilizada para o tratamento de logs. Neste trabalho, a fermmenta foi usada para a construgäo do histogramas, mas nada impede cue ela seja aproscitada para outros fins, como. por exemplo a remogão de registros expúrios presentes en algum log.

- Alteracões/adicoes executadas no htperf. A este benchmark foi acrescontada a capacidade de leitura (utilizagão em experimentos) dos histogramas gerados pela Ferramenta já mencionada. Assim, de forma indireta, foi possivel lazer com que o hut tyert se valesse de características extraídas de logs para gerar a carga do trabalho utilizada em seus testes.

\subsection{Dificuldades encontradas}

O trabalho relacionado a Web, por si só, traz algumas dificuldades, pois esta área encontra-so cm evidência, o que faz com que surjam novos aspectos em intervalos pequenos de tempo. Pode-se citar, como exemplo, a caracterização de carga que está sempre apresentando novos parâmetros.

A escolha da lerranenta a ser utilizada também não foi trivial, pois estas se apresentaram en diversas alternativas, cada uma contendo ainda algunas variagoes. Além disso, o aprendizado de cada ferramenta teve o seu custo. Como mostrado no Capítulo 4 , cada benchmark apresentou pontos positivos e negativos, podendo qualquer um deles ser escolhido. O que acabon definindo a decisäo a favor do httperf foi a estrutura em que o 
código fonte se apresentou. Testa terramenta o código aparece mais simples, comentado e simples de entender.

Outro ponto importante foi a obtenção dos logs utilizados, pois o objetivo ta conseguir logs que representassem cargas distintas. O que causou dificuldades foi o fato de que empresas responsáveis por site comerciais näo disponibilizan facilmente sens logs: alegando questós de seguranega. Aqui a excegäo boi o log da copa do mundo de 98 . Nesses caso, já havia um estudo publicarlo disponibilizando o próprio log e informagcoes a respeito dele.

O benchmark Surge represontou un problema considerável, pois foi dispendido muito tempo na tentativa de sua utilizaçäo. O que se mostrou en väo pois, mesmo após todo o coloreso, a ferranenta não funcionou a contento.

De forma mais especifica, durante a fasc de implementação apresentaram-se fatores cue trouxeram dificuldades para o andanento do trabalho. Alguns desses fatores foram:

- Estudo minucioso do código forte das ferramentas, visando selecionar uma delas para receber as implementacoons objetivadas. Esse esundo foi de extrema ulilidado prara a compreensão do funcionamento dos benchmarks, principatmente do hatperf que for o excolhido para tal objetivo.

- Implementagão da est rutura utilizada para o amazenamento dos registros presentes no log. As implementacoes iniciais näo obtiveram bom resultado pois comsumiam muita momória. Assim, quando eram tratados logs com mais 100.000 registros. o programa causava o travamento da máquina. A implementasgio atual executou sem problemas com logs que continham mais de j.000000 de reggistros.

- Deliniçáa de um mecanismo de redirisão das laxas/classes do histograma que apresentavam peso muito grande. Foi utilizado, inicialmente, un número grandes e fixo de faixas, por exemplo 100. Nas mesmo assim algumas dessas faixas apresentavam peso arima de $90 \%$. Finalmente optou-se por criar um número de classes pequeno e redividir as que apresentavam peso mator do que o desejado.

\subsection{Trabalhos futuros}

Como mencionado diversas vezes no decorrer desta dissertação, a avaliação de servidores wob é uma tarefa bastante complexa, se apresentando en constante evolução. Com isso, sempre há pontos a serem abordados por novos trabahos desenvolvidos neste escopo.

Algumas sugestōes para a realização de novos trabalhos sãu:

- Acrescentar novas funcionalidades ao httperf como: 
- Controlar testes com a utilização de diversas mánuinas clientes, de forma centralizada.

- Novos métodos para a geração de diferentes cargas.

- Mecanismos para controlar uma sequîncia de testes, tratar os resultados e disponibilizar um resultado geral - como é feito no Webstone.

- Construgão de conjuntos do dados para a execucão de testes específicos.

- Estudo e comparação de novas versões do Wobstone e httperf, ou ferramentas totalmente novas que venham a ser construídas.

- Modificar a ferramenta aqui construída para trabalhar com arquivos de log em formato binário, exigindo assim, menos espaço on disco.

- Acrescentar à ferramenta a capacidade de extrin mais informagós do log: tempo entre requisişoos: requisiçós dinamicas: entre ontras.

- Obençăo de novos parâmetros de caracterizasón de carga para utilizaçáo nos benchmarks.

- Construgão de mecanismos que possibilitem a avaliaçóo de servidores web com diferenciaça de serviços (Teixeira et al., 2003).

- Inplementação de um necanismo de redivisão baseado em variancia. O problema de se redividir uma classe/faixa é saber até quarido repetir o processos, isto é, até quando continuar dividindo. Cma propesta inieresante é: verificar a variância do tamanho dos objetos contidos na classe: se estiver acima do valor desejado, dividir a classe; repetir o processo para as novas classes criadas. 


\section{Referências Bibliográficas}

Abdelzaher, T. F.; Bhatti, N. (1999). Web content adaptation to improve server overload behavior. Computer Networks (Amstendom, Nethedonds: 1999), v.31, n.11-16: p.1563 1577.

Apache Software Foundation (2003). Apache HTTP Server Project. Disponivel en http: //httpd.apache.org.

Arlitt: M. (1996). A performance study of internt web servers.

Arlitt: M. F.: Williamson, C. L. (1996). Web server workload characterization: The search for invariants. Procedings of the ACM SIGMETHICS:96 Conforence p. 126-137.

Banga, C.; Druschel, P. (1999). Measuring the capacity of a web server under realistic loads. World Wide Web, v.2, n.1-2, p.69-83.

Berners-Lee, T.; Fielding; R.; Frystyk. H. (1906. Hypertext Transfer Protocol ...HTTP/1.0. REC 1945, LETF.

Borenstein. N. (1993). MME (Mullipurpose Intert Wal Eutcrsions) Fant One: Mechanisms for Spccifying and Describing the Fomat of Intemet Hessage Bodies. RFC $1521, \mathrm{IETF}$.

Calzarussa, M.; Serazii, G. (1993). Workload characterization: a survey.

CGI (2002). The common gateway interface. Dispuratel em http://hoohoo ncsa uiuc. edu/cgi/.

Collin, S. A. H. (1993). MICHAELIS: Dicionário Prático de Informática. Melhoramentos.

Comer, D. F. (2000). Internetworking with TCP:IP: Principles, Protocols and Archileclume. Prentice Hall, 4. edição.

Crovella, M.: Frangioso, R.; Harchol-Balter, M. (1990). Connection scheduling in web servers. USENIX Symposium on Internet Technologies and Systems.

Crovellat, M. E.; Bestavros, A. (1997). Self-similarity in World Wide Web traffic: Evidence and possible causes. IEEE/ACM Transactions or? Veluorking, v.5. n.6, p.835. 46.

Fan, L.; Cao, P.; Almeida, J.; Broder, A. Z. (2000: Summary cache: a scalable widearea Web cache sharing protocol. IEEE/ACW Tranactions on Networking, v.8. n.3. p.281-293.

FastCGI (2002). Fastcgi specification. Disponícel en http://ww .fastcgi.com/.

Fielding; R.; Gettys, J.; Mogul, J.; Frystyk, H.; Masinter, L.; Leach, P.; Berners-Lee, T. (1999). Hypertext Transfer Protocol …HTTP/1.1. RFC 2616, IETF. 
Fonseca, R.; Almeidla, V.; Crovella, M. (2003). Locality in a web of streams.

Francès, C. R. L. (1998). Stochastic Feature Charts -..- Uma extensão estocástica para os statecharts. Dissertação (Mestrado), USP/ICMC, São Carlos, SP.

Harel, D. (1987). Statecharts: a visual formalism for complex systems. Science of Computer Programming, , n.8, p.231-73.

Harel, D.; Politi, M. (1998). Modeling Reactive Systems wilh Stalecharts. MCGRAWHILL TRADE.

Hu, J.: Mungee, S.; Schmidt. D. (1998). Principles for developing and measuring highperformance web servers over atm.

IIt, J.; Pyarali, I.; Schmidt, D. (1997). Heasuring the impact of avent dispatching and concurrency models on web server perfomance over high-speed networks.

Than Heman (2003). World wide web consortium. Disponínd en http://www.w3.org.

J. Hu (1998). The jaws adaphive web server. Disponiwel em http://www cs. wust l edu/ jxh/research/.

Kleinrock. L. (1976). Queueing Systems - Volume 11:Computer Applications. WileyInterscience.

Kirishamurthy, B.; Rexford, J. (2001). Redes para a Web. Campus.

Maciel, P. R.: Lins; R. D.; Cunha, P. R. (1906). Introducho d.s Redes de Pelri e Aplicacoes. Unicamp.

Maltzahn, C; Richardson, K. J.; Grunwald. D. (1997). Performance issues of enterprise lewel web proxies. Procedings of the ACM SIGMETRICS:g7 Conference, p. $13-23$.

Menascé, D. A.; Alneida, V. A. F. (1998). Capacity Planning for Web Performance: Metrics, Models and Methods. Prentice Hall.

Menascé, D. A.; Almeida, V. A. F.; Dowdy; I. W. (199-4). Capacity Planning and Performunce Wodeling: From Mainframes to Client-Server Systems. Prontice Hall.

Vindoraft (2002). Webstone - the benchnark for web servers. Disponível em http: //www. mindcraft. com/webstone/.

Nosberger, D.; Jirl, T. (1998). httperf - a tool for measuring web server performance.

Orfali, R.; Harkey, D.; Edwards, J. (1999). The Client-Seneer Survival Guide.

Orlandi, R. C. G. S. (1995). Ferramentas para Análise de Desempenho de Sistemas Computacionais. ICMSC/USP. Dissertação de mestrado.

Provos, N.: Lever, C.; Tweedie, S. (2000). Analyzing the overload behavior of a simple web server. p. 1-12.

Red Hat (2003). Red hat limux. Disponível en http://www.redhat. com.

Scheuermann, P.; Shim, J.; Vingralek, R. (1997). A case for delay-conscious caching of Web documents. Computer Networks and ISDN Systems, v.29, n.8-13, p.997-1005. 
Silva, D): Kulesza, U. (2000). Reengineering of the jaws web server design using aspectoriented programming.

Soares. L. F. G. (1992). Modelagem e Simulaga Discreta de Ststemas. Campus Ltda.

SPEC (1999). Specweb99 benchmark. Disponivel em http://www. specbench.org/osg/ web $99 /$.

Stading. T.: Maniatis, P.; Baker, M. (2002). Peer-Lo-peer caching schenes to address flash crowds 1st International Peer To Peer Systems Workshop (IPTPS 2002), Cambridge, M. LSA.

Stevens. H. R. (1996). TCP/IP llustrated, v. 3. Addison-Wesley.

Tanenbaum, A. S. (2002). Computer Netuorks. Prentice-IIall, 4. edicão.

Teixeira. M. M.; Santana, M. J.; Santana, R. H. C. (2003). Avaliação de algoritmos de escalonamento de tarefas em servidores web distribuídos. XXX Seminário Integruto de Handure Eoftuare (SEMISH). XXXII Congresso da SBC, Campinas, SP.

Tittel, E. (1996). Benchmarking the wob. Disponivel em http://sunsite.uakom.sk/ sunworldonline/swol-09-1996/swol-09-webbench. ht \%ml.

Trent, C.: Sake, M. (1995). Webstone:the first gencration in hetp server benchmarking. MTS Shiron Gmphics.

Vallamsety: C. (2003). Characterization of e-commerce traffic.

W3C (1999). HTML 4.01 Specification. Disponivel em http://www.w3.org/TR/htm14. 